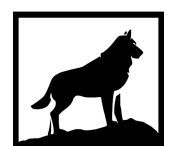

\begin{tabular}{lllll}
1 & 8 & 8 & 5 \\
\hline
\end{tabular}

Michigan

\title{
ECOLOGICAL SANITATION OPPORTUNITIES IN RURAL PANAMÁ: EFFECTIVENESS AND SOCIAL IMPLICATIONS OF INTRINSIC AMMONIA-BASED TREATMENT FOR PATHOGEN INACTIVATION AND INCORPORATION OF FERROCEMENT TECHNOLOGY
}

David Kierys

Michigan Technological University, dkierys@mtu.edu

Copyright 2017 David Kierys

Recommended Citation

Kierys, David, "ECOLOGICAL SANITATION OPPORTUNITIES IN RURAL PANAMÁ: EFFECTIVENESS AND SOCIAL IMPLICATIONS OF INTRINSIC AMMONIA-BASED TREATMENT FOR PATHOGEN INACTIVATION AND INCORPORATION OF FERROCEMENT TECHNOLOGY", Open Access Master's Thesis, Michigan Technological University, 2017.

https://doi.org/10.37099/mtu.dc.etdr/343

Follow this and additional works at: https://digitalcommons.mtu.edu/etdr

Part of the Environmental Engineering Commons 
ECOLOGICAL SANITATION OPPORTUNITIES IN RURAL PANAMÁ: EFFECTIVENESS AND SOCIAL IMPLICATIONS OF INTRINSIC AMMONIA-BASED TREATMENT FOR

PATHOGEN INACTIVATION AND INCORPORATION OF FERROCEMENT TECHNOLOGY

By

David R. Kierys

\begin{abstract}
A THESIS
Submitted in partial fulfillment of the requirements for the degree of MASTER OF SCIENCE

In Environmental Engineering
\end{abstract}

MICHIGAN TECHNOLOGICAL UNIVERSITY

2017

(C) 2017 David R. Kierys 

This thesis has been approved in partial fulfillment of the requirements for the Degree of MASTER OF SCIENCE in Environmental Engineering.

Department of Civil and Environmental Engineering

Thesis Advisor: $\quad$ Dr. Brian Barkdoll

Committee Member: Dr. Kari Henquinet

Committee Member: Dr. Jacob Hiller

Department Chair: $\quad$ Dr. David Hand 



\section{Dedication:}

Dla moich rodziców, „Ucz się, ucz, bo nauka to potęgi klucz.” Ti muko kräke. 



\section{Table of Contents}

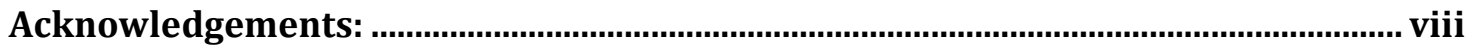

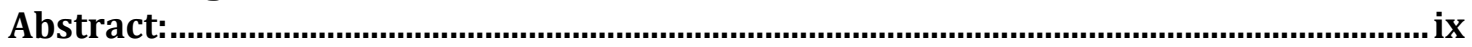

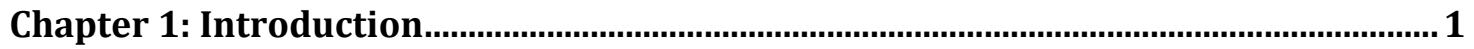

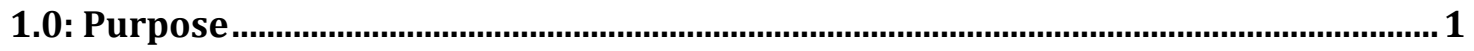

1.1: Barriers and Approaches to Improved Sanitation Adoption ................................... 4

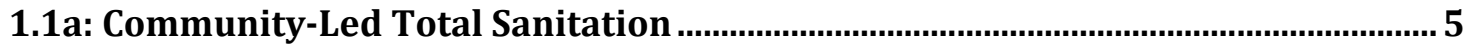

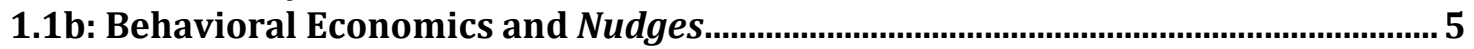

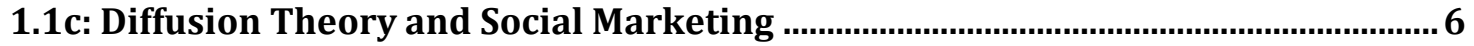

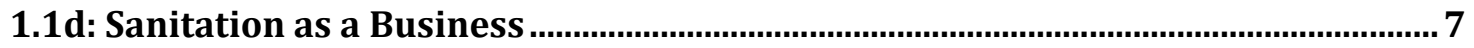

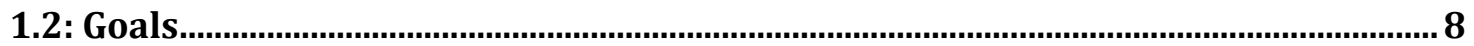

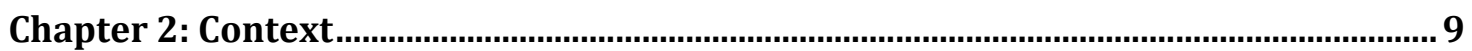

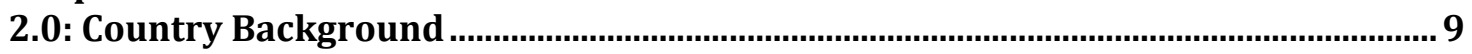

2.0a: Economic Inequalities in Panamá............................................................................ 11

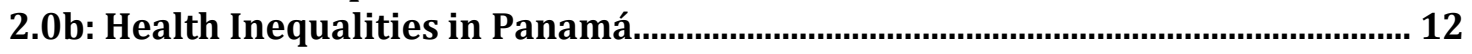

2.1: Regional Background: Bocas Del Toro and the Comarca Ngäbe-Buglé .............. 12

2.1a: Influences on the Culture of Bocas Del Toro and the Comarca Ngäbe-Bugle region of ÑoKribo

2.2: WASH in Bocas Del Toro-Nokribo and among The Ngäbe Population................. 16

2.2a: WASH Comparison - Urban vs. Rural Populations ................................................. 17

2.2b: WASH Comparison - Water vs. Sanitation in Two Ethnic Groups of Panamá. 18

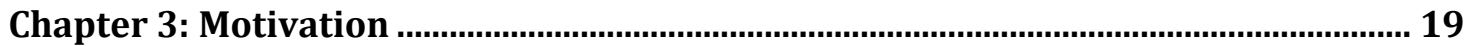

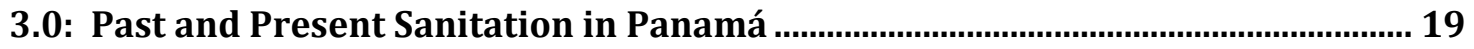

3.1: Sanitation Intervention in Drigari, Comarca Ngäbe-Buglé, Panamá .................... 30

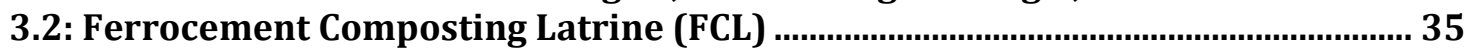

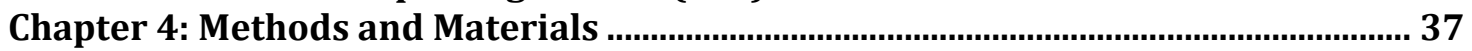

4.0: Ammonia-Based Sanitation Background................................................................ 37

4.1: Effectiveness of Ammonia-Based Sanitation (ABS) in Composting Latrines of

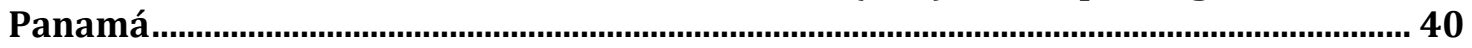

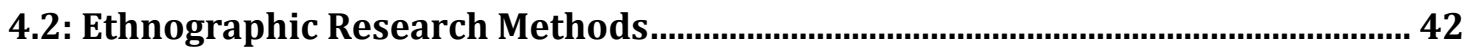

Chapter 5: Results and Discussion .................................................................................. 45

5.0: Intrinsic Ammonia-Based Sanitation by Urine and Ash Amendment: The Effect

of Ash Amendment on Ammonia Concentration......................................................... 45

5.1: Intrinsic Ammonia-Based Sanitation by Urine and Ash Amendment: Pathogen

Inactivation and Microbiological Results ....................................................................... 49

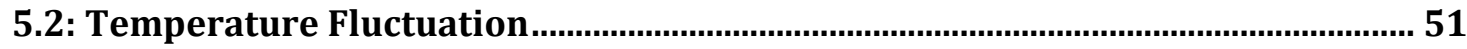

5.3: Qualitative Data: First Impressions of Urine Storage and its Use in Ammonia-

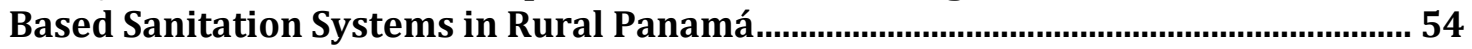

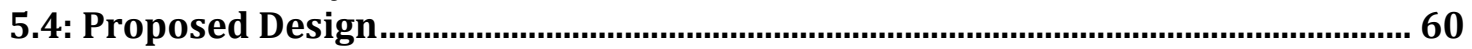

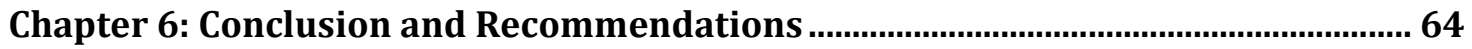

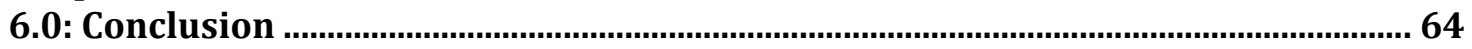

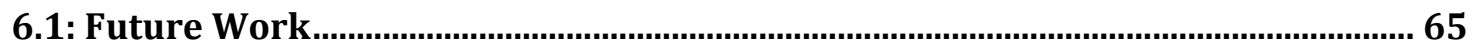

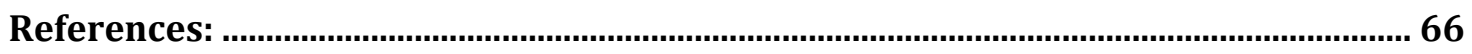

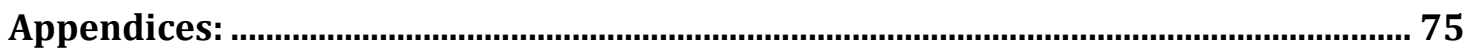

Appendix A: Ferrocement Composting Latrine Construction Guide........................... 75

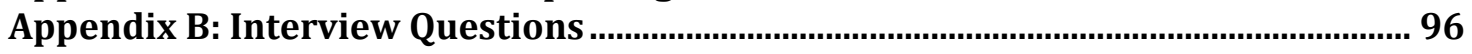




\section{Acknowledgements:}

First, I'd like to thank my thesis committee. Thank you, Dr. Hiller for coming onto a strange study with such little notice. Also, many thanks to Dr. Kari Henquinet for her incredible expertise and guidance through a field unknown to me. Lastly, I want to offer a great deal of appreciation to Dr. Brian Barkdoll for bringing me through this experience, especially for the task of producing this thesis.

I want to thank all of Panamá; its cellphone signal-providing hills, its cleansing lifeline of rivers, its pifá and banana producing forests, its welcoming mangroves and beaches, its highs and its lows, my faithful boots and its challenging mud. I want to show my gratitude to all of the people that allowed me to survive 3 years in a wilderness that became my home, the PCVs, the office, the Cubillas, Clinicó Navarro, the families of Valle De Riscó, and to all the people of Drigari, mun ta koin krubäte, siempre será Chächi Drigaribo, ja tuaita kä noi. Lastly I want to thank all of my friends and family and for waiting patiently and accepting me back. 


\begin{abstract}
:
The Millennium Development Goals (MDGs) the United Nations created more than 15 years ago established a global developmental framework that set a precedent for many governmental agencies and non-governmental organizations (NGOs.). With the deadline having come and gone many of the objectives set out in the original eight MDGs have come to fruition (Joint Monitoring Program, 2015). One exemplary achievement by the global community, specifically to the Water, Sanitation and Hygiene (WASH) sector was providing 91 percent of the world's population with access to improved sources of drinking water (UNICEF/WHO, 2015). But, as the Joint Monitoring Program (JMP) - the institution that oversees the monitoring and evaluation of development goals - itself points out in stark contrast, sanitation lags behind. 2.4 billion people are still without access to improved sanitation facilities (ISFs) with more than 900 million practicing open defecation.
\end{abstract}

One form ISFs take alongside conventional flush toilets and protected pit latrines is the composting latrine (CL). Along with providing a suitable fertilizer a CL, in theory, "hygienically separates human excreta from human contact (WHO, 2015)." CLs emphasize a conscientious, environmentally-friendly approach to sanitation by creating a cycle of nutrient transfer between human waste, soil, food and humans commonly known as Ecological Sanitation (EcoSan). EcoSan technologies make use of principles relevant to the next 15-year timeframe that the new Sustainable Development Goals (SDGs) will define.

However, as is the case for many sanitation interventions, barriers exist to the acceptance of EcoSan that question whether the cycle that is broken is instead with WASH sector and its beneficiaries. This fact is compounded in areas where there is little choice of ISFs like rural areas or floodplains. A case study herein discusses the potential of a novel CL design that incorporates ferrocement to reduce costs and labor, in an effort to alleviate issues that arise in EcoSan promotion, most prominently economic ones. The featured pilot design was able to decrease costs by $300 \%$.

In addition to the economic concerns, it has been contended whether EcoSan facilities are truly effective from a health outcome standpoint per JMP guidelines. In this vein, the effectiveness of ammonia-based sanitation (ABS) as a process with potential to vindicate CLs was studied. During a 12-week investigation, compost and urine obtained from CLs in Bocas Del Toro, Panamá were mixed in equal proportions and amended with wood ash at $0 \%, 25 \%, 50 \%$, and $75 \%$ by volume of compost. Temperature, $\mathrm{pH}$, and total ammonia concentration measurements were taken every two weeks, along with microbiological analysis before and after the treatment period to test for Ascaris L. ova, an indicator species.

These results were compared alongside CL users' perceptions of urine storage and its use as an agricultural fertilizer. Findings showed that ABS could address both, technical concerns over pathogen elimination in CLs in-situ and economic concerns when integrated with ferrocement. However, issues brought up during the five interviews with persistent users of traditional CLs suggest that this method would be difficult to maintain, implicating the results of other latrine adoption studies. A potential design is offered for implementation as an affordable, appropriate complement to current behavior change promotion approaches including sanitation through social business models or container-based sanitation. 



\section{Chapter 1: Introduction}

\section{0: Purpose}

According to the World Health Organization (WHO) and the United Nations Children's Fund (UNICEF), 842,000 deaths could be prevented annually by improving water, sanitation, and hygiene (WASH). This is despite the final progress report on the Millennium Development Goals (MDGs) by the WHO/UNICEF Joint Monitoring Programme (JMP) stating that 91 percent of the world's population has access to an improved water source. This disparity lies in the sanitation situation many of the same families included in the above statistics face, mainly the 2.4 billion of them that have no access to improved sanitation facilities (ISFs).

An ISF is defined by the WHO as (a) not being shared among households and (b) able to "hygienically separate human excreta from human contact" (WHO, 2014, Exley, et al., 2015). These denotations distinguish ISFs from unimproved sanitation facilities, which include the absence of any facility at all, as is the case for 946 million people that practice open defecation worldwide (JMP, 2015). Current ISFs include pit latrines, pour-flush latrines, and the focus of this thesis, composting latrines (CLs). (Exley et al., 2015). The JMP has developed the "sanitation ladder" hierarchy for sanitation technologies that include open defecation on the bottom "rung" and ISFs like flush toilets connected to sewerage on the top (Kvarnström et al., 2011).

Traditional CLs are constructed and function in many ways, yet this study focuses on the typical design found in Panamá. These CLs are composed of two concrete block chambers upon which a wooden superstructure with a "zinc" roof is constructed as seen in Figures 5 and 6. The purpose of the dual vault design is to facilitate the continued harvesting of the sanitized compost, a valuable soil amendment - at times the main incentive for improved sanitation adoption (Jensen et al., 2008; Wilbur, 2014). Also, due to the aboveground construction, CLs can be used where it is difficult to implement other sanitation facilities as in floodplains or areas with high water tables. Both of these conditions are ubiquitous to the areas of interest presented in this study.

In order to fulfill definition (b) of an ISF, CLs employ heat and storage to treat excreta enough to be considered hygienic. Heat is an outcome of the aerobic decomposition process that takes place inside the latrines' chambers when a series of factors like moisture content, a proper ratio of carbon to nitrogen and $\mathrm{pH}$ create the environment necessary for thermophilic microorganisms to thrive and essentially raise the temperature of the compost heap, sanitizing it free of pathogens (Pebler, 2014). Currently, to be considered improved in the sense of separating human excreta from contact; CLs must be built to store compost for one year before harvesting the sanitized end product. As will be shown later in the study, definition (a) has been considered inappropriate by the WHO for the new Sustainable Development Goals (SDGs) created for the next 15-year period per new studies into the effectiveness of shared ISFs. 
The motive of CLs is to both realize definition (b) and to create a link in the broken nutrient cycle that occurs when our waste and its nutrients go unused (Myers, 2013). This is the case in modern agriculture where synthetic or organic alternative fertilizers that are not locally sourced are used. This environmentally conscientious approach to sanitation is part of the larger school of thought known as ecological sanitation or EcoSan. This sentiment of attempting to solve environmental issues from an appropriate technology standpoint can be found throughout the SDGs that attempt to ensure a future free of the stresses caused by natural resource depletion and climate change. These implications are not only environmental, but as will be discussed herein, they are multi-variable and include, for instance economic outcomes.

The present study focuses on CLs present in Panamá, which are commonly misidentified or confused with another EcoSan latrines - the Urine-Diverting Dry Toilet (UDDT). Although they share many similarities, they are distinguished by their operation. Namely, UDDTs capitalize on the separation of urine from the excreta to lower the moisture content and raise the $\mathrm{pH}$ of the compost through ash amendment, which, in tandem, have been found to inactivate pathogens. CLs, on the other hand, require the addition of carbon-rich desiccants (i.e. sawdust, cut grass, rice husks, etc.) to drive the aforementioned aerobic decomposition process with urine being separated initially, as in UDDTs, or through a false floor that allows the drainage of fluids away from the chambers.

It has been found that many CLs (and UDDTs alike) do not, in fact, exhibit the conditions necessary for pathogen elimination. Instead, moldering at near ambient temperatures that creates compost over a much longer period of time (1-2 years) seems to be the mechanism found in CLs in Panamá (Hurtado, 2005). The WHO recommends storing compost for more than 1 year at temperatures between 20-35 degrees Celsius (WHO, 2006). However, this technical component alone does not fully illustrate the difficulties of improved sanitation uptake and especially the adoption of CLs. The great failure in sanitation interventions in Panamá and perhaps worldwide is not the lack of technical reviews of ISFs, but that an ISF's role has been studied for its efficacy, but not its effectiveness.

The WHO informs much of development interventions worldwide for what an effective ISF is through concepts such as the sanitation ladder that attempts to articulate the above notion of what truly is an ISF. Shared facilities have been shown to be appropriate solutions when users are better off economically and uphold cleanliness, but do have negative results in terms of both, uptake and technical efficacy compared to private facilities. These findings have garnered enough respect from WHO/UNICEF that the SDGs, that succeed the MDGs for the next 15 years, have addressed this change in their new framework - accepting an ISF to be shared with up to five households (Exley, 2015). A similar policy change would be difficult for sanitation facilities that cannot assuredly create a barrier between human waste and humans, yet not impossible - an opportunity arises in the use of container-based sanitation models like the ones to be discussed in the following sections.

That being said, creating a barrier does not end at the toilet nor start at the faucet. Studies focusing on improved hygiene practices have shown that disaggregating WASH data into their constituent parts reveal hygiene, not sanitation nor water interventions, to be the most effective single WASH intervention. It is difficult to separate the impact of ISFs from those associated with improved hygiene, but even the most modern and robust sanitation 
measures can be undone by an unwashed hand, and, vice versa, effects of poor sanitation environments can be greatly undermined by simple hand washing. In spite of what statistics are able to reveal about the daily circumstances these individuals experience, academia disputes whether any definition of improved can accurately describe the conditions necessary to alleviate the issues associated with illness, poverty and equality (Cumming et al., 2014, Hurtado, 2005).

Current studies approach improved sanitation adoption and the whole WASH initiative from a behavioral perspective, due to the revelations that the "if you build it, they will come" approach has had on the current state of sanitation. This approach believes that when individuals have received western-minded solutions they will act accordingly. Methods like these fail to grasp the history of sanitation in the western world and the difficulties cities like London, Paris and Chicago had at their beginnings. Sanitation has become so efficient and streamlined in the developed world that it is an afterthought in modern times. This impacts the developing world because the innovators, inventors, promoters, and financiers are foreigners. Developing nations with early federal support have shown better results, but change agents that understand local sentiments are also key (Heppleston, 2009). A multi-scalar influence on a nation's sanitation initiative is necessary as some findings conclude that nations receiving the most capital from foreign aid had no correlation on whether that nation saw improved sanitation health outcomes (Botting et al., 2010; O’Reilly, 2014).

This being said, there are strong correlations between improved sanitation and health and economic outcomes, in general (Bartram, 2010). Two studies found that any of the three components of WASH (i.e., water, sanitation, or hygiene) were effective in reducing diarrheal illness and are thus critical to achieving all of the other global development goals (Fewtrell, 2005; Cheng et al., 2012). These health outcomes ultimately translate into economic returns due to the relationship between health, DALYs and aspects like entry into the labor market (Bartram, 2010; Halpenny et al., 2013).

For example, in 2012, "502,000 deaths were attributed to inadequate drinking water, 280,000 to inadequate sanitation and 297,000 to inadequate hygiene" (Pruss-Ustun, 2014). The prevention of these deaths could account for $\$ 3.6$ billion per year and limiting symptoms associated with water-borne, water-washed and water-based diseases can attribute to another $\$ 7$ billion savings due to lowered use of healthcare services (Mara, 2010). In 2007, the cost-benefit ratio (the monetary worth of the benefits compared to the costs of the intervention) of achieving the MDGs for sanitation for Latin America and the Caribbean was 37.8 - or $\$ 37.8$ earned for every $\$ 1$ spent - the highest of any region. These figures are determined not only by improved health, which saves a family or government money in the costs of medicine and treatment, but also savings associated with disabilityadjusted life years (DALYs), which impact the labor force and life expectancy.

Yet, sanitation and other WASH interventions are not only economically viable, the social ramifications of ISFs have elevated improved sanitation by the UN to an essential human right (UN General Assembly, 2010). In general, improved sanitation is a synonym for dignity or respect and is correlated with safety and convenience (Evans et al., 2009). A growing body of work has examined the need for improved sanitation with respect to social 
equity - relating to class, ethnicity and gender - education, and nutrition, not only health (Unicef, 2015).

Some argue that due to the stringent focus on pathogen removal, other issues like menstrual hygiene management (MHM) are continually left behind in the realm of the taboo (Tilley et al., 2013; Sommer et al., 2013). Qualitative research in India found that women also attribute inadequate latrine access to sexual harassment, violence and insecurity, in general (Pradyumna, 2015). Gender equity is inherently linked to access to education, which is also reciprocally related to access to improved sanitation. Female students have been found to decrease absences in schools that had proper WASH facilities or hygiene trainings (Freeman et al., 2011). Needless to say, these findings also extend to the household sanitation situation and poorer and female students (Dreibelbis, 2012). This goes to show that sanitation promotion and technology studies and initiatives have only begun to coalesce ideas long-held by the users they are apparently designed for. The following section will introduce some of these approaches and their potential in the areas studied herein. This present thesis attempts throughout to compare and contrast the technical and sociological components of improved sanitation uptake and effectiveness.

\section{1: Barriers and Approaches to Improved Sanitation Adoption}

Despite the proposed benefits gained through improved sanitation interventions including those involving CLs - there still exist sizeable issues aside from the aforementioned technical ones. Throughout the following sections, a multi-disciplinary, holistic approach will be cited as a correct means of overcoming unimproved sanitation issues. This is due to the complexity of aspects sanitation touches on that had not been totally considered until recent years, namely some aforementioned social elements. O’Reilly and Louis (2014) suggest that political will is also a key barrier to improved sanitation adoption. It has mentioned that ISF adoption is key to improving the quality of life for billions of individuals around the world, yet solely supplying a community with the "hardware" (latrines, septic tanks, etc.) as it has been referred to fails to fully accomplish this and that the "software" (promotion, seminars, etc.) should be emphasized (Campbell et al., 2014). This can also be described using a supply and demand model (Van Der Hoek et al. 2010).

It is often the case that national governments cannot provide the funding necessary to do either the supply or demand side, yet governmental policy can make sustained latrine use more possible (Van Der Hoek et al., 2010; O’Reilly and Louis, 2014). However, in some cases when communities begin having expectations of hardware handouts, incentives can greatly prolong a project due to demands of subsidies. There can also be mis-coordination and misuse of funds associated with sanitation projects as a top-down approach can create, leading to parallel efforts or counter-acting different stakeholders' projects (Van Der Hoek et al., 2010; Midkiff, 2013).

Many studies point to the idea of "behavior change" as the main difficulty or, as some have posited, the main opportunity to ISF adoption and ultimately an improved quality of life (Langford, 2013; Marshall 2016; Riboli-Sasco, 2015; Nawab, 2006, Bartram, 2010). This agrees with others (Evans, 2005; Jenkins and Scott, 2007; Peat et al., 2010) that latrine use 
has much more to do with other barriers like convenience, comfort, privacy and safety. Many behavior change models exist including: Community-Led Total Sanitation (CLTS), Participatory Hygiene and Sanitation Transformation (PHAST), Social Marketing, Community Health Clubs (CHCs), Diffusion theory, Behavioral Economics and the general ideas associated with social entrepreneurship and the willingness-to-pay (WTP) associated with the "demand" model to sanitation.

Similarly, to the technical aspects of sanitation, many of these models have been shown to be at times ineffective (Langford, 2013). The sheer quantity of these behavior change models or health promotion approaches do not necessarily prove that sanitation is a lost cause in the developing world, but rather that context is extremely important. Each approach might have a more correct context than another, but for rural health workers and change agents, using existing motivations might be the most pragmatic approach (Marshal and Kaminsky, 2016). The author would like to highlight CLTS, Behavioral Economics or the Nudge strategy, Diffusion theory in the form of Social Marketing, and finally traditional business models as a sanitation promotion method to provide examples of common approaches to sanitation intervention promotion.

\section{1a: Community-Led Total Sanitation}

Community-Led Total Sanitation is one of the most successful "software" implementations studied, found to decrease the practice of open defecation in over 20 countries (WHO, 2015; Mehta and Movik, 2010; Campbell et al., 2014; Midkiff, 2013; Mara, 2010, Van Der Hoek, 2010). Achieving open defecation-free (ODF) status is the main objective of CLTS achieved not necessarily through education on germ theory and improved health implications, but instead, through triggering direct emotional responses to open defecation, mainly shame (WHO, 2015).

This method has been successful in creating the demand to compliment the supply-side of sanitation, yet it is important not to generalize the success of CLTS into a complete solution, as it will be discussed in the specific case of the rural Ngäbe community of Drigari in rural Panamá. There is also some commentary on the lack of long-term adoption and continued adherence to improved behaviors using CLTS and its absence of hygiene and health promotion (Van Der Hoek, 2010; Whaley and Webster, 2011; Movik and Metha, 2010). For instance, Nepalese mothers claimed that washing hands with soap was vital after defecation since it made them feel "disgust" and "dirty" yet found it unnecessary and impractical during other critical moments (Langford, 2013). Also, it is necessary to incorporate some type of governmental or private subsidy to provide opportunities for all community members since it has been found that some interventions only end up benefitting the rich or families already in an advantageous position to change their behavior ( $O$ 'Reilly and Louis, 2014).

\section{1b: Behavioral Economics and Nudges}

CLTS can be effective in decreasing ODF in certain regions and contexts, yet not all; for instance, in a study on 18 West African countries only $17.16 \%$ had success in creating ODF communities. An approach that has found success in changing behaviors in both industrial 
and less-industrialized nations that doesn't involve potential alienation of individuals due to their sanitation practices is the use of Behavioral Economics or Nudges (Dreibelbis, 2016). The concept of a nudge is thoroughly outlined by two behavioral economists, (Thaler and Sunstein, 2008) as:

“...any aspect of the choice architecture that alters people's behavior in predictable way without forbidding any options or significantly changing their economic incentives. To count as a mere nudge, the intervention must be easy and cheap to avoid. Nudges are not mandates. Putting the fruit at eye level counts as a nudge. Banning junk food does not."

Nudging has been shown to be effective at reducing food waste, promoting positive recycling habits and reducing food consumption by providing smaller bowls yet increasing individual perception of food intake (Dreibelbis, 2016). These findings extend to sustainable development, as well, from an investigation on handwashing habits in a primary school in Bangladesh (Dreibelbis, 2016). Baseline measurements of handwashing at the school were observed to be $4 \%$ pre-intervention. No hygiene education interventions or behavior change tactics were employed; solely a path from the latrine units to a simple handwashing station with soap was paved and painted with brightly colored footprints to indicate where one could go after defecation. The day after implementing the nudges handwashing with soap was observed to rise to $68 \%$ and then $74 \%$ two and six weeks after baseline observations.

\section{1c: Diffusion Theory and Social Marketing}

Hygiene must be inherently linked to both water and sanitation, as it has been shown to be the single most impactful intervention (Fewtrell et al., 2004). In other words, hygiene could explain why certain sanitation and, for that matter, water interventions do not necessarily improve health if pathogens are still being transmitted by the most culpable of vectors in ourselves. Projects like the above show that environmental indicators of an improved hygiene practice can become internalized and habitual even in the absence of emotional drivers or motivations like CLTS or other similar methods (Orville and Orozco, 2014). The idea of social influence is a strong one, but not all decision making is emotionally or logically derived, and knowing what others do can be enough to drive a behavior change (Orville and Orozco, 2014).

This topic of self-initiated behavior change in a community through social pressure and norms will be revisited in the context of CL users in a rural Ngäbe community in Panamá. In brief, Valle De Riscó showed evidence of changing social norms through social cues provided by the sole presence of other CL users, enough so to compel some households to self-fund and construct their own ISFs. In the case study of Drigari, initial uptake of the pilot CL project could be attributed to the convenience offered through a nearby facility that offered all of the benefits associated with the default open defecation option. Also, rather than promote the outright cost of the CL to the family, the total savings associated with the subsidy provided was promoted as an initial discount. Both cases also evoke the concepts of early adopters associated with Diffusion Theory, which is part of the basis for the ideas behind social marketing. Diffusion theory is also implicit in the participatory or usercentric design methodology, which is informed by principles like relative advantage, compatibility, simplicity, observability, and trialibility (Cole et al., 2015). 
Social marketing for rural sanitation was integral in the designs discussed in the ensuing chapters. Market-based approaches in WASH programs have been popular in the last ten years (Inter-American Development Bank, 2016). Social marketing uses existing motivations like convenience, comfort, safety, and privacy to promote ISFs and their adoption in a similar fashion to free market products and services like cellphones, clothes, appliances and the like. The premise stems from classical marketing concepts that focus driving demand through analysis of what have been described as the "4 P's" or "product, place, price, promotion" (Riboli-Sasco et al., 2016). These concepts are meant to provide a means for designers to approach any type of market including the "bottom of the pyramid" referring to the world's underserved population including those with inadequate sanitation access.

\section{1d: Sanitation as a Business}

This is an attempt to shift the paradigm of sanitation from one primarily funded, designed and implemented from a central governing body to making it a business enterprise that capitalizes on the demand being produced from the aforementioned models. It attempts to sell an idea by "convincing the target audience that it provides a solution to a problem they believe is important, and/or offers them a benefit" (Langford and Panter-Brick, 2013). Several existing businesses exhibit these principles to, at once, provide a service for an underserved population and become sustainable through the lack of external change agent intervention when the enterprise becomes profitable (Rieck et al., 2012). The user instantly retains "ownership" of the product and continues its use from the built-in value it is perceived to contain (Inter-American Development Bank, 2016). A service provider completes the cycle and produces a sustainable business that also promotes access to improved sanitation. These models aren't successful in all cases due to the need for scaling, but some examples seem to be promising (Rieck et al., 2012).

In the case of EcoSan, Sustainable Organic Integrated Livelihoods (SOIL) is a NGO out of Haiti that has integrated "container-based sanitation" into a business model that provides an alternative sanitation solution for Haitians while providing a service to the agricultural sector and employing Haitians to manage and perform these services (Tilmans et al., 2015; Russel et al., 2015; Remington et al., 2016).). A user-centric design was utilized to create a sustainable and appropriate solution through customer participation in an iterative process that considers a product or services "desirability, viability and feasibility" (IDE brochure). Findings from studies done on this specific NGO's approach show that 71\% of users that initially participated in a free pilot phase decided to enroll in the monthly service costing $\$ 5$ per month for an entire household. SOIL completes the cycle by then selling the treated biosolids as a viable soil amendment. Urine is a worthwhile amendment, as well. In a comprehensive review of UDDTs by GIZ (2015Riech et al. (2012), it was determined that its value can range from four to seven Euro annually and feces as a product can be worth between 4.6 and 6.2 Euro annually per person. They close by mentioning the growing concerns around phosphate production through mines is becoming costlier, while synthesizing nitrogen fertilizers continues to be high-energy consuming.

Attempts such as these to address the entire cycle of inadequate sanitation from a non-aid means is optimistic and can be employed with or without subsidies in the form of microloans to further increase the likelihood of success even in poorer households and create 
more social equity (Van Der Hoek, 2010; Sparkman and Sturzenegger, 2016; (Myers, Mittermeier, Mittermeier, da Fonseca, and Kent, 2000)World Bank 2010; Van Minh et al., 2012).2013). Willingness to pay (WTP) for latrines and sanitation services are also critical to this approach. Numerous studies have taken on the question of how much a beneficiary is willing to pay seeing as governmental subsidies are sometimes not possible or counteractive (Hall et al., 2015, Russel et al., 2015). The most appropriate sanitation technologies might be cost-ineffective yet if subsidies were used originally demand might still exist towards a technology that is outside the range of the user's budget as was the case in Cambodia where households favored a $\$ 150$ latrine over a simpler $\$ 5-\$ 10$ one (Mara et al., 2010). Because of the iterative process these approaches offer affordability and can be an important factor in creating initial adoption and can be factored in when better technologies are ready to be used as the sanitation ladder presents - as was the case in rural Ethiopia where arborloos provided an entry point into adequate sanitation access (Fry et al., 2015).

These efforts and strategies were considered during the design and implementation of one of the case studies offered herein of the ferrocement composting latrine (FCL) in Drigari, CNB, Panamá, and applies to the motivations and findings from the qualitative study of sustained CL adoption in the rural Ngäbe community of Valle De Riscó in Panamá. The usercentric design and social marketing approach was also considered in the proposed design of an experimental on-site EcoSan latrine incorporating ferrocement and urine storage for ammonia-based sanitation.

\section{2: Goals}

This study approaches the discussed global sanitation issues from the investigations of indigenous Ngäbe communities with CLs in the rural Panamánian regions of Bocas Del Toro (BDT) and the Comarca Ngäbe-Buglé (CNB). Commentaries will be made on the current state of sanitation in this region using an extensive amount of previous data collected regarding this specific geographic area and its composting latrines. The main purpose of this study is to contextualize the potential of a new method of improved sanitation treatment for CLs in the setting of rural Panamá with consideration to topics discussed above and findings into the technological and sociological aspects of EcoSan drawn from:

1) A review of EcoSan effectiveness studies performed in and about the rural Panamanian regions of BDT and CNB along with the role of rurality and new literature on the efficacy of ABS and its implications on EcoSan.

2) Quantitative data collected from a 12-week investigation into the effectiveness of ammonia-based sanitation (ABS) using urine and compost from three CLs in a representative rural community of the Ngäbe population.

a) The effects of ash amendment on the performance of ABS in the context of resource stressed areas.

b) An analysis of an experimental CL design incorporating the appropriate technology of ferrocement developed from a case study herein with ABS. 
3) Qualitative data gathered on the perceptions of current and future EcoSan practices including urine storage and use as a soil amendment along with their implications to ABS adoption collected from interviews with five families that have used CLs for more than a decade.

With these goals in mind, the questions they intend to answer are: Can ABS, be an effective treatment from a technical (meaning it destroys pathogens in field conditions) and sociological standpoint (meaning it is within the bounds of current behavior change models). This could be said in another way as analyzing the quantitative and qualitative components of WASH.

In an effort to scrutinize the findings into an appropriate real world setting, the investigations and their findings will be discussed in a multi-disciplinary approach. For that reason, the motivations behind the current study will be presented prior to the investigations. Chapter two will provide context into Panamá and the specific regions of Bocas Del Toro and the Comarca Ngäbe-Buglé. With these topics examined, a brief history of the experiences of the author with sanitation interventions in the rural community of Drigari in the Comarca Ngäbe-Buglé, Panamá will exhibit a short guide on the ferrocement CL (FCL) integral to the proposed implementation of ABS into a household latrine design.

Other motivations will be outlined in Chapter 3 regarding the previous work on CLs in Panamá and their relation to the current situation in the area in question, implications of behavioral models and sociological studies on the sanitation component of WASH promotion, and political and economic barriers to improved sanitation there. Chapter 4 will explain the methods and materials used in the technical and ethnographic investigations. Later, Chapter 5 presents the results of both studies and a discussion of each. Finally, Chapter 6 will offer conclusions and recommendations based on the findings and areas of future work.

\section{Chapter 2: Context}

\section{0: Country Background}

Panamá is a Central American nation (Figure 1) of an estimated 3.9 million people encapsulating the famous man made division between the two Americas that is the Panamá Canal (World Bank, 2015). This relatively small country of 75,420 square kilometers has a wealth of biodiversity comparable to areas considerably larger than itself like the Amazon River Basin and the Malayan peninsula (Myers et al. 2000). For instance, Panamá has 929 species of birds, amounting to more than the total found in the U.S.A. and Canada combined (Miller et al. 2000). 2001) Many attribute this disproportionate bounty to its geographic location at, an outcome of volcanic activity three million years ago that produced "a biological corridor" between the Atlantic and Pacific Oceans and connecting connected two ecologically different continents (Condit et al. 2001, Miller et al. 2001). Now Panamá is connecting the entire world with this geographic anomaly through the canal that took advantage of this narrow "corridor" in 1914. 


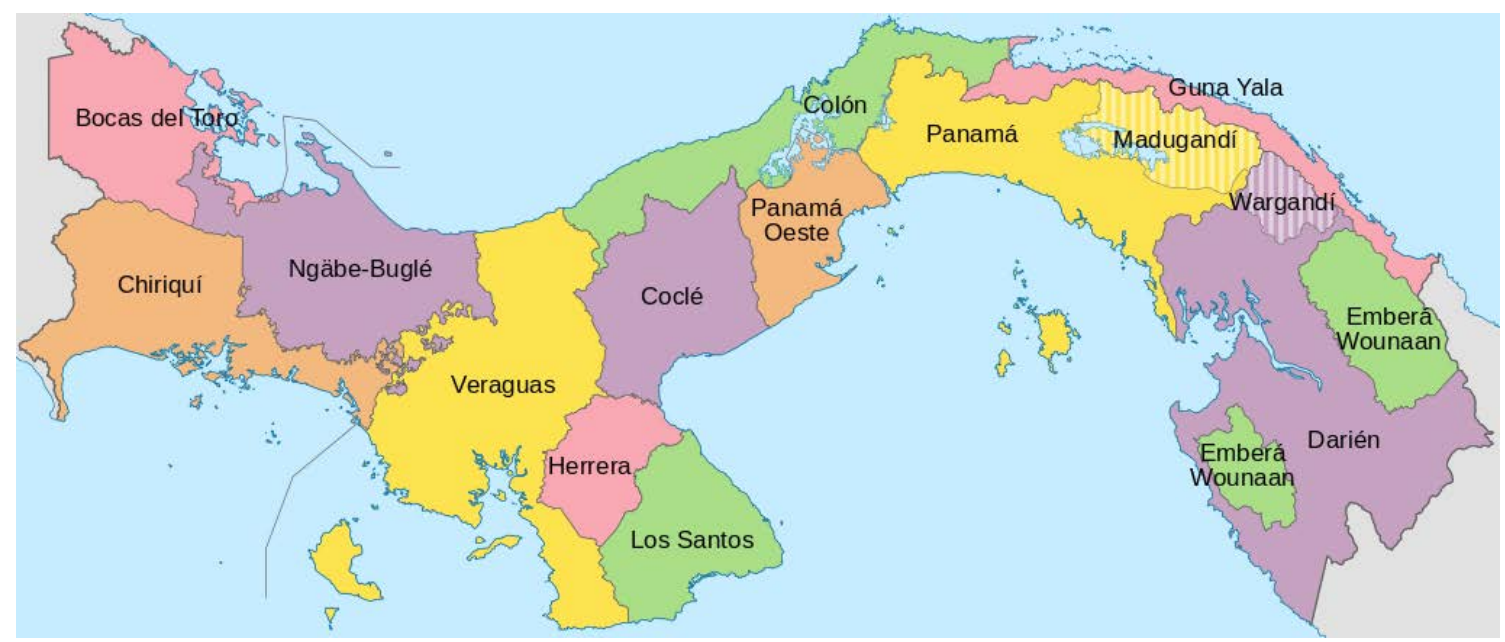

Figure 1 - The Provinces of Panamá

From:

https://upload.wikimedia.org/wikipedia/commons/3/36/Mapa_de_Panam\%C3\%A1.svg

(Licensed under the Creative Commons Attribution-Share Alike 4.0 International, 3.0 Unported, 2.5 Generic, 2.0 Generic and 1.0 Generic license)

Panamá has a diverse demographic, as well, due to Spanish, French and American interference throughout its recorded history. Beginning in 1502, Columbus first made contact with an indigenous Ngäbe chieftain known as Urracá or El Quibian in modern day Veraguas province (Young, 1970). Panamá's first exploitation as a trade route began with Vasco Nunez de Balboa in 1513 (Strassnig, 2010). As early as that next year, African slaves were brought to Panamá that had considerable influence on the culture from there on out (Stewart, 1942). Around the turn of the century French engineers and diplomats first arrived looking into the prospect of a sea-level canal in Panamá or Nicaragua. Panamá was selected and after appreciable efforts at constructing the canal the French had to pull back operations. The U.S. seized the opportunity and inextricably tied itself to the young nation's destiny, implicating itself in Panamá's separation from Colombia (McCullough, 2001).

Today, Panamá is composed mainly of 65\% Mestizo (mixed Amerindigenous and White), 12.3\% Indigenous, 9.2\% of African-descent, 6.8\% Mulatto (mixed Black and White) and 6.7\% White. These unsolicited interactions with European and American influences greatly shaped the demography, as well as the culture and politics of Panamá. Either from the canal or the banana plantations, Panamá has attracted individuals and families from around the world during its' post-colonial era (McCullough, 2001). Its geopolitical circumstance has placed it in the middle of the world economically. Today Panamá sees ship traffic from more than 160 different countries and through the canal alone has produced $\$ 2.6$ billion in revenue (Panamá Canal Authority, 2015). In fact, in 1999 after the U.S. relinquished the canal to Panamá it has become the device that Panamá has wielded to defend itself from foreign interests and towards sovereignty, enough so to fully finance the $\$ 5.25$ billion expansion of the canal itself (Panamá Canal Authority, 2015). This incredible account of a former "banana republic" is setting a precedent for Central America and the Caribbean of how a nation can become its own economic force. However, the money generated by the 
canal does not wander far away from it. To know Panamá is to know two countries divided not by a canal, but by class and more importantly, urbanization.

\section{0a: Economic Inequalities in Panamá}

According to the CIA fact book, Panamá ranks 15th in the world in family income distribution by a Gini coefficient of 51.9. The Gini coefficient is an indicator of income inequality with 100 being perfect inequality or only one family owning all the wealth and 0 being a perfect egalitarian society. Thus, despite Panamá's impressive growth by indicators like GDP, the wealth is divided quite unequally, secluded to the elites and in not the rest of the country as could be seen in Figure 2 . The top $10 \%$ holds nearly $40 \%$ of the country's wealth and the lowest $10 \%$ of Panamá own a little over $1 \%$ of the wealth.

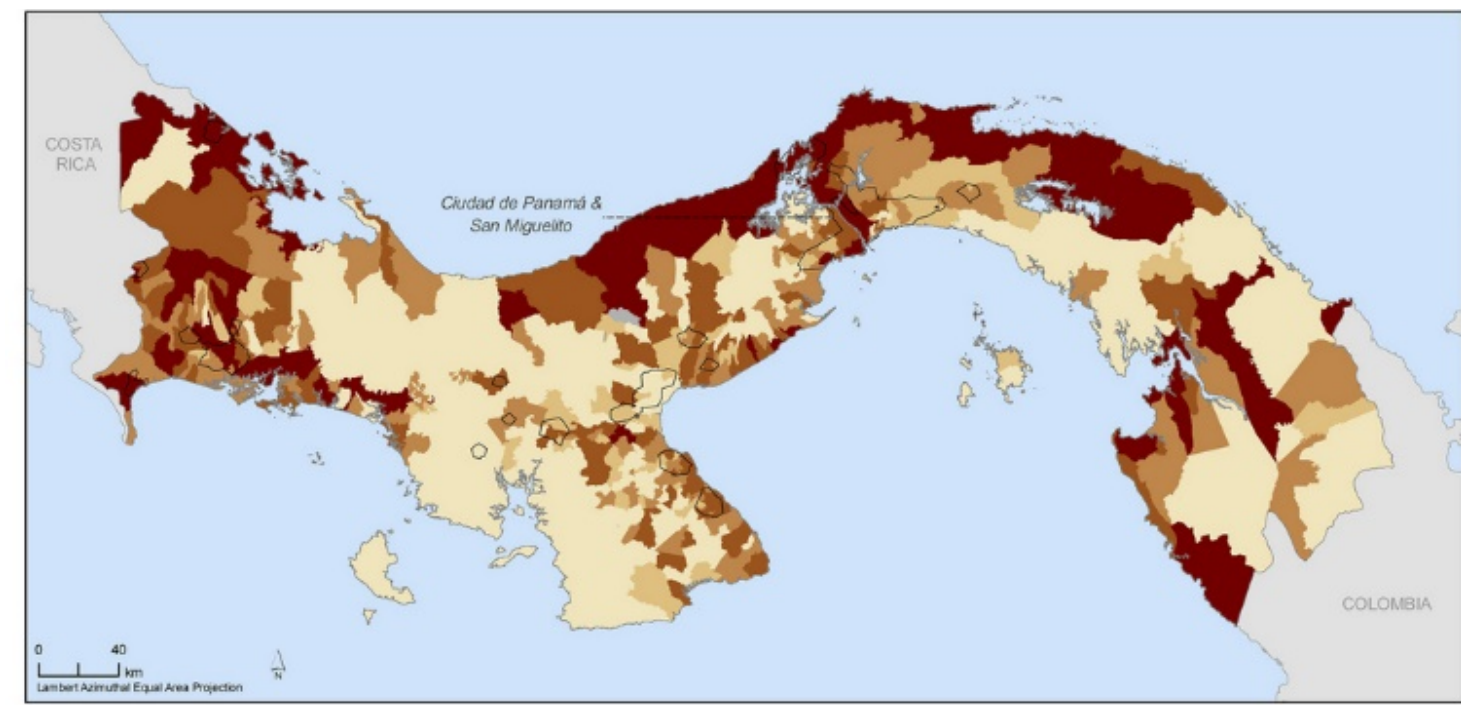

Panamá

Administrative Level 3: Corregimientos

Measures of Inequality

GINI

GINI, or the Gini index, is a measure of the extent to which the distribution of welfare deviates from a perfectly equal distribution. A Gini index score of 0 implies perfect equality, whereas a seore of 1 implies perfect inequality (i.e. all resources belong to one household).

Copyright 2007. The Trustees of Columbia University in the City of New Work.

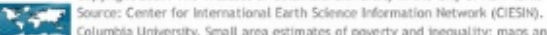

II:AN Columbia Untrersity, Small aresestimates of poverty and inequality; mags and
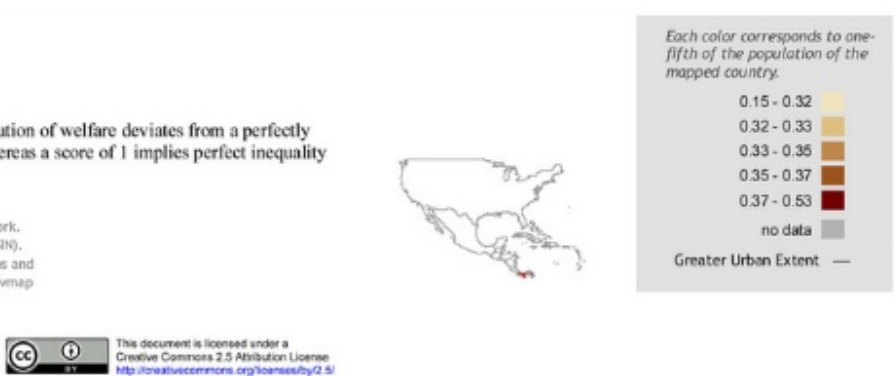

Figure 2 - Gini Index of Panamá by County

Yet the World Bank projects these kinds of figures to subside according to a report this year (World Bank, 2016). This is due to the fact that no other country in Latin America has grown faster since 2001 (World Bank, 2016). This is evident in the decline of those living in poverty from $39.9 \%$ to $26.2 \%$ during the $2007-2012$ period. However, as less people are living in poverty - a by-product of the influx of the urban population around the wealthy 
Panamá City metro area - an astounding 93\% of the indigenous Ngäbe population lives in poverty and $83 \%$ live in extreme poverty (less than $\$ 1.25 /$ day). This fact is not lost on many Ngäbe families that choose to leave their home for work in the city of Panamá. However, despite its far reaching impact, the canal employs not a single individual from the Ngäbe-Buglé Comarca, the semi-autonomous indigenous reservation in Western Panamá that is a focus of the current study. This shows, once again, that the canal's wealth only goes so far (Panamá Canal Authority, 2014, INEC, 2010).

\section{0b: Health Inequalities in Panamá}

Similar disparities are seen when the perspective is shifted to health instead of economics. Life expectancy is 10 years less when a Panamánian is born in an indigenous region or comarca. The rural poor, in general, face the unfortunate circumstance of a country in transition where both communicable diseases and degenerative diseases associated more with the developed world like Type II-Diabetes are widespread (WHO, 2014). As of 2015 the Panamá's rural population comprises $33.4 \%$ of the entire population, but $76 \%$ of the indigenous population lives rurally.

Rural inhabitants are less accessible to regular transportation and less likely to have public services such as health care, electricity, water and sanitation. By the terms of the INEC or the National Institute of Statistics and Census data of Panamá, all of the Comarcas are 100\% rural. The province of Bocas Del Toro (BDT) - one of the two regions highlighted in the present study - by comparison, is $60 \%$ rural and is the only province in Panamá that has a majority indigenous population.

Although the urban/rural dichotomy cannot fully explain the discrepancies in health and poverty, some observations can be made comparing the urban and rural Ngäbe populations of Bocas Del Toro to inform us if urbanization can be a valid approach to counteract WASH and, more importantly, health inconsistencies. For instance, although a Ngäbe family lives in urban BDT, they will be more likely than their non-indigenous counterparts to not have any ISF, at all (INEC, 2010). Around 66\% of all urban Bocas Del Toro inhabitants without access to an ISF are Ngäbe. This figure is even more significant when juxtaposed to the rural population that should see less sanitation coverage yet comparatively only $36 \%$ of the entire rural Ngäbe population has no access to an ISF. To expound more on topics involving the target population of the Ngäbe, the specific regions of Bocas Del Toro and the Comarca Ngäbe-Buglé these will be discussed in the following section.

\section{1: Regional Background: Bocas Del Toro and the Comarca Ngäbe-Buglé}

These two regions are pertinent to the current because of their need for unorthodox sanitation solutions due to their rurality. Even if it's been disconnected form the rest of the Panamá, Bocas Del Toro has a deep history that distinguishes it in many ways. Although it was the first region in the area to be explored by westerners, it was mainly avoided due to the indigenous Ngäbe people that earned them the cognomen, "Indios Valientes" or "Brave 
Indians." The Ngäbe chieftain, Urracá interacted with the Columbus fleet in present day Veraguas province, but many subsequent victories over the Spanish deterred outsiders from infiltrating further into the Ngäbe territory known as the "Valley of the Guaymi *". The Bocas Del Toro Archipelago, Almirante Bay and the Peninsula Valiente make up the outer boundaries of the Chiriquí Lagoon seen in Figures 3 and 4, which with its calm waters made it a great refuge for pirates and conquistadors alike.

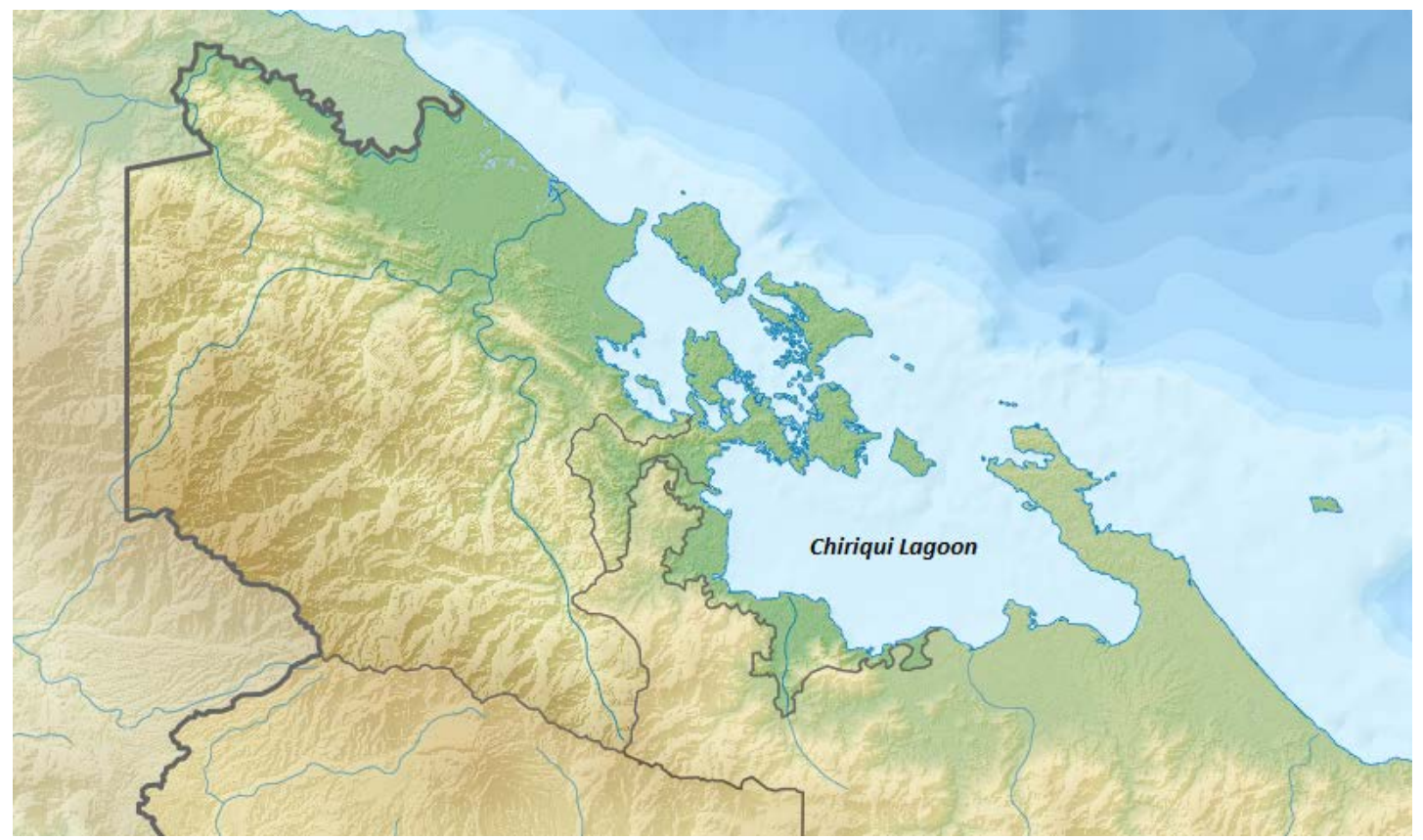

Figure 3 - Relief Map of Bocas Del Toro Province

From:

https://upload.wikimedia.org/wikipedia/commons/a/a4/Panamá_Bocas_de_Toro_relief_map. png (Licensed under the Creative Commons Attribution-Share Alike 4.0 International license.)

It should be noted that Guaymi is an outdated term and many pertaining to this indigenous group have promoted the preferred terminology, "Ngäbe" pronounced $N A W$-BAY, meaning "indigenous". Earlier literature regarding the Ngäbe people or the Comarca Ngäbe-Buglé refers to both groups, the Ngäbe and the Buglé, collectively, as Guaymi, which has loosely based origins referring back to the Buglere word for their Chibchan language family member, meaning either "worm" or "indigenous" (Author's personal experience). Additionally, the other common spellings, Ngöbe, Ngobe, Ngwabe, Guaimi shall be avoided to respect the culture and language of the people herein described. The Buglé, are a culturally similar group, but make up less of the population found in Bocas Del Toro and the Ño Kribo region of the Comarca Ngäbe-Buglé. 


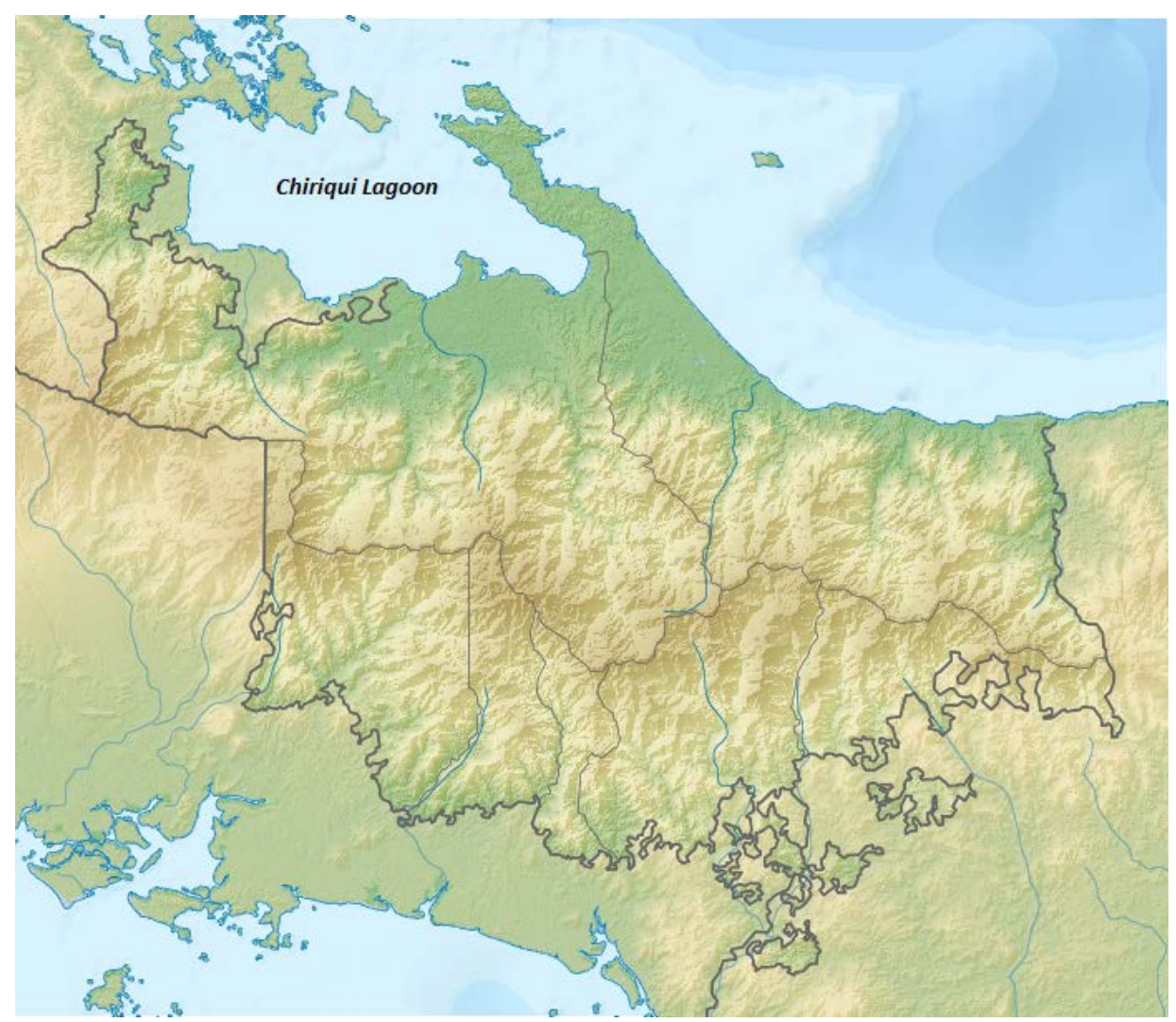

Figure 4 - Relief Map of the Comarca Ngäbe-Bugle

From:

https://upload.wikimedia.org/wikipedia/commons/a/a5/Panamá Ngobe Bugle relief map.p $\underline{n g}$

Licensed under the Creative Commons Attribution-Share Alike 4.0 International license.

This area is now known as No Kribo meaning "of big water", a reference to the historic Cricamola river valley often cited in historic texts as a center of Ngäbe culture and is distinct in dialect and modern cultural practices from the other side of the CNB found on the south of the Continental Divide. Yet, despite the differences Ngäbe culture is fairly uniform even with the lack of a central unifying power structure (Young, 1970). Strong family structures exist that are able to pass on uniting traditions and the language that is not only the most spoken outside of Spanish, but the most preserved. Part of this lies in the isolation and lack of outside influence that is both intentional and involuntary due to some Ngäbe cultural beliefs and practices along with the harsh terrain and lack of access to the region.

The road linking BDT to the rest of the country was only built in the latter half of the 1970s and even then neither party was exceptionally eager to connect "the [mostly autonomous] backwaters of Panamá," which even celebrates its own distinct "independence" days. The influential United Fruit Company had been content with marine shipping of its precious yellow cargo, and the steep Cordillera Central that spans eastern Costa Rica to central Panamá deterred traversal road construction. The real catalyst for construction was the $L a$ 
Fortuna hydroelectric dam and the subsequent need for infrastructure to carry the electricity being sold to Costa Rica.

Thus the Ngäbe had been cordoned off from the rest of Panamá, its national issues and spoils. Many older generations claim to have never seen the Pan-American highway, the canal or even the skyline of Panamá and regaled the author with stories of days-long trips to cross the Cordillera to obtain salt from Chiriquí and often asked about the features of the very country that they were citizens of (Author's Personal Observation). This isolation continues today, but the barrier is less so the terrain, but economics. Transportation exists, but in the form of expensive and long journeys over water-in NoKribo boats rides can exceed four hours and cost more than $\$ 20$, one way, in old, dilapidating dugout canoes. To put this into context, $91 \%$ of the CNB makes $\$ 100$ or less every month, making this a significant toll on a family's income. For that reason, the Ngäbe population is exceedingly growing in BDT proper since access to roads and improved water and sanitation facilities is more common. In 2000, Ngäbe families made up nearly $48 \%$ of the population or 41,700 individuals and in ten years' time this figure rose to $57 \%$ of the total population being Ngäbe and the total Ngäbe population rising by 72\% (72,000) (INEC, 2000 and 2010).

\section{1a: Influences on the Culture of Bocas Del Toro and the Comarca Ngäbe- Bugle region of ÑoKribo}

Since colonization, despite the difficulty of access, other groups have made contact in Bocas Del Toro from British pirates to various European missionaries (Runk, 2012). A large group that has influenced and been influenced by the Ngäbe are Afro-Antilleans primarily of Jamaican descent that make up the Etnia Negra, or the Afro-Panamánians of Bocas Del Toro. During the mid-18th century many Jamaican immigrants arrived in Bocas Del Toro and surrounding areas after first working for the French canal construction or seeking employment in the very influential United Fruit Company that owned extensive plots of land for banana production.

In the early 1930s, Ngäbe men began leaving their more rural homes to work on the vast banana fincas or farms in northwestern Bocas Del Toro and further increased contact with the outside world. Many older men, especially of the coastal regions of Bocas Del Toro/ÑoKribo are trilingual for this reason, speaking Ngäbere, Spanish and the Jamaican Patois commonly known as Guari Guari that itself borrowed many words from Ngäbere.

These types of dynamics are not as prominent nowadays - integrated ethnic communities are scant and in spite of apparent diversity in the demographics of BDT, the majority of the population is still alienated from its non-indigenous minority. Although there weren't large non-indigenous populations before the 1997 rectification of the Comarca Ngäbe-Buglé as its own semi-autonomous reserve, after the historic signing only Ngäbere or Buglére descendants can legally own land within its 2500 square miles (Rosengarden, 2007). Yet the government up to recently fought to own all mineral rights in the CNB, but due to protests and highway closures orchestrated by the Ngäbe politicians had to rescind the unpopular laws offering up contracts to numerous mining companies in 2011(Runk, 2012). The Panamánian government continues to literally test the boundaries of its reach with 
potential mines and two large hydroelectric dams that have received international attention (Young, 1985; Jandreau, 20112012; del Rosario, 2011).

Much of the political force projects like these encounter comes not from organized political party representatives, but from large enclaves of even more rural communities that make up a grassroots folk Christian sect known as the Mamachi or Mama Tata movement (Young, 1970). The movement proposes tenants that would at once return its people to their origins and throw off "bad" elements of its culture. The custom of balsería or krün, for instance, is entirely gone in ÑoKribo. The movement also dissuades Ngäbe from interacting with foreigners including development workers or medical providers and discourages the accumulation of wealth as in the prohibition of fences, such as the ones necessary for large cow-grazing lands.

Further up in the Continental Divide made up by the Serranía de Tabasará or more commonly known as the aforementioned Cordillera are where these large populations live living up to thousands in a community despite the 16 hours of estimated travel to motorized transportation. These areas are much more secluded, conservative and practice a way of life not unlike that of the first people to meet early colonists. The author received accounts that some more "uncivilized" communities still practice polygamy, face painting, wear the traditional ni kwata or bachi and käta, for men and women, respectively. Modern day Ngäbe women wear naguas, long multicolored gowns with triangular stitching that makes up an important system of symbols. These naguas were presumably introduced by early missionaries in other parts of Latin America as the name enagua used in other parts of Central America stems from the Taino word, nagua for cloth. Women in southern CNB wear this dress exclusively, while on the Caribbean CNB, 50's styled housedresses or denim skirts are more common. Men wear colorful or drab pants, typically sewn by a local tailor and are not particularly distinguishable from modern fashion.

\section{2: WASH in Bocas Del Toro-Nokribo and among The Ngäbe Population}

Modern technology doesn't extend much into these rural areas, except in the form of Cellular phones, Smartphones, radios and generators. In agriculture, for instance, the Ngäbe still are primarily subsistence farmers growing tubers like ñame, yuca, taro, etc., as well as rice, bananas and plantain, the last of which, is known as mrä and has considerable significance since it takes the meaning of food, as well. The Caribbean coast provides the substantially wet climate that produces verdant rainforests and an abundant supply of food, although malnutrition is still rampant in the Ngäbe population. A counteractive outcome due to the persistent rains is that nutrients are easily washed away, which can be compounded by deforestation from cattle ranching and the like. These effects can themselves be counteracted by some of the characteristics that EcoSan preaches, mainly soil rehabilitation through natural fertilizers in the form of compost and urine. Yet, these benefits might not be fully taken advantage of since deforestation can be further exacerbated by increased populations as it is the case for both BDT and CNB, having the highest growth rates of 3.84 and 3.60, respectively, compared to the national rate of 1.84 (INEC, 2014). 
Besides, the environmental impact these findings present, a more important issue could be an increase to negative health effects that this impressive rural growth might create as an outcome to the lack of access to WASH and medical facilities as two key statistics illuminate:

1. In 2012, there were 2.0 medical professionals (includes both nurses and doctors) per 10,000 individuals in the CNB and 15.7 in Bocas Del Toro compared to the national average of 29.5 per 10,000 .

2. In $2013,50.3 \%$ of all births took place in the home in the CNB compared to $91.2 \%$ of the rest of the population that received public or private medical support.

The juxtaposition of these two statistics shows that a marginalized population can be further impacted by the lack of modern facilities. This has drastic implications when infant mortality rate is introduced. 20.6 and 17.4 infants under the age of five in the CNB and BDT, respectively, die per every 1000 births compared to 13.8 nationwide. Also, 31.3 out of every 100,000 births a mother in the CNB dies from complications related to birth, compared to 4.1 for the rest of the country. Figures such as these can be ascribed to the difficulties associated with the lack of infrastructure or access by regular transportation. Teachers, as well, find it difficult and, at times, distasteful to live and work in these areas, which also decreases opportunities to for education and ultimately an improvement in one's quality of life (Author's Personal Experience).

\section{2a: WASH Comparison - Urban vs. Rural Populations}

In Panamá, the Institute of National Aqueducts and Sewerage (IDAAN) provides services that include water and sewerage administrate urban areas, whereas communities under 1500 individuals are in the jurisdiction of the Minsty of Health (MINSA). As has been shown through the data, urban residents are far more likely to receive both improved water and sanitation coverage, and this might be reflected in the fact that an entire MINSA regional office is staffed by just three technicians and two supervising engineers, yet the regional IDAAN administration just in the same area has four offices staffed with double that number. The contrast between and rural and urban has been discussed on the national level, but extends to the Ngäbe population in Bocas Del Toro, as well. As of 2010, 57\% of the BDT population described themselves as Ngäbe, yet unlike the CNB, there are considerably more modes of reliable transportation and large urban centers due to the influence of the banana plantations.

In $2010,61 \%$ of the entire BDT population was rural and $75 \%$ of the Ngäbe population living in BDT was living rurally. This allows for some comparison to the living conditions of each respective group. Irrespective of being urban or rural, Ngäbe families living in BDT were $31 \%$ more likely to have access to ISFs (categorized as either a latrine, sewerage or septic system) compared to families living in Ñokribo. Of the urban Ngäbe families, 89\% had access to ISFs and $68 \%$ of rural Ngäbe families did the same, compared to $38 \%$ for the CNB. This trend extends to improved water access with $66 \%$ of the entire Ngäbe population in BDT having access composed of an impressive 95\% of the urban Ngäbe population, and $56 \%$ of the rural population with access to an improved water source through the means of an aqueduct, whereas the CNB has only $38 \%$ with access. 
As mentioned before, the Ngäbe are drastically underserved in terms of WASH coverage compared to a non-indigenous Panamánian, but as shown above, their rural status can explain this. Being accessible requires government investment in roads, healthcare facilities and the like, which is more difficult to employ when not the entire Ngäbe nation is not particularly accepting of this concept. Despite still being marginalized in certain aspects of urban living, rural populations are far more vulnerable (Redclift, 1984). For instance, $87 \%$ of the $504 \mathrm{~km}$ of the vehicle-accessible roads in BDT are paved, whereas only $61 \%$ of the CNB is so (Ministry of Public Works, 2013). Also, to the best of the author's knowledge, none of that $61 \%$ is found in the Nokribo region of the CNB, the entirety of which, being found on the Pacific side of the CNB that exhibits a distinct dry season that would allow for construction of road projects more readily.

\section{2b: WASH Comparison - Water vs. Sanitation in Two Ethnic Groups of Panamá}

With all of this being said, the Comarca Ngäbe-Buglé was not the first indigenous reserve and the Ngäbe are not the only indigenous group indigenous group in Panamá, just the most prolific. The Guna people that reside in the Comarca Guna Yala also known as San Blas pertain to the same language family as the Buglé and the Ngäbe. These two groups will not be used to describe the current WASH situation as an issue of ethnicity, but instead to exhibit a lack of correlations between a single WASH intervention track and potential health outcomes. Their cultures and language are linked, but cannot explain their current circumstances. In terms of improved sanitation, the $38 \%$ of the CNB with some type of improved sanitation seems meager. Yet, the Comarca Guna Yala has a significantly lower $5 \%$ with improved sanitation coverage. Water coverage is quite the opposite, where, again the CNB has $38 \%$ of its population with improved water coverage whereas the Comarca Guna Yala has 77\%.

These stark differences in WASH coverage could provide insight into the effectiveness of a single intervention strategy in this specific setting, but also that living rural also can be characterized by the political nature of each region. WASH coverage in Panamá nationally is commendably high and is reflected in the mortality rate of children under five years old of 17.8/1000 children (Panamánian Ministry of Social Development, 2014). As of 2012, the CNB had a mortality rate of 29.3 and the Comarca Guna Yala of 52.6. Despite, more medical service providers per 1000 inhabitants (11.1 for the Guna vs. 2.0 for the Ngäbe) and near double the amount of individuals with an improved water source, 22 more children out of 1000 die each year in the Comarca Guna Yala. Although the Comarca Guna Yala is far more autonomous as implied above, the CNB is considered semi-autonomous and has not decided collectively against any single interventions but accepts each stakeholder, like an NGO, on the merit of the proposed project and the need of the specific community.

Although a people's language, culture and customs might not be immediately connected with a more technical study on improved sanitation uptake, attempting to understand a culture holds merits by informing development workers and the like on differences between habits and customs, personal choice and culture. By comparing what is inherently an aboriginal custom and something that has been adopted, extension agents can make 
informed decisions on what can be done by either party. A few examples of cultural adaptation with respect to cooking habits - a daily activity much like finding water or relieving oneself - can illustrate this.

Ngäbe families even in the most accessible areas can be seen cooking on fogones or the ubiquitous 3-stone hearth seen in many parts of the world. However, in these and even more remote areas, the practice of raising the hearth to waist-height is common, for convenience of the cook (primarily a woman or girl) and as many have described in conversation, for the safety of the children since many toddlers can fall into the fire or burn themselves (Author's Observation).

Additionally, in more modern households, a propane gas tank and stove is visible despite the lack of subsidization or NGO or governmental interventions to promote improved cooking stoves. When asked about the fact that propane tanks are considerably more expensive than seeking firewood, individuals once again cite convenience and the lack of strenuous work. Some mention that they had seen others practicing this either within the Ngäbe community or a patron or benefactor having one in their home.

This is to say that attributing difficulties and shortcomings of a technology or habit like practicing improved sanitation to the culture of an entire peoples is disparaging and removes the condition of choice from the formula. The idea that any particular family or individual can make decisions against or in line with their cultural values to improve their quality of life must be considered valid as much as it was the case for the industrialized world.

As it stands, improved sanitation practices have been cited as improving health outcomes and ultimately quality of life. In the CNB studies have shown that children using latrines are less likely to contract Ascaris Lumbricoides or roundworm, a persistent parasite that produces diarrhea, which can ultimately lead to malnutrition, stunted growth and, unfortunately, death (Halpenny et al., 2013). Other studies, however, show that latrine coverage does not imply latrine use and latrine use does not indicate positive health outcomes. This can be attributed to the lack of hygiene behavior change - the single most effective WASH intervention - that will be discussed at length in another section (Eisenberg et al., 2007; Strunz, 2014). All three WASH components (Water, Sanitation and Hygiene) are necessary to achieve improved health outcomes, yet water is often singled out due to its global acceptance as a necessity and, strangely enough, its easily assessable indicators. The following chapter will approach the topic of improved sanitation through a review of previous research done in these areas.

\section{Chapter 3: Motivation}

\section{0: Past and Present Sanitation in Panamá}

Despite the rich history of BDT-Ñokribo described earlier, not many of its residents are privy to the content of the numerous academic papers written on their region and them. Besides extensive work on the anthropologic elements of the CNB and the Ngäbe done by 
Young (1970), there are a great deal of studies - as is the case of the current study - on WASH promotion, implementation, monitoring and evaluation here in the region. This is due, in part, to the Peace Corps - Panamá Environmental Health sector's presence in BDTÑokribo and the CNB and the Peace Corps volunteers who have gone on to write theses and investigations on their experiences. The following section is intended to further contextualize the development of improved sanitation interventions in the region and more precisely, the introduction of the EcoSan technology that is the CL from its inception to the present day (Figure 5). These studies along with the historic context informed the author to approach the issue of what ISFs could and should look like when integrated with the needs and feelings of their users.

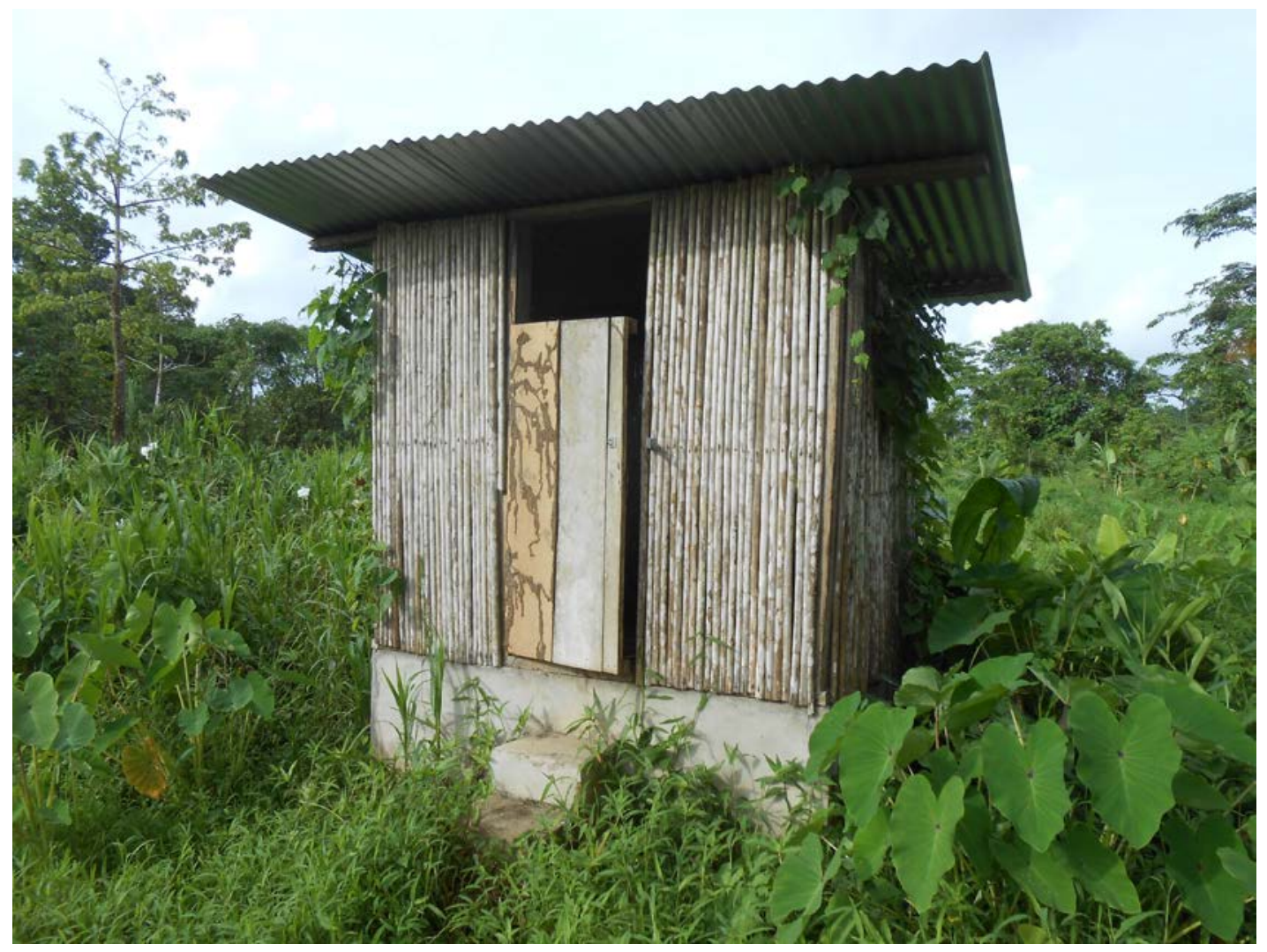

Figure 5 - Traditional 90-cement block CL in a neighboring community utilizing sugar cane as wall enclosure (Photograph by Author) 


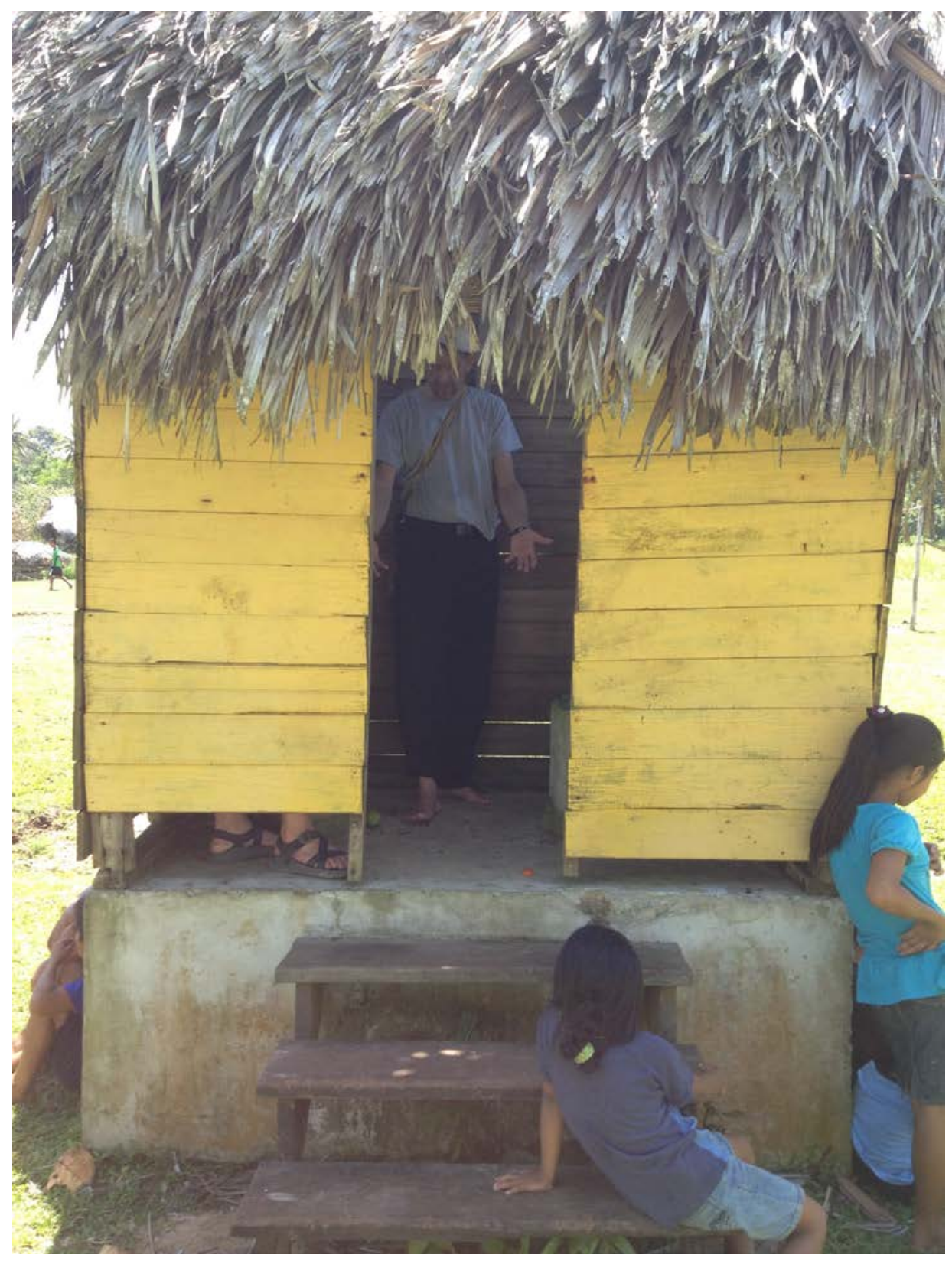

Figure 6 - Original CL using traditional thatched roof construction; note the smaller vault volume designed for 6-month use (Photograph by Author)

\section{(2002-2006):}

Due to issues with implementing other types of ISFs in coastal areas with high water tables or flood-prone riverine communities CLs are often the only alternative. These situations are common in BDT-Ñokribo and for this reason after various meetings and revisions a grant 
was proposed to provide these facilities to the communities of the region. In 2003 Peace Corps - Panamá in corporation with USAID, and ANAM received an IMF grant for $\$ 50,000$ to provide seminars, trainings and the materials for 208 Composting Latrines in 17 communities. Composting latrines as an EcoSan technology have the advantage of an aboveground chamber that can overcome issues associated with flooding and high-water tables that trouble pit latrines and septic systems.

The original design called for the use of carbonaceous desiccant in the form of sawdust, limiting moisture through urine diversion and chamber volumes sized for a family of 8-12 for a period of six months. This design (Figures 5 and 6) and a thorough construction guide are outlined in the first relevant study done on this area (Hurtado, 2005). Hurtado goes on to evaluate the performance of 107 CLs in BDT-Ñ using temperature readings taken from inside the composting chambers. Of 97 CLs highlighted in the study, only around $30 \%$ had readings above the ambient temperature (Hurtado, 2005). Although, temperature alone does not account for the mechanism of pathogen inactivation that takes place when aerobic decomposition takes place during composting, it is one of the most important factors. Therefore, as early as 10 years ago, it was known that the CLs in BDT-Ñ were inadequately treating human waste, yet there had not been any studies done then or now on the health outcomes of the beneficiaries of these projects.

\section{(2006-2012):}

This seminal research was followed by two more studies focusing on the pathogen inactivation in CLs specific to the region. In 2006, Kaiser inspected and surveyed 103 latrines and 70 individuals across six communities. A discrepancy was found between the $98.6 \%$ of CL users in BDT-N that believed they used enough desiccant and the $71 \%$ of the latrines found to not have properly desiccated compost. The inside chamber was also inspected with $94.7 \%$ showing evidence of some type of desiccant used and correlated closer with the interviewees' responses. $95.7 \%$ of the participants answered that sawdust was their main desiccant of choice, $76.8 \%$ reported using ash, as well, $7.2 \%$ said dried grass or leaves were used, and $14.4 \%$ referred to a different desiccant choice, either dirt or sand, rice or coffee husks. $20 \%$ of users claimed to only use sawdust and $4 \%$ to have only used ash.

As in the previous study, it was suggested that if thermophilic conditions are not present in many CLs, and if the main inactivation method was desiccation at high $\mathrm{pH}, \mathrm{CL}$ users should change their operation to reflect through the use of ash or other high $\mathrm{pH}$ desiccants. This conclusion is found in other EcoSan investigations and correlates Ascaris ova inactivation with low moisture contents and high pH (Endale et al., 2012).

In 2008, Mehl was able to conduct another a round of surveys on five of the original six communities from Kaiser's study. This study focused on a quantitative approach using temperature and, $\mathrm{pH}$ measurements to compliment the previous study's use of qualitative data. Five compost samples were also taken for laboratory physio-chemical analysis including $\mathrm{pH}$, moisture content, carbon-to-nitrogen ratio and a microbiological assay to determine pathogens present. Field observations were made of 63 CLs in the respective communities regarding desiccants used. $26 \%$ of CLs were to found containing ash, $60 \%$ with sawdust, and $14 \%$ having a combination of both. These findings correlate with the 
other figures referenced previously and show a general trend towards the use of sawdust and operating the CLs for aerobic decomposition and not desiccation. Yet, in both, users mentioned that a desiccant of any sort was, at times, difficult to acquire.

The quantitative results showed that only $12 \%$ of 50 CLs surveyed were found to have temperatures exceeding the average ambient temperature of 29 degrees Celsius as originally reported by Hurtado. 46 sealed chambers were also evaluated for $\mathrm{pH}$ value showing, again, that the average value of 7.7 was not sufficient to enable pathogen inactivation. This was verified through the microbiological assay performed by a laboratory in David, Panamá where all five CL samples tested positive for fecal coliform and in particular Ascaris or roundworm, a main indicator species of ISF effectiveness. Of note is that three of the five latrines tested had a pH greater than nine and were still not able to inactivate pathogens in the prescribed treatment duration of six months.

These findings were supported by many other similar studies concluding that EcoSan latrines, mainly CLs and UDDTs, were not able to inactivate pathogens within the previously suggested 6-month timeframe (Redlinger et al., 2001). The current WHO guidelines reflect studies like these, and now recommend new CLs to increase storage to one year and subsequently increase their chamber volume as needed. Other recommendations include increasing desiccant use and including more high- $\mathrm{pH}$ materials like wood ash to lower moisture content and increase the inactivation likelihood that has been observed with alkaline desiccants. Peace Corps-Panamá and the Panamánian Ministry of Health have also updated their training and promotion to comply with these recommendations, yet the more than 200 CLs found throughout BDT-Ñ were built to the previous guidelines and not been modified.

\section{(2012-Present):}

In more recent years, through the myriad of EcoSan reports coming from NGOs, governmental institutions and academia worldwide, the Ministry of Environment throttled back its implementation of new composting latrine projects and now favors the newlyelected President's campaign platform to reform improved water and sanitation in rural Panamá with flush toilets promised to every household and community. Peace CorpsPanamá has followed suit, but only due to the lack of stakeholder funding, with current CL projects being funded through either crowd-sourcing via Peace Corps promotion or selffunded by community contributions.

The improved sanitation promotion and implementation focus on pit latrines as they conform to the need of many of the communities throughout the areas where Peace CorpsPanamá operates. In 2013, a study on the adoption, use, monitoring and evaluation of pit latrines shows that more than roughly $75 \%$ of pit latrines were described as "in-use". The greater majority of the pit latrine projects were subsidized and the study proposes that similar to other studies, sanitation projects are more likely to succeed when subsidized (Midkiff, 2013; Happleton, 2009). Project "ownership" is suggested to be a critical component of any development intervention by the Peace Corps to in promoting a deeper commitment more likely to sustain use and maintenance after completion. Ownership can be endowed to a project through post-project initiatives like "health clubs" or committees 
devoted to overseeing that latrines are well operated and maintained (Midkiff, 2013; Happleton, 2009).

Later, in 2014, a similar study was published focusing more on the sociological aspects of CLs intending to further the knowledge of ISF uptake in Panamá and especially the regions in question. Wilbur (2013) revisited 12 of the 27 initial beneficiary communities that were discussed in the three prior studies on CLs in BDT-Ñ plus 11 communities that had participated in CL projects since then. More than 200 CLs in total were visited and 100 of individuals or families were surveyed or interviewed with respect to: CL use, likes and dislikes of CLs, and perceptions of feces and the use of composted human feces as a soil amendment. Similarly, to the study on pit latrines, around $71 \%$ of the CLs visited were completed and, of those, $72 \%$ of CLs were considered in use. According to observations made during the study, only $46 \%$ of CLs were being used correctly. Reasons stated for construction incompletion were mainly attributed to a lack of interest from the beneficiary. Reasons for abandoning the CLs included broken or clogged urine diverting pipes, poor site selection, inadequate construction, and flood damage.

Other significant takeaways from the user perceptions recorded were the need to address water-washing issues and the daily maintenance including the demand for desiccant. There exists a water-washing solution known as the "Ngäbe bidet" as seen in Figures 7,9 and 11 that is currently very rare and found in only two communities associated with the study. Certain recommendations were suggested for current and future users to increase the likelihood that CLs would be used correctly. These included post-implementation educational seminars to correct possible misinformation and update users on current practices. On the technical side, urine-diverting tubes must be sized correctly to decrease the chances of clogging that alone could put a CL into disuse. A major takeaway incorporating both social and technical aspects of the CL was the need for water-washing functionality (Figures 7, 9, 10 and 11). As mentioned previously, judging by ethnicity alone would provide a false representation of the issues associated with CL adoption. Here, however, it is the culture that dictates the user's appropriate or preferred sanitation solution. Open defecation in a river or stream is very complimentary to a culture that values and lives in riparian areas.

Also, of note, was the concern over desiccant availability. Along with the urine-diversion, dry material is a vital component to provide the lack of odor that users value greatly in CLs (Wilbur, 2013). This shows where technical and social elements coalesce again, and where both parties - users and stakeholders - agree that more desiccant should be used. This point also relates to the previous comment made on the need for educational sessions and, in general, a better understanding of user demands common in participatory design methods advocated by the appropriate technology movement. That is to say that, although the approach had been partially community-led and employed by local technicians and families, this alone did not connect the users to the project to develop the "ownership" other studies have noted is critical to long-term sustainable adoption of a technology or WASH intervention. Another way to do this, besides monetary or "sweat-equity" contributions, is to involve the beneficiaries in the entire process from identifying sanitation as a local issue, to designing an appropriate sanitation method and implementing it on solely through community involvement, as is embraced by the Community-Led Total Sanitation (CLTS) method. 
A concern that had been suggested herein and in other studies, is whether it is worthwhile to promote ISFs if improved health is not always linked to it on the long-term (Joshi and Amadi, 2013). Earlier it was mentioned that throughout the studies above, no measureable health outcomes were investigated in BDT-Ñ. Starting in 2008 and extending over the course of 16 months into 2009, Halpenny et al. (2012) investigated 250 households from 12 communities in the southern CNB that participated in a study to determine this very subject, specifically focusing on "regional, household and individual factors" in preschoolchildren and their relationship with Soil-Transmitted Helminths (STHs) like the previously mentioned roundworm, being the most resilient (Halpenny et al., 2012). To readdress the issues associated with poor sanitation mentioned in the introduction, more than a billion people are infected STHs and is attributed to causing "between five and 39 million disability-adjusted life years, largely attributable to anemia, stunting, and reduced cognitive development" (Strunz, et al., 2014).

The main objective of the study was to determine "reinfection dynamics" or the conditions that might exacerbate infection and, as in the study, reinfection after chemotherapeutic treatment. 356 children were tested and treated in the two cycle groups and each household surveyed on particular demographic and anthropometric indicators to determine correlations between susceptibility to reinfection and factors like living in clusters (regional), wealth, mother's education (household), and height-for-age and children's latrine use (individual factors). One noteworthy conclusion is the correlation between malnourished children and their vulnerability to reinfection rather than helminthiasis causing malnutrition, suggesting that health and nutrition are not isolated and need to be included in sanitation programs, as well. This also had a bearing on the mother's educational level or years in school, which was said to relate to whether she would take children to a health post or practice poor hygiene found to be true in other studies, as well (Mara et al., 2010). Also, latrine use proved to be positively correlated with uninfected children (Halpenny et al., 2012).

Most recently, Gibson presented a model for an experiment to investigate the efficacy of the use of ammonia disinfection towards STH inactivation in CLs of BDT-Ñ. This process is an experimental sanitation method using uncharged $\mathrm{NH}_{3}$ to act as an ovicide through its toxicity and ability to dissolve the tough outer layer of STH ova (especially roundworm) by moving freely back and forth through the cell barrier (Nordin, 2007). This study focused on STHs due to the global burden soil-transmitted helminthiases create. In order for enteric parasites like soil-transmitted helminthes to be viable in human feces, they must be ingested during their infective stage. Human feces from an infected individual does not contain embryonated ova or ova, instead a period of fertilization needs to occur in soil containing the proper conditions - moist, warm, shaded soil (WHO, 2014).

There have been several developments of this sanitation method in other studies, but none have been carried out in the present region nor with considerable focus on a user-centric design. A significant amount of practical information regarding rural communities in BDT-N has been accumulated through the studies presented above. The author attempted to capitalize on the cumulative knowledge gained through the previous work in the design, promotion and implementation of a demonstrative "pilot" CL in a community within the very region discussed throughout. Due to the flood-prone characteristics of a riverine 
community mentioned throughout and the recommendations of the above studies, special consideration was put into providing an economically accessible, user-friendly, culturally appropriate design in a participatory manner that will be discussed in the following section.

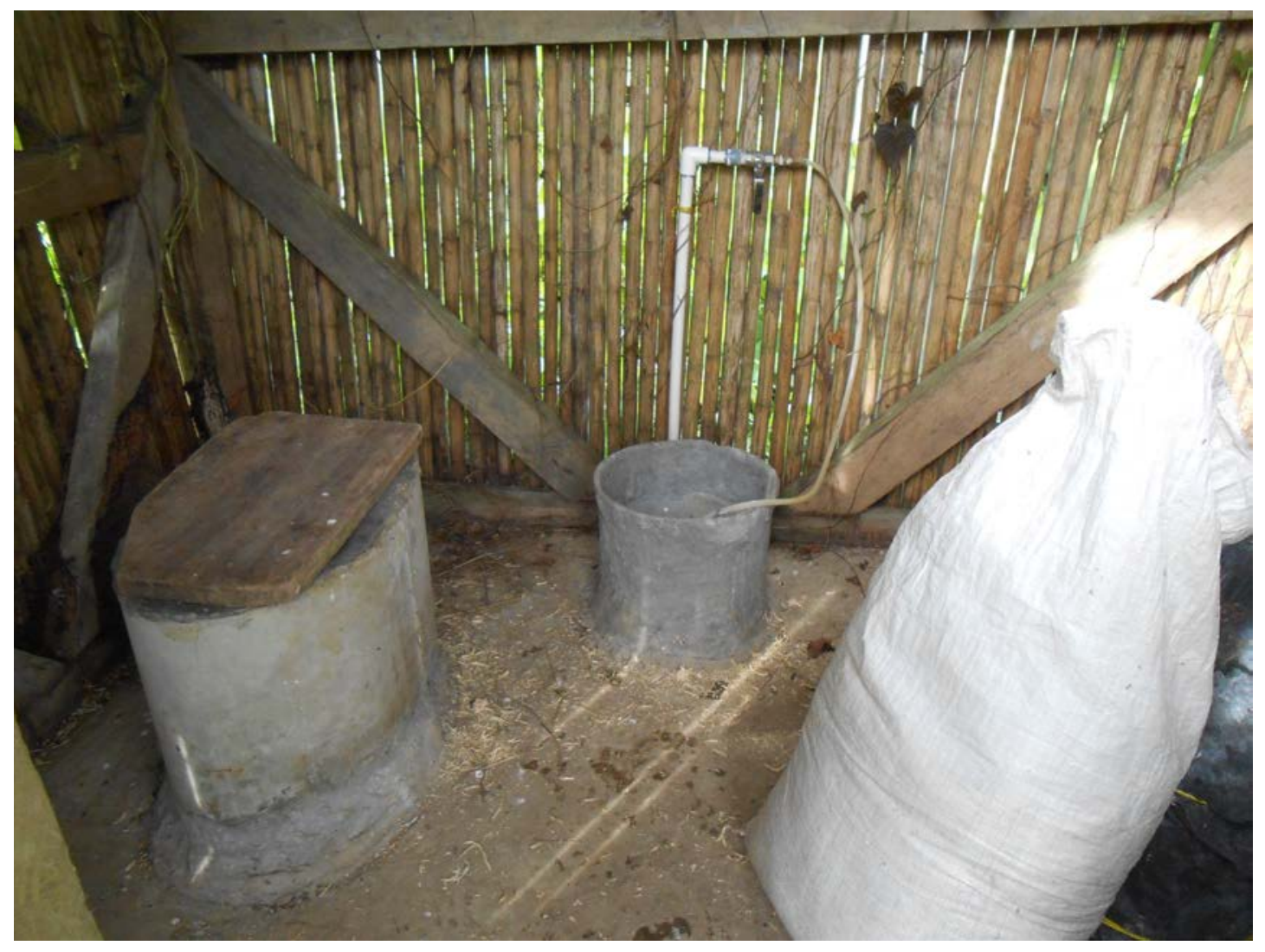

Figure 7 - Inside view of completed CL incorporating a "Ngäbe bidet" between the two toilet seats and a hose connected to a water system (Photograph by Author) 


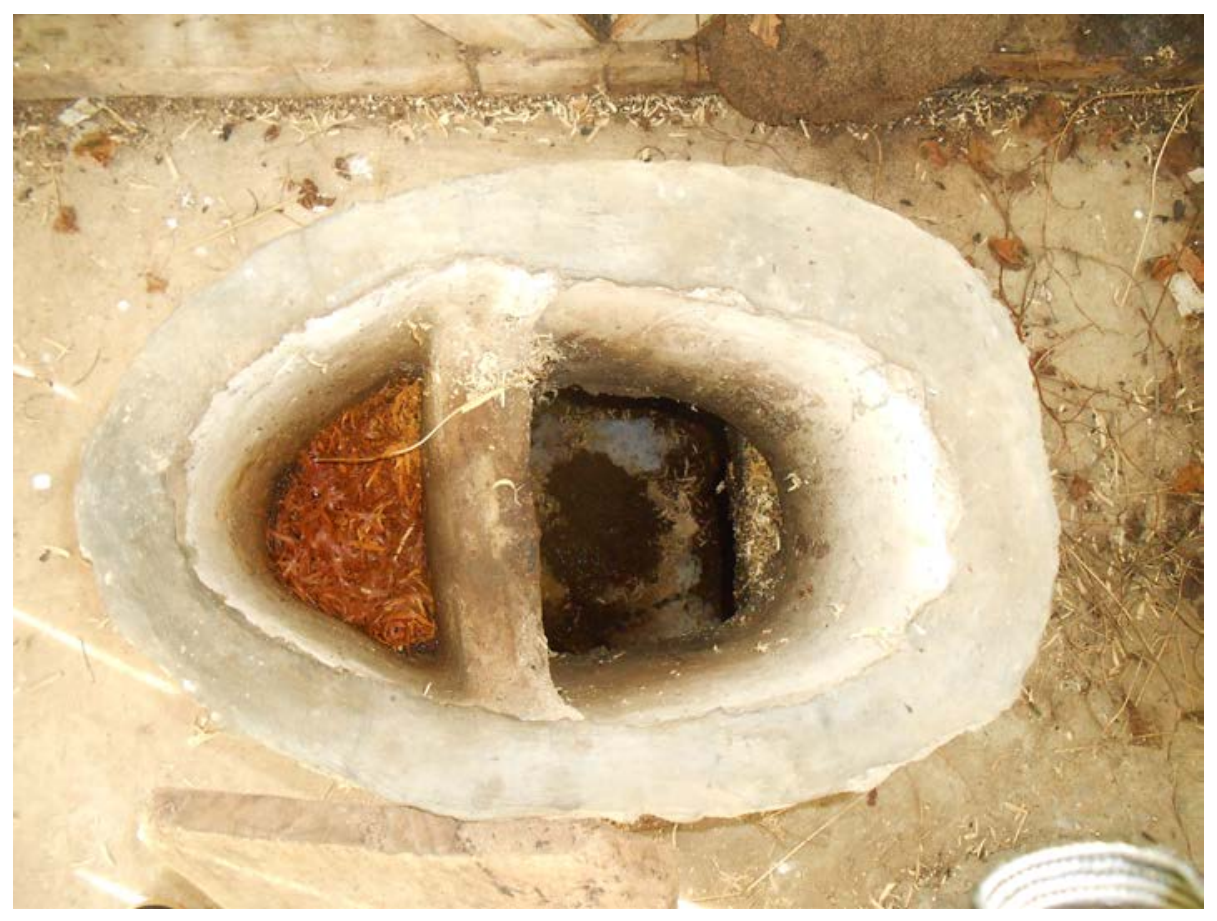

Figure 8 - Traditional urine-diverting seat with the left hole serving as the urinal and the right for excrement; note the sawdust mistakenly placed in the urine-diversion portion (Photograph by Author)

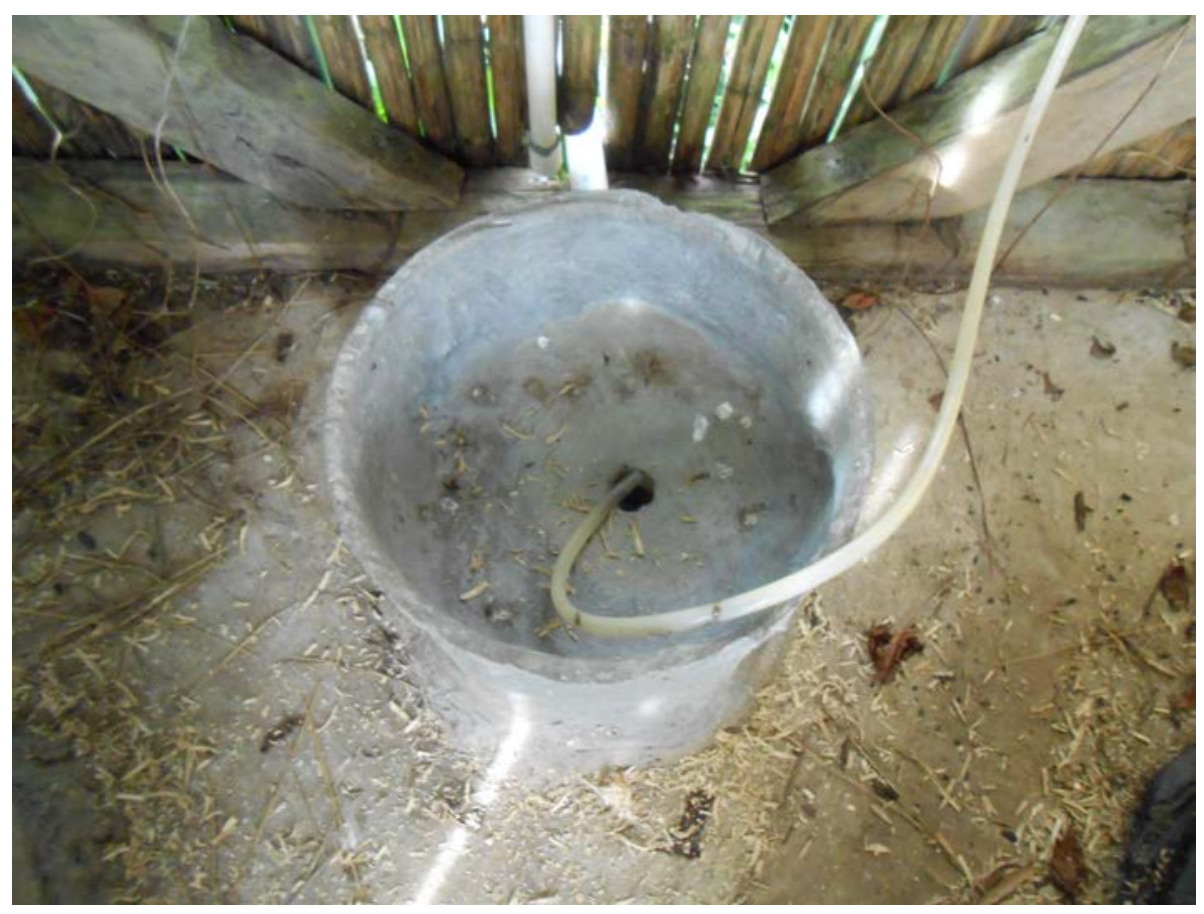


Figure 9 - Close-up view of the "Ngäbe bidet" (Photograph by Author)

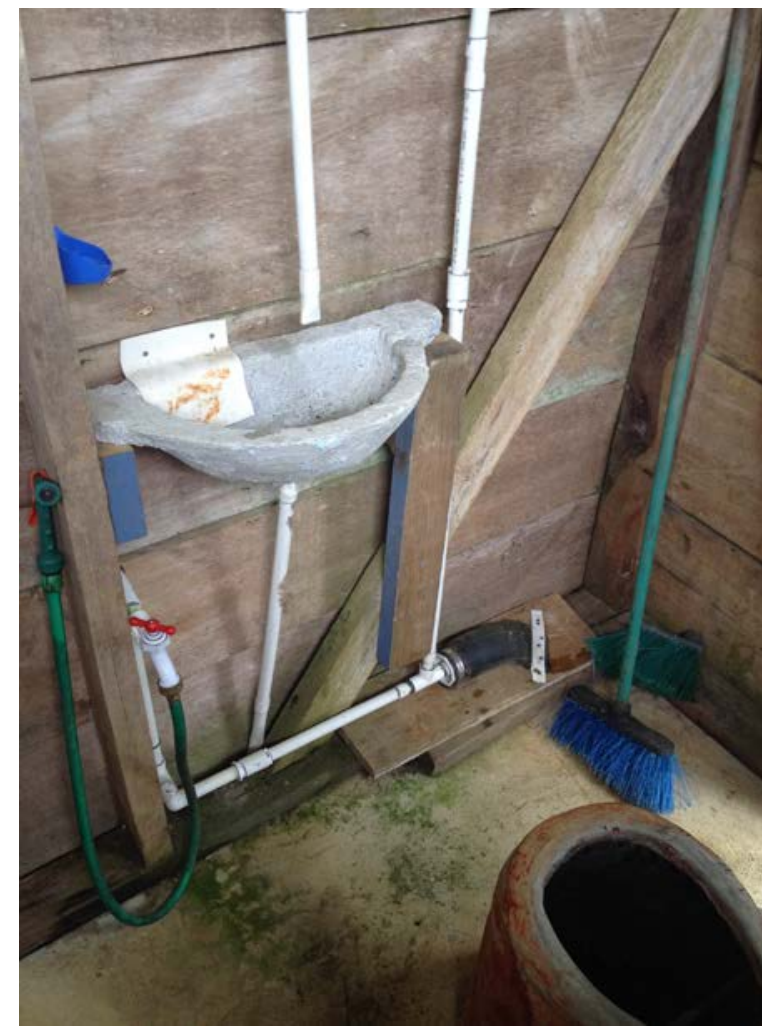

Figure 10 - A foot-pumped handwashing station utilizing ferrocement and appropriate technologies like rainwater harvesting (Photograph by Author)

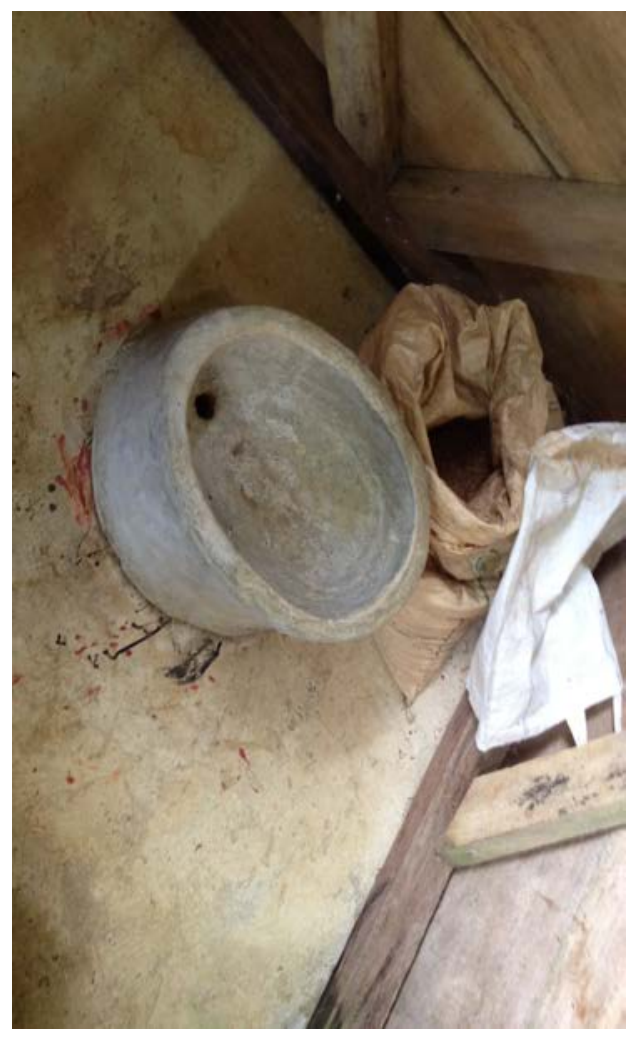

Figure 11 - Alternate design for a bidet utilizing ferrocement and intended to be switched after each compost harvest (Photograph by Author 


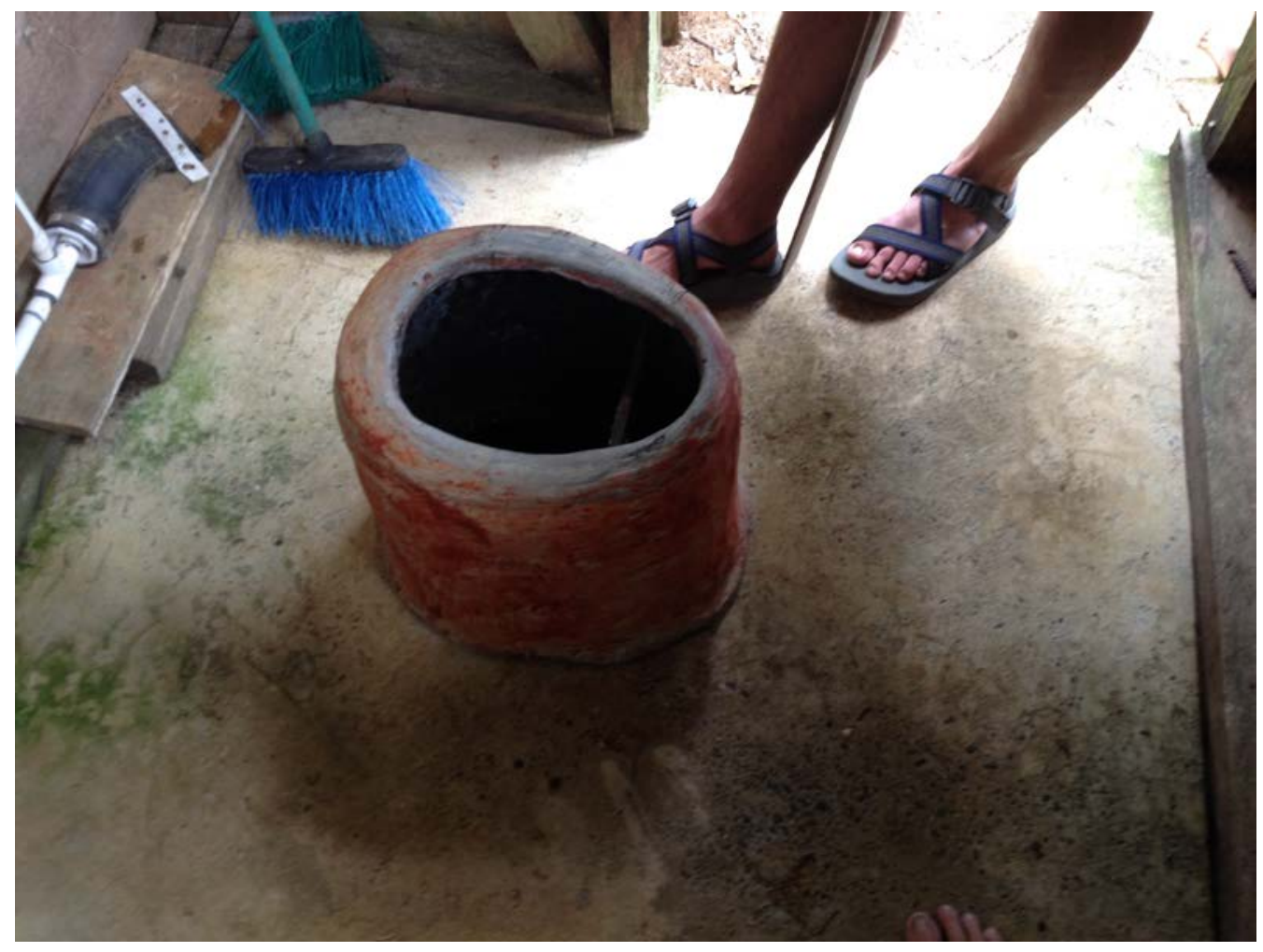

Figure 12 - Alternate urine-diverting seat design utilizing ferrocement instead of a fiberglass mold to create an easily constructed, light-weight seat to be paired with Figure 11's bidet design (Photograph by Author) 


\section{1: Sanitation Intervention in Drigari, Comarca Ngäbe-Buglé, Panamá}

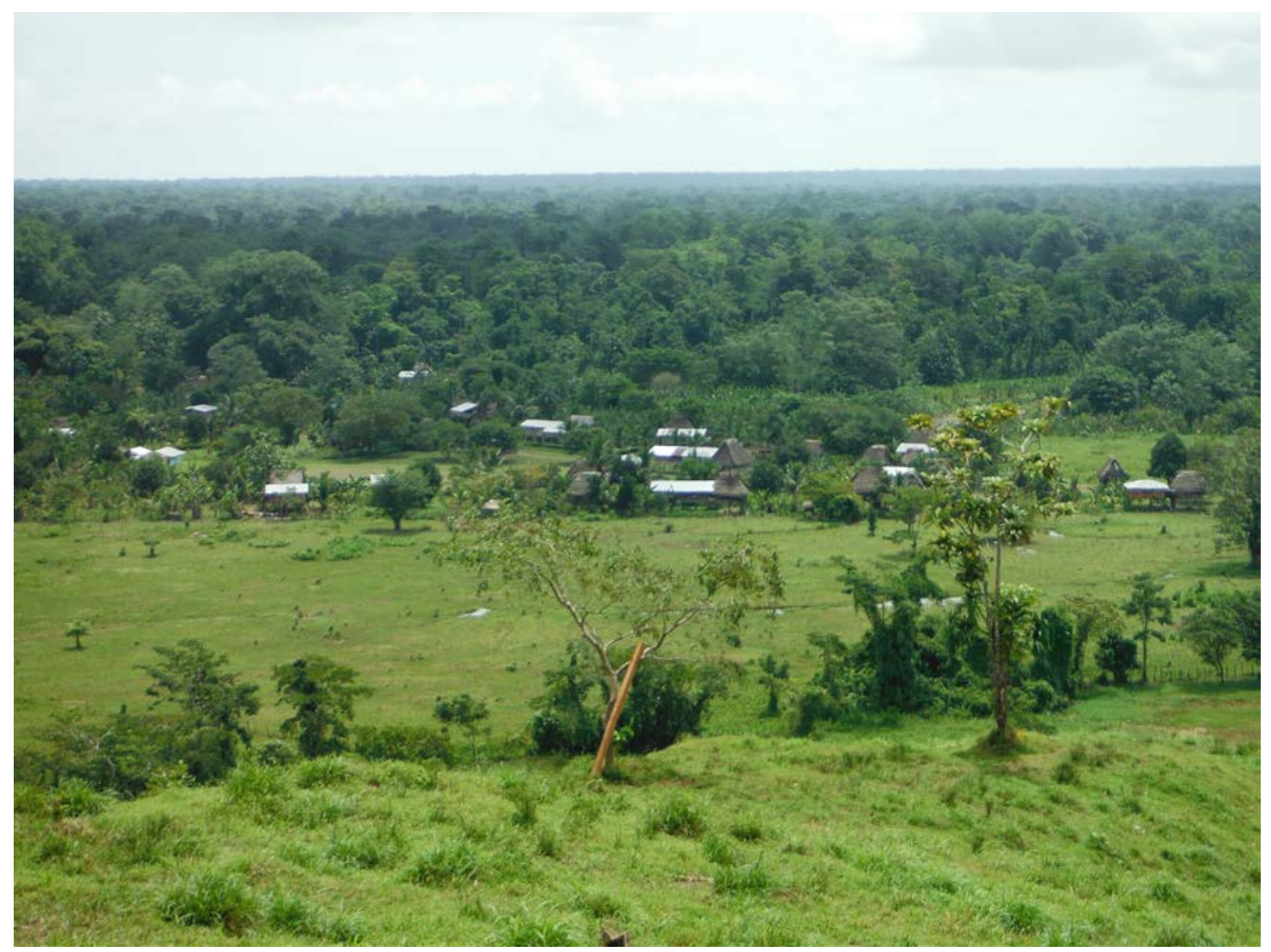

Figure 13 - Drigari from a hilltop (Photograph by Author)

The present chapter will discuss the community of Drigari and describe an sanitation intervention the author and community set out to implement using the knowledge and insight gained from the studies described in the preceding chapters. The Environmental Health Sector of the Peace Corps-Panamá program focuses on reaching the most underserved communities, typically indigenous. As such, the author was invited to serve in the rural Ngäbe community of Drigari in the Caribbean CNB region known as Nokribo. Drigari is Ngäbere for Tarpon Creek, driga meaning tarpon and the suffix -ri meaning stream and was named due to the vast quantity of these fish found there during flood conditions.

The condition of flooding plays a critical role in the lives of the families in Drigari, at once providing increased accessibility to other communities along the waterways and dumping nutrients onto the floodplains that make up their fincas or farms of bananas, plantains, taro, rice etc. Of course, these imperceptible benefits can quickly be outweighed when the dangers of flooding are considered, as seen in the juxtaposition of Figures 14 and 15 . For 
this reason homes are stilted about six feet off the ground and dugout canoes are abundant. Travel to the nearest port town of Chiriquí Grande to acquire merchandise like clothes, electronics, food and the like takes 2-4 hours either by larger motorized versions of the dugout canoes used by families or modern fiberglass speedboats and can cost between $\$ 8$ $\$ 10$ one-way.

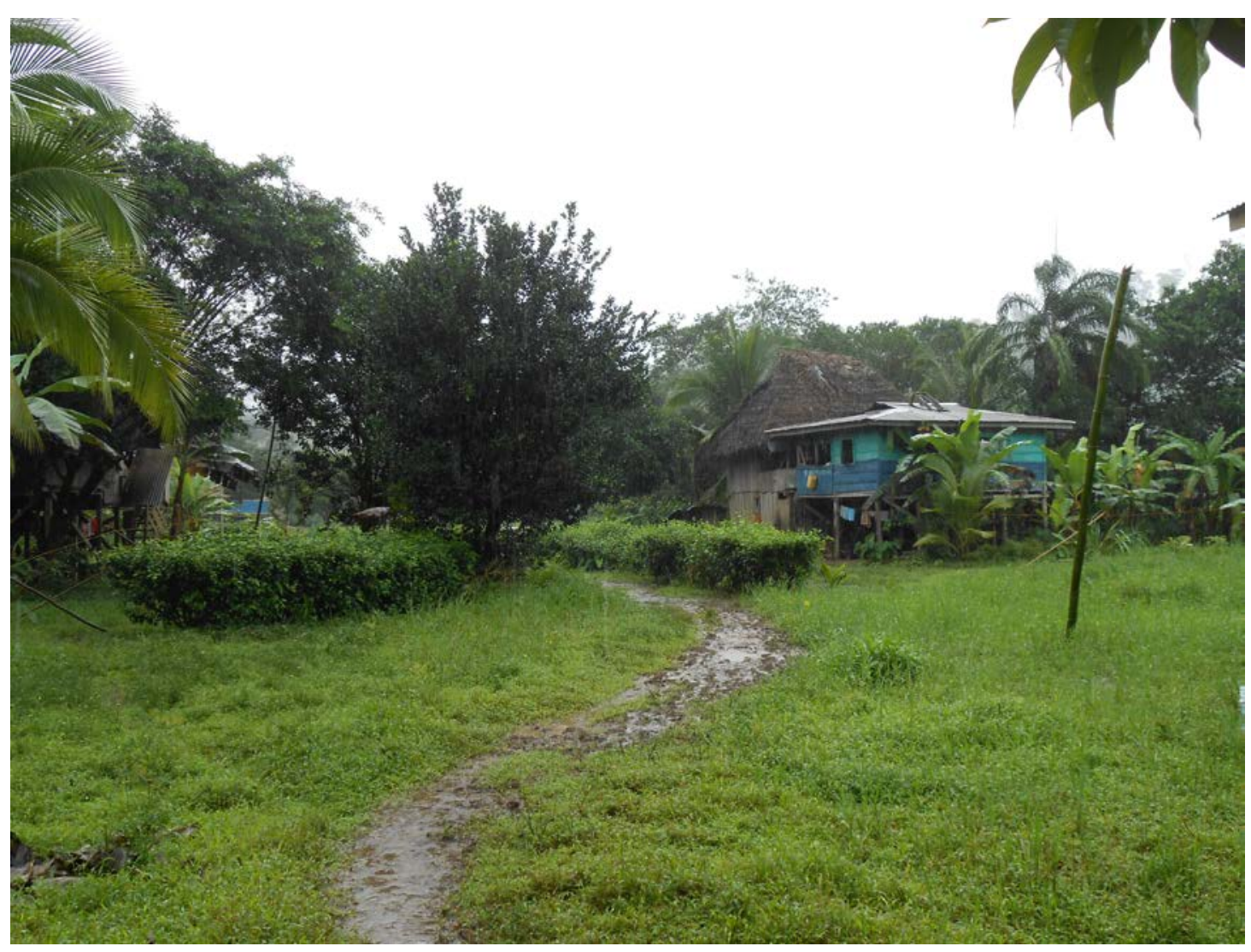

Figure 14 - Drigari prior to a flood event (Photograph by Author)

These conditions make Drigari a transitional community being modernized by every trip up and down the Manatee River. Globalization, however, is a class-dependent phenomenon requiring considerable wealth in order to just leave since a typical family makes anywhere from $\$ 2000$ per year to no considerable income, at all. Some incomes are supplemented if a single mother collects on the Red De Opportunidad welfare program where $\$ 200$ is provided every two months. A $\$ 20$ roundtrip, then, can account for $10 \%$ of that in a single day. Despite all of this, a great deal of the population does leave at least once a year to harvest coffee in the volcanic soil-rich farmlands of the neighboring Chiriquí province or in Costa Rica. 


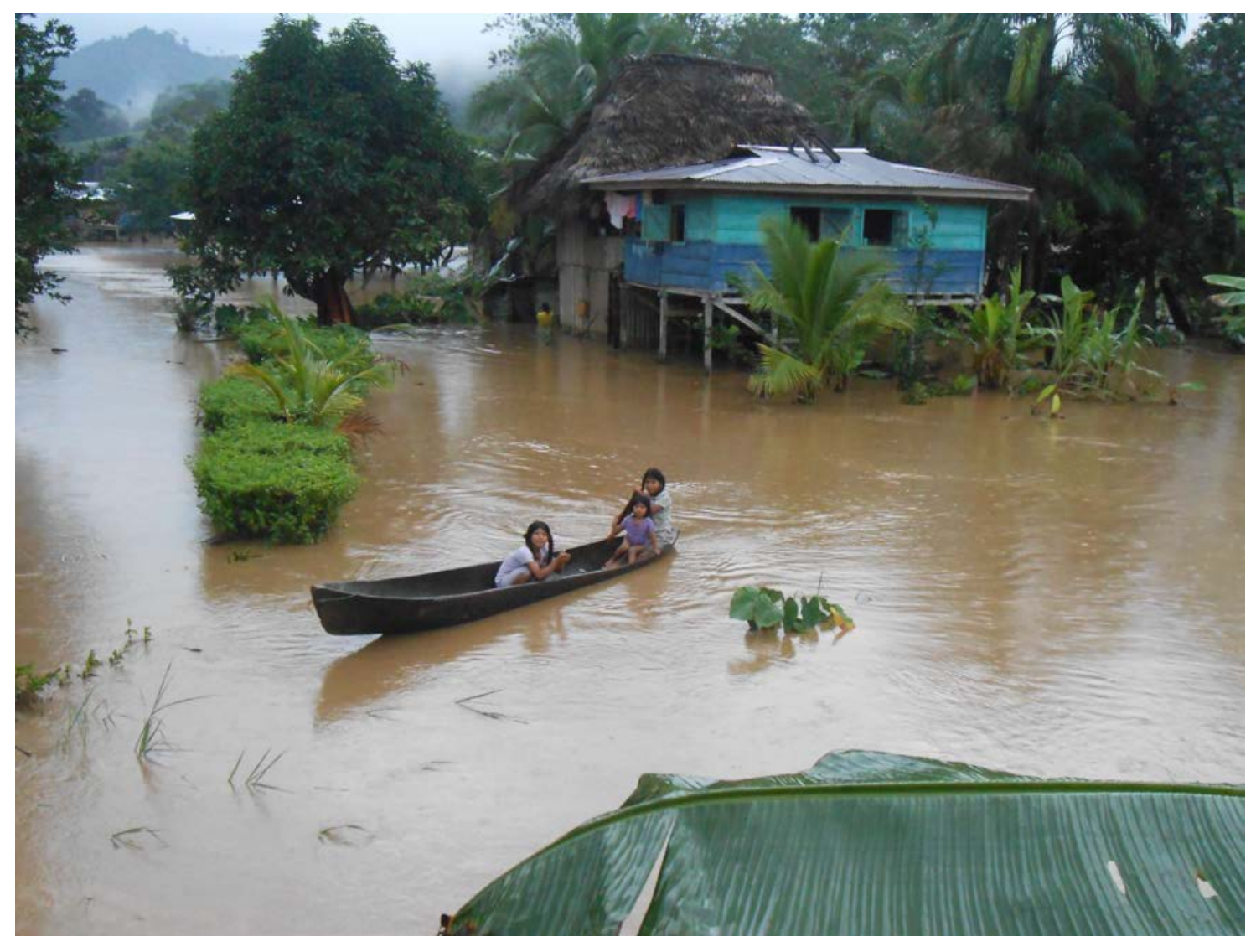

Figure 15 - Drigari experiencing a flood event (Photograph by Author) 


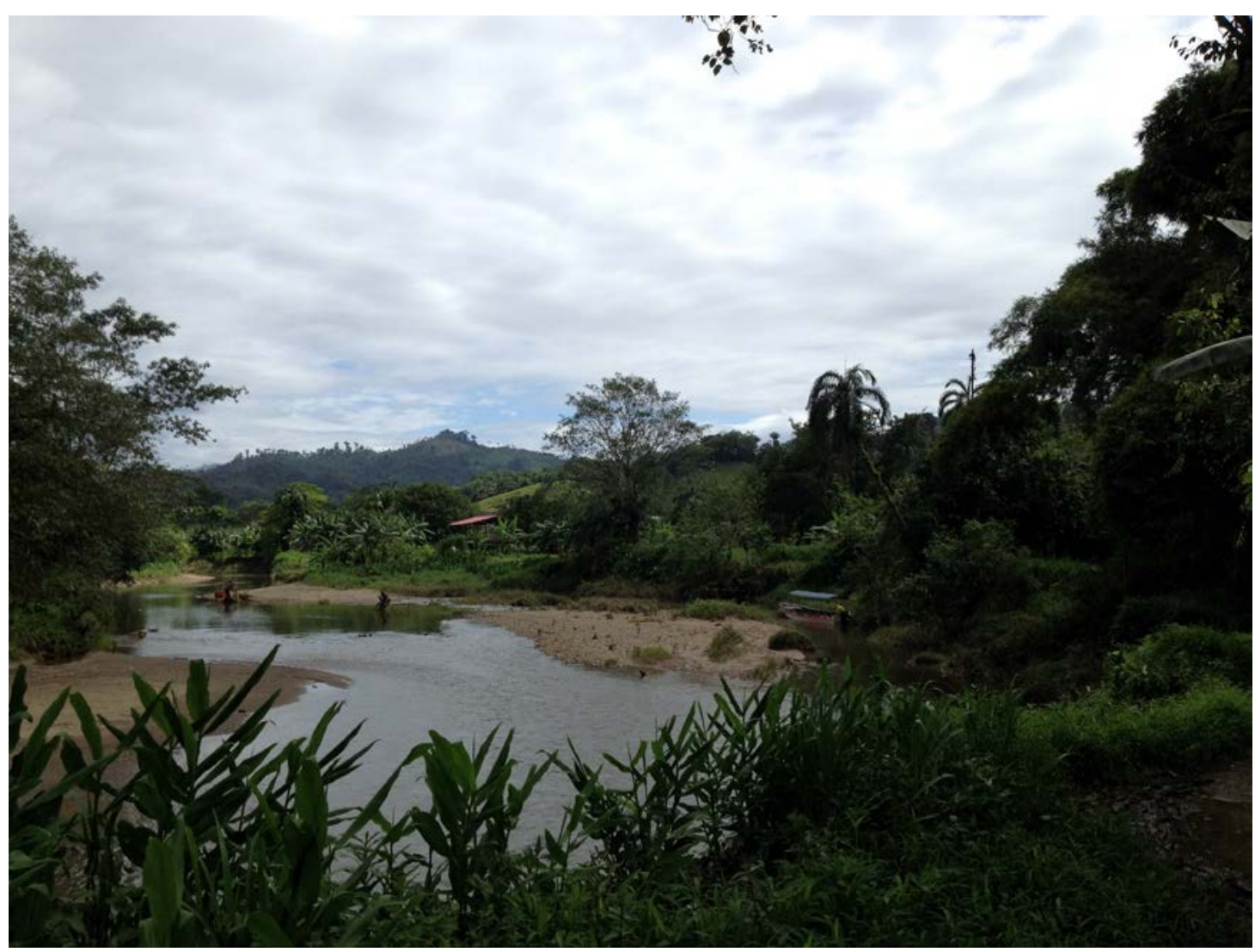

Figure 16 - The confluence of the Drigari and Manatee Rivers (Photograph by Author)

The influx of money each March brings the purchase of livestock - mainly chickens as only a few families have land maintained enough for cattle - clothes, and costlier items like gasoline-powered generators, freezers and cellular phones. Besides the yearly workmotivated migration, people work as boat drivers, sawyers, tailors, shop-keeps and work manual odd jobs called chamba like hauling heavy items long distances and for hours at a time and, cleaning farms of overgrowth with machetes. Typically, the families with the most social mobility are ones that own many heads of cattle or a boat for transportation.

The 200+ residents of Drigari, are made up of mainly two families dispersed through approximately 30 households. A gravity-fed aqueduct serves about 27 of the homes and is sourced from a stream in the adjacent hillside of Drigari. Water service is occasionally interrupted during strong rainstorms, which are quite frequent, as the Caribbean side of Panamá does not have a distinct dry season. This, then, necessitates the women of the household to look for water in the Manatee River, which also serves as the main sewerage of the entire watershed. According to the leaders of the water committee in Drigari, the community came together and self-funded the initial aqueduct, which was simply 500 feet of PVC pipe connecting the hillside, stream to the community. This initiative and the community's protests motivated a local politician to elect to use money set aside for infrastructure projects to donate the materials necessary to construct a 3000-gallon tank and to amplify the stream source with a dam. 
Accounts like the above motivated the author to approach a project to improve the sanitation situation of the community by creating a similar communal initiative. There are many programs developed by NGOs, WHO/UNICEF, and governmental institutions to promote WASH interventions and uptake of improved water, sanitation and hygienic practices. Sanitation and hygiene, often less alluring to communities, families and developmental workers alike, than water projects can create tensions between all participating parties since, simply put, water is an immediate, global concern and sanitation is more taboo.

Despite this, the Community-Led Total Sanitation (CLTS) approach has had particular success in eliminating the practice of open defecation (OD) in India, which apparently accounts for 600 million of the previously mentioned 900 million people that practice it. One concept it promotes is known as "shit-shaming" - attaching a visceral and antagonistic reaction to open defecation and "community-led" campaigns to alienate anyone caught defecating in the open. Another less controversial practice it advocates for developmental interventions is staying in a community until $100 \%$ latrine coverage is adopted after monitoring and evaluation is executed (Hanchett et al., 2011).

CLTS was ineffective in the area of Drigari due to the inherent shame already associated with excrement. In fact, community members claimed that they prohibit open defecation already and enforced it readily. Families in Drigari do not find OD relevant to their community since the rivers and streams of the area serve as a ready-made, natural sanitation system. Not a single individual would argue that excrement is disgusting, odorous and a health concern, only that they do not contribute to environmental contamination as described throughout. For this reason, arguments such as the one made by Luby (2014) in a commentary in The Lancet that health outcomes are inconclusively tied to improved sanitation without behavior change ring true, summarized with this quote below:

"With the present state of scientific knowledge, it is unclear whether or not changing a longstanding, culturally acceptable community practice of open defecation in an area some distance from human settlement towards concentrated defecation in a makeshift pit latrine located much closer to the households' food preparation area actually improves the health of household members."

That is not to say that open defecation in waterways can be sustainable, especially with the population projections for the CNB and BDT. Untreated waste not only contaminates waterways with water-based pathogens like guinea worm and schistosomiasis (Cairncross, 1983), but high nitrogen and other nutrient concentrations found in human wastes cause eutrophication in waterways that causes fish and other aquatic species kill due to anaerobic conditions (Jenkins, 1994; Nordin, 2007; Fidjeland, 2014; Wichuk and McCartney, 2010). Just performing daily chores like washing clothes can expose women to E. Coli, Giardia and other enteric diseases or bathing for the elderly, children or any immune-deficient adult can be enough for contamination to cause gastro-intestinal or general health complications (WHO Guidelines for Recreational Water Environments, 2003). Although these issues are not among those considered important by some CL users, it is important regardless, and can be addressed through common beliefs or perceptions like the concerns surrounding contamination through dead animals, or the general aesthetics of water. 
Acceptability, adoption or uptake of a new sanitation technology or hardware requires the subsequent investment in software, as well. Also, efforts must be made so that the technology is "appropriate" or invokes a "human-centered" design. These efforts were attempted in the rural community of Drigari, where issues revolving around current practices like privacy, convenience, comfort and the safety of children and elderly were invoked during community meetings and household discussions to drive a possible solution in-line with the Peace Corps - Environmental Health sector's objectives.

\section{2: Ferrocement Composting Latrine (FCL)}

Areas like the above exist in many parts of the world (Gomes, 2015). For cultures tied to water, rivers and streams, or areas that experience seasonal flooding are not necessarily disaster areas, but rather ancestral lands. Pit latrines are a much more ubiquitous around the world including floodplains, yet they can exacerbate water contamination by concentrating biologically active and hazardous human excreta, especially during flood events. For this reason, these areas often offer no improved alternative other than CLs or UDDTs mentioned previously. In a case study of two riverine communities that were part of a CL project in 1998, Gomes et al. report that only 44\% were using the latrines after 14 years. Yet, just five years prior $88 \%$ had been still active, a discrepancy caused by an influx of new homeowners that began sharing facilities that were designed for less users. A more likely cause of the CL abandonment could've been the flood damage during two large events between the monitoring periods where vaults were left underwater for a considerable amount of time and the compost completely inundated.

This case study highlights some problems associated with EcoSan interventions, especially when thorough training on maintenance and operation are not provided - a subject to be discussed in the following sections. Other observations include the fact that flood events were considered in the choice of CLs yet the implementation didn't succeed in making waterproof chambers. Also, the beneficiaries were not trained in the construction methods used preventing future repairs, nor was an appropriate or locally known or available construction material used. Overall, the beneficiaries were not included in the design, construction or any part of the general discussion over their own sanitation future. This case study brings issues to light that were considered in the gestation of the design offered herein.

Peace Corps - Panamá has used ferrocement since at least, 2011, mainly for the construction of small rainwater harvesting tanks of around 90 gallons in volume. These tanks are typically self-funded and promoted using similar methods found in commercial marketing since they offered an $80 \%$ discount from the blue plastic tanks most families would purchase to store water. This method provides a simple, low-entry, low resourceintensive way of constructing customizable and durable structures. It involves mainly four elements, cement, sand, water and metal reinforcement in very small quantities compared to reinforced concrete.

In Drigari, this method was utilized to create 2-260 gallon vaults to serve as an alternative to the typical 90-concrete block design used previously. Besides solving the issue of 
creating a water-tight structure to store compost for the recommended year -typically addressed by applying water sealing plaster coats on the concrete block- ferrocement is much more forgiving to individuals lacking skilled labor expertise and maybe most importantly, cuts down the costs associated with CLs from $\$ 400$ to $\$ 80$. Focus was placed on eliminating the need for plastering shut the door to the chambers that can undo the entire purpose of improved sanitation during a flood event and making certain that the chamber is watertight throughout. Also the design featured an available bidet connected to the water system and a rainwater tank to supplement water use if the aqueduct becomes unavailable. Also, per the relevant suggestions made throughout the literature on this area, larger diameter PVC pipes were used to avoid clogging.

Ferrocement contrasts with concrete block construction primarily for its substantially higher steel-to-cement ratio. The "ferro" part of ferrocement refers to this fact and can come in the form of chicken wire or any similar light-gauge wire mesh, as shown in Appendix A. The cement portion refers to the 1:2 or 1:3 cement-to-sand mortar that is plastered over the reinforcing steel. These ratios must be prescribed by weight rather than volume for optimal performance and differ depending on cement country of origin and fabricator. Ferrocement calls for a quite workable mortar consistency for application, yet the water-to-cement ratio must not fall between 0.4-0.5 for best strength conditions - more water creating a weaker structure and less making it difficult to apply at all. Although not the focus of the current study, thicker wall for insulation or applying a dark material to the outside of the ferrocement could improve the mechanisms described for pathogen inactivation in CLs and in ABS.

After numerous non-obligatory informational/training events revolving around improved sanitation and hygiene, framed around social marketing concepts like prestige, convenience, sensory appeal (lack of smell), privacy and security, one family agreed to participate in the experimental ferrocement composting latrine program. The idea to build a single "pilot" latrine rather attempting full coverage has certain advantages (Shayo, 2013; Pebler, 2014). From a development standpoint it should prove to be the first stage of an iterative process where user perceptions can be expressed and improvements realized. For a user or future user, the abstract idea proposed by an outsider can be fully evaluated, seen, touched, smelled and, if they dare, used.

The family in question agreed to participate due to their desire to own a latrine, having spent enough time abroad during the coffee harvest to see the practical value of one. The matriarch of the household was very adamant that it be built to alleviate the stress associated to when her four children and two granddaughters use the river, especially during flood events. Certain features had already been in mind such as a bidet for postdefecation ablution, a handwashing station and ample room, making the collaborative design process easier and less one-sided. Due to cost concerns, the very popular idea of incorporating an adjacent shower was postponed, although many families do accomplish this independently. This simple addition could provide the necessary motivation for some families, and has been implemented in other parts of the world like Bolivia and Peru and more notably in Cambodia with IDE's "easy shower" system (Hoffman, 2012). A detailed guide and materials list for the construction of the FCL can be found in Appendix A. The following section will introduce the concept of ammonia-based sanitation or ABS that will later be coupled with the FCL design to mutually benefit both ideas. 


\section{Chapter 4: Methods and Materials}

\section{0: Ammonia-Based Sanitation (ABS) Background}

As of yet, ABS, which will be introduced herein has not been applied in any meaningful way to large-scale sanitation interventions and has been studied exclusively in laboratory studies for, as has been mentioned before, efficacy. The current section will describe ABS in the context of the academic literature to introduce the author's research performed in his third year abroad after serving in the aforementioned community of Drigari for two years. Although, the results of this ABS study were not entirely positive, its future could more readily coalesce with sanitation business models that remove users from an overtly active role.

Ecological sanitation as a whole, on the other hand, has the potential to alleviate many of the concerns over environmental impacts associated with treating wastewater and can simultaneously "close the loop between sanitation and agriculture" (Langergraber and Muellovaer, 2004)." As it has been discussed in the introduction and throughout, composting latrines (CLs) do not, in fact, compost (Hurtado, 2015; Pebler, 2013). They instead rely on secondary treatments off-site or extended periods of storage on-site; for this reason, some argue CLs should be rebranded as "dry toilets" (Hill et al., 2013). In fact, Hill et al. found that mature, stable compost and pathogen-free fertilizer are mutually exclusive end products within the confines of CLs. A theme throughout the present study is the fact that this dichotomy is irrelevant to the majority of CL users in areas like riverine communities where the CL is the only "improved" choice available.

Many NGOs, like X-Runner in Peru, Sanergy in Kenya and the aforementioned SOIL in Haiti provide successful examples of secondary treatment models where a business model approach creates demand for latrines, provides franchise opportunities to local entrepreneurs to sell the treated compost for a profit. Yet in places that might not be viable for a business venture like the rural, difficult-access communities of Panamá primary treatment is necessary to be considered improved. Continuing off the knowledge available through the various studies performed in BDT-Ñ , the effectiveness of the use of urine as ammonia for pathogen inactivation was evaluated alongside user perceptions of this yet undeveloped bench-scale sanitation method. Several studies on the efficacy of ammoniabased sanitation (ABS) have been performed in a laboratory setting (Pecson et al., 2007; Nordin, 2009; Fidjeland, 2015).

These investigations rely on modeling or directly measuring Ascaris Lumbricoides ova or roundworm ova viability to rate treatment performance. Its use as an indicator of the efficacy or effectiveness of a sanitation method can be attributed to its ability to withstand most treatment methods better than other species (Feachem, 1983). ABS depends on the presence of uncharged or un-ionized molecule, $\mathrm{NH}_{3}$, to create a toxic environment for microorganisms or, for these purposes, pathogens through, as some posit, the disintegration of the protein membrane of the cell wall. The $\mathrm{NH}_{3}$ molecule has the freedom to travel between this membrane and alkaline properties might raise the internal $\mathrm{pH}$ and cause this 
cell disintegration. This has an added benefit to biosolids or compost in that the process does not consume ammonia, but rather increases its nutrient potential (Sossou, 2016; Fidjeland, 2015; Nordin, 2009).

Pecson et. al investigated the performance of ABS on Ascaris ova in sewage sludge at different regimes of temperature, $\mathrm{pH}$ and ammonia concentration. These parameters were found to be intertwined and their individual effects difficult to dissociate, yet temperature was found to be an important determinant of roundworm inactivation when alkaline conditions and ammonia concentration are held constant. Other studies attempted to build off of the implications of ABS on roundworm viability by further exploring the interaction between these three parameters in a more methodical way compared to previous studies. Also investigations into the application of ABS in other sanitation methods like EcoSan dry latrines that have a considerably higher total solids concentration compared to the single digit readings found in sludge yield higher ammonia concentration readings were shown to be promising (Pecson et. al, 2007).

As the previous study investigated the direct addition of ammonia to the treatment matrices, other studies attempted to see what the effects of adding urea were to the performance of ABS due to its increased safety in handling since ammonia is highly volatile and toxic to humans (Nordin, 2007; Fidjeland, 2015). $\mathrm{CO}\left(\mathrm{NH}_{2}\right)_{2}$, also known as Urea, accounts for more than half of the Nitrogen fertilizer used in the world and unlike $\mathrm{N}_{2} \mathrm{O}$ is not a primary greenhouse gas (Saggar et al., 2012). Its value as a nutrient conforms to the ideals of EcoSan - closing the loop between agriculture and sanitation. Nordin et al. studied the application of urea on source-separated feces collected from dry toilets with or without ash amendment at urea concentrations of $0 \%$ to $2 \%$ by weight and temperatures of 24 and 34 degrees Celsius (Nordin, 2009). Their findings suggested that $3 \log _{10}$ roundworm ova inactivation could be achieved within three months at 34 degrees Celsius, and that temperature had a sizeable impact on ammonia production - a 10-degree Celsius difference in temperature caused a fivefold decrease in the inactivation period.

Fidjeland et al. (2013) investigated the use of intrinsic ammonia found in urine as a potential source for ABS treatment of fecal sludge (Fidjeland et al., 2013). Similarly, to previous findings, $3 \log _{10}$ reduction of roundworm ova viability could be achieved in $1-1.5$ months at uncharged ammonia $\left(\mathrm{NH}_{3}\right)$ concentrations of $170 \mathrm{mM}(2895 \mathrm{mg}-\mathrm{NH} 3-\mathrm{N} / \mathrm{L} / \mathrm{L})$ at $23^{\circ} \mathrm{C}$ or $60 \mathrm{mM}(1022 \mathrm{mg}-\mathrm{NH} 3-\mathrm{N} / \mathrm{L} / \mathrm{L})$ at $28^{\circ} \mathrm{C}$. Fidjeland was also able to produce an effective model for Ascaris ova inactivation that will determine the inactivation times presented in the present study (Fidjeland, 2015):

$$
t=\frac{3.2+L R V}{10^{-3.7+0.062 \cdot T} \cdot N H_{3, \text { Pitzer }} 0.7} \cdot 1.13
$$

Where, $\mathrm{t}$ represents the time in days for pathogen inactivation to occur, LRV representing the log removal value (i.e. "3" if 3-log reduction is being sought), T meaning temperature in degrees Celsius and $\mathrm{NH}_{3}$ standing in for the un-ionized ammonia concentration. McKinley was able to synthesize the approaches of the previous studies - replacing urine for urea and source-separated compost for fecal sludge - and simplify the ABS procedure for EcoSan latrines in Bolivia (McKinley, 2012). Single-chamber CLs or UDDTs that function for aerobic 
decomposition using sawdust were the source of the fecal matter for the study. The six matrices were composed of small volumes of compost, urine, and ash amendment with one control group and five treatment groups made up of different combinations of ash, stored urine and fresh urine. After 16 weeks two treatment groups were determined to have inactivated Ascaris ova to 99\%; compost with stored urine and ash and compost with fresh urine and ash, 7.5 and 14.9 weeks respectively. Ascaris ova viability was determined microscopically and using a linear regression method. This was the first study to show promising potential for the application of ABS as a primary or on-site treatment method.

Another study attempted to bring the potential of ABS to UDDTs in Uganda, which in contrast to CLs function through the use of ash amendment to dehydrate and alkalize human feces towards pathogen reduction (Trimmer, 2015). These latrines are optimal for ABS treatment due to the high $\mathrm{pH}$ produced through ash amendment that pushes unionized ammonia, $\mathrm{NH}_{3}$ to predominate over the ionized ammonium salt, $\mathrm{NH}_{4}{ }^{+}$, that is inert and does not contribute to pathogen inactivation (Fidjeland, 2015). Trimmer set out to investigate other uncertainties revolving around ABS in the context of UDDTs and optimizing the proportions of ash, urine and feces for pathogen inactivation. The study concluded that a 2:1 ratio of urine to "ash-amended vault products" was optimal for UDDTs in Uganda and that outdoor storage could yield Ascaris egg inactivation within three months and two months for indoor storage.

Regardless of ammonia source, all cited studies are informed by urea hydrolysis and its kinetics, a fairly well understood process. The full chemical reaction from urea hydrolysis to uncharged ammonia volatilization is described by Eqns. 2-4, Eqns. 5-6 complete the relevant formulas used in analyzing experimental data:

$$
\begin{array}{ll}
(\mathrm{CO})\left(\mathrm{NH}_{2}\right)_{2}+3 \mathrm{H}_{2} \mathrm{O} \stackrel{\text { Urease }}{\longrightarrow} 2 \mathrm{NH}_{4}^{+}+\mathrm{OH}^{-}+\mathrm{HCO} & \text { (Equation 2) } \\
\mathrm{NH}_{4}{ }^{+} \leftrightarrow \mathrm{NH}_{3(a q)}+\mathrm{H}^{+} & \text {(Equation 3) } \\
\mathrm{NH}_{3(a q)} \rightarrow \mathrm{NH}_{3(\text { gas })} & \text { (Equation 4) } \\
p K_{a}=\frac{0.09018+2729.92}{273.15+T} & \text { (Equation 5) } \\
f_{\mathrm{NH}_{3}}=\frac{1}{\left(10^{p K_{a}+p H}+1\right)} & \text { (Equation 6) }
\end{array}
$$

Eq. 2 describes the ureolysis that occurs in the presence of urease, an enzyme found in various bacteria in soil and human feces, as well (Nordin, 2007). In Eq. 3, ammonium salt along with carbonates that have been proposed as contributing to reduction of pathogens 
are produced $-\mathrm{NH}_{4}{ }^{+}$being mainly inert. Eq. 4 describes how ammonium is in equilibrium with aqueous ammonia determined by $\mathrm{pH}$ and temperature as shown in Eqns. 5 and 6. Eq. 5 determines $\mathrm{pK}_{\mathrm{a}}$, the $\mathrm{pH}$ that describes when ammonium and ammonia are at equilibrium according to T, temperature in degrees Celsius. This is used in tandem with Eq. 6 to calculate the fraction of $\mathrm{NH}_{3}$ in a chemical sample along with the $\mathrm{pH}$ of the sample. These studies have been integral for providing the scientific foundations for scaled-up implementation yet no studies have produced a potential design for its realization.

\section{1: Effectiveness of Ammonia-Based Sanitation (ABS) in Composting Latrines of Panamá}

The following study attempted to resolve issues regarding desiccant availability and optimization not for pathogen inactivation, but for effective implementation of ABS in onsite EcoSan units of Panamá described throughout as CLs. As mentioned previously, CL users in Panamá are not afforded the accessibility demonstrated in case studies found throughout this research paper (Inter-American Development Bank, 2015). That is to say that CLs in BDT-Ñ are intended for primary treatment within the CL chambers since secondary treatment off-site could provide unwanted pathogen contamination due to the climate, geography and the most extreme case disaster potential when coupled with floodprone areas. For this reason, pit latrines create a similar issue when potential pathogens are concentrated in a pit prone to being filled and, at times, emptied by floodwaters.

An experiment was designed to determine the role of ash amendment in ABS using intrinsic ammonia found in stored urine collected from dual-chamber, urine-diverting composting latrines of BDT- $\tilde{N}$. The impetus of investigating wood ash as a desiccant in CLs was spurred by other studies describing it as critical for alkalizing ABS-treated human wastes, yet difficult to attain or of variable availability for EcoSan latrine users (Fidjeland, 2015; Trimmer et al., 2016; Mehl et al., 2008; Wilbur, 2013; Kamuteera, 2013). 18 reactors described in Table 1 - composed of matrices of compost and urine obtained from three CLs in the community of Valle de Riscó, Panamá and some ratio of ash were assembled in 2.5gallon plastic containers. Based on previous studies (McKinley, 2012; Nordin, 2009; Trimmer, 2015), practical limitations and calculations, 12 weeks was determined to be sufficient time to allow for the experimental period. Every two weeks, measurements of $\mathrm{pH}$, temperature, and ammonia concentration were obtained from the 18 matrices.

Table 1 - Matrix Reactor Components

\begin{tabular}{|c|c|c|c|c|c|c|}
\hline $\begin{array}{c}\text { Latrine } \\
\text { Name: }\end{array}$ & Control $_{1}$ & Treatment $_{1}$ & Treatment $_{2}$ & Treatment $_{3}$ & Treatment $_{4}$ & Control $_{2}$ \\
\hline $\mathrm{A}$ & $\mathrm{A}_{1}$ & $\mathrm{~A}_{2}$ & $\mathrm{~A}_{3}$ & $\mathrm{~A}_{4}$ & $\mathrm{~A}_{5}$ & $\mathrm{~A}_{6}$ \\
\hline $\mathrm{B}$ & $\mathrm{B}_{1}$ & $\mathrm{~B}_{2}$ & $\mathrm{~B}_{3}$ & $\mathrm{~B}_{4}$ & $\mathrm{~B}_{5}$ & $\mathrm{~B}_{6}$ \\
\hline $\mathrm{C}$ & $\mathrm{C}_{1}$ & $\mathrm{C}_{2}$ & $\mathrm{C}_{3}$ & $\mathrm{C}_{4}$ & $\mathrm{C}_{5}$ & $\mathrm{~A}_{6}$ \\
\hline
\end{tabular}

$\mathrm{A}, \mathrm{B}, \mathrm{C}_{1}$ : Control Group 1: Compost

$A, B, C_{2:}$ Treatment Group 1: Compost and Urine $(\mathrm{C}+\mathrm{U})[1: 1: 0]$

A,B, $C_{3}$ : Treatment Group 2: Compost, Urine and Ash $\left(\mathrm{C}+\mathrm{U}+\mathrm{A}_{25 \%}\right)$ [1:1:0.25]

$A, B, C_{4}$ : Treatment Group 3: Compost, Urine and Ash (C+U+A50\%) [1:1:0.50]

$\mathrm{A}, \mathrm{B}, \mathrm{C}_{5}$ : Treatment Group 4: Compost, Urine and Ash (C+U+A $\left.\mathrm{A}_{75 \%}\right)$ [1:1:0.75]

$\mathrm{A}, \mathrm{B}, \mathrm{C}_{6}$ : Control Group 2: Urine 
The constituents from the three latrines were mixed only with their respective counterparts throughout the experimental procedure. Ash was collected from three-stone hearths from each respective household. All matrix components were measured volumetrically and added to identical 2.5-gallon containers that had been modified with the addition of a spigot commonly used for household water use as seen in Fig. 17 to diminish the effects of ammonia volatilization other studies had posited as producing errors or decreasing ammonia concentrations (Nordin, 2007; Trimmer, 2015). Because of the addition of the spigot, ammonia levels were steadily rising up to the $12^{\text {th }}$ week of the experiment. Each of the compost treatment reactors were then placed outside on individual concrete platforms raised off the ground and were covered by found lumber to keep out of direct sunlight (Fig. 18 ), as would be the case in an actual CL.

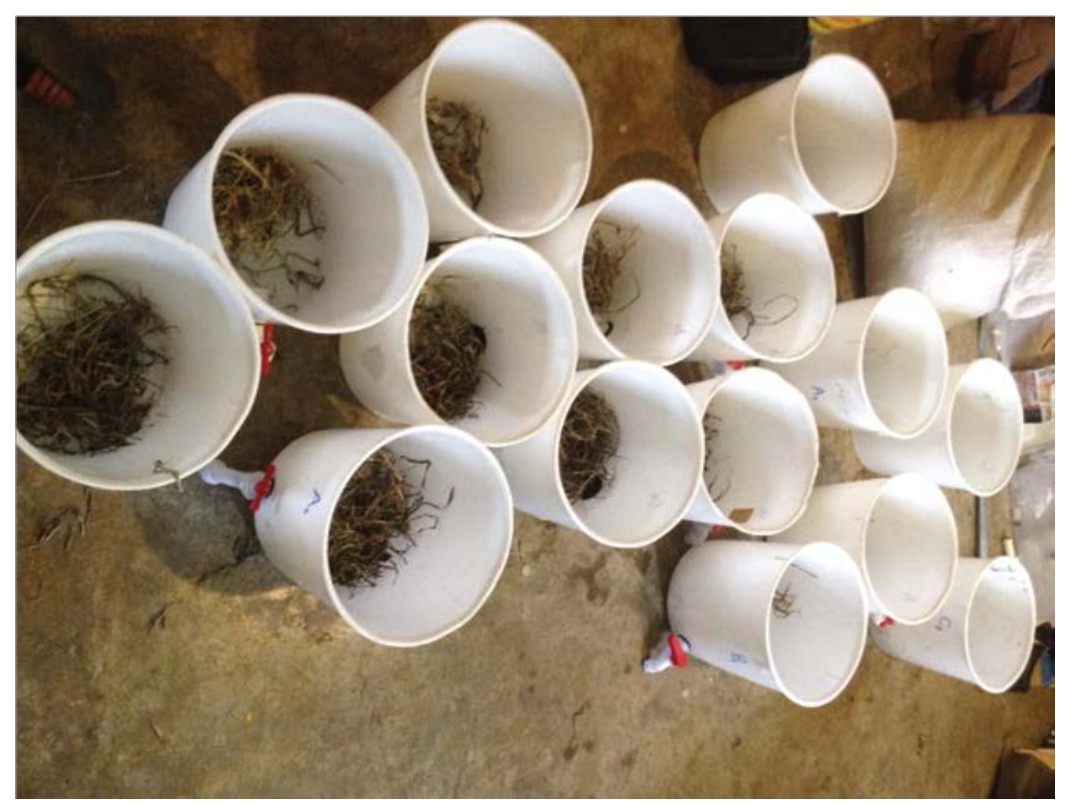

Figure 17 - Matrix Reactor Preparation (Photograph by Author)

Measurements of $\mathrm{pH}$ and sample temperature were obtained using an Oakton $\mathrm{pH} 5+$ Handheld Meter with pH Probe. Samples were taken in $15 \mathrm{~mL}$ test tubes, which facilitated the ammonia concentration testing developed by Trimmer using Seachem Multitest: Ammonia Test Kits. The ammonia testing required dilution of each sample by 1000 and, in some cases, 1500 times to fit within the manufactured range of $6.0 \mathrm{mg}-\mathrm{NH} 3-\mathrm{N} / \mathrm{L}$, and used a color-changing disk to determine ammonia levels, similarly to litmus strips. Additionally, ambient temperatures were taken on all days samples were measured, as well as the days in between that the author was near instrumentation to observe and record a temperature.

All previous studies of this kind looked at EcoSan latrines that used ash or sawdust as the primary amendment. Due to serendipitous circumstances, the main desiccant found throughout all the participating latrines was dried grass. Also, the "compost" was much less 
mature or stabilized than in previous studies - grab samples being collected after same day or previous day's use whereas Trimmer (2015) and McKinley et al. (2012), collected samples after three months of stabilization. There have been no studies to date to investigate the effect of compost stabilization on ammonia production potential in ABS. Lastly, compost was not mixed as the majority of families in BDT-N do not tend to mix their compost, just 34 of 102 claimed to have mixed their compost, at least once (Wilbur, 2013).

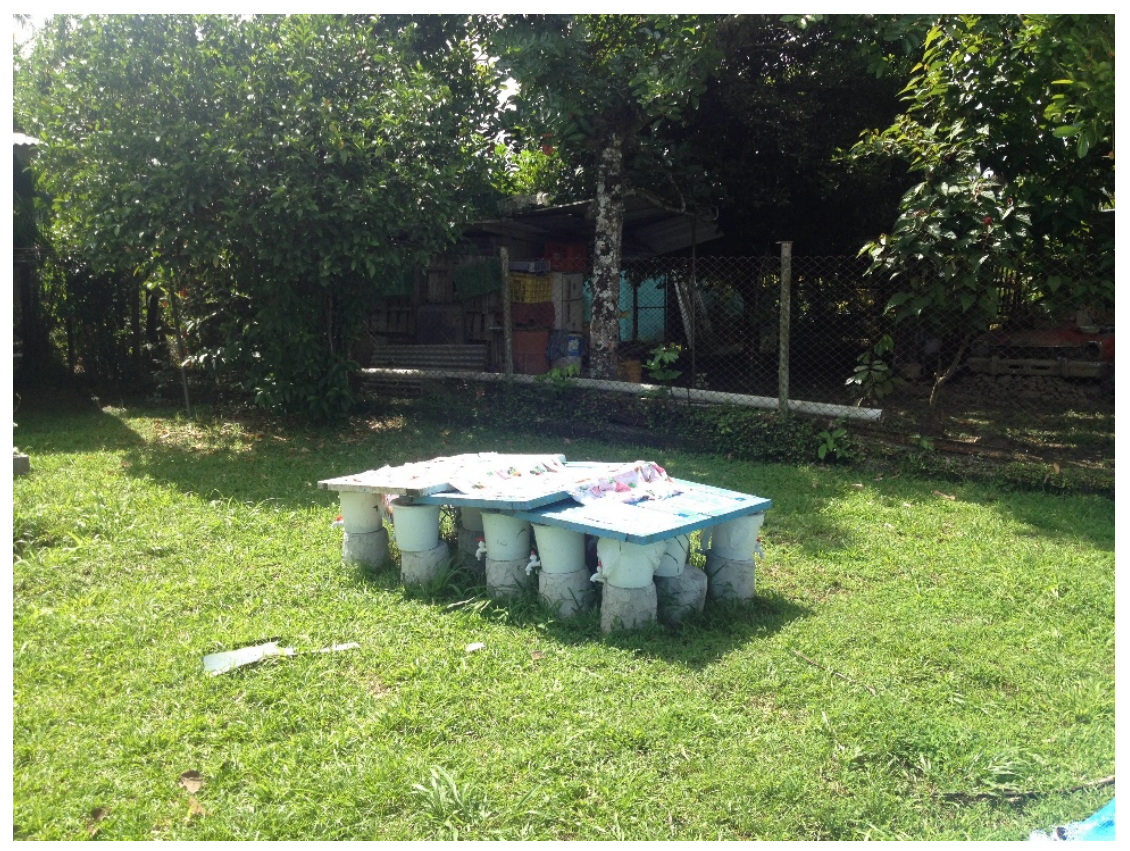

Figure 18 - Reactors assembled outside (Photograph by Author)

A laboratory microbiological test was performed at the beginning and end of the experimental period to provide, at least, any evidence that roundworm eggs had been completely inactivated as it was calculated for the period in question. The procedure was performed microscopically on the primary sources of all of the matrices that were the three respective CLs used by the participating families. Other studies were able to describe inactivation rates empirically or using ammonia concentration to insinuate inactivation rates, the purpose of the current study was to determine the effectiveness of the ABS method.

\section{2: Ethnographic Research Methods}

In light of the convincing findings made by many other studies (Wilbur, 2014; Trimmer, 2015) technical efficacy of ISFs - including ABS - must concede to their social effectiveness. ISFs are only as good as their usage, not their function per se. Harking back to commentary made about the behavior change model known as social marketing, Langford and PanterBrick (2013) state:

"It moves away from traditional health education models that simply tell people what to do, towards an approach that seeks to 'sell' the behaviour in question by 
convincing the target audience that it provides a solution to a problem they believe is important, and/or offers them a benefit they value. The first step in this process is uncovering and understanding people's perspectives, preferences, and aspirations."

A considerable amount of information has been gathered on the perspectives, preferences, and aspirations of the Ngäbe people in BDT-Ñ. This includes a thorough ethnographic investigation by Wilbur (2014) into motivations and perceptions of EcoSan technology and its components, along with an evaluation of current usage and acceptance of CLs by stakeholders. Emulating the efforts of this study, families from the community of Valle de Riscó were interviewed into the social acceptance of the experimental ABS method that has been discussed throughout this current document. Many studies have addressed the barriers to EcoSan or ISF adoption, yet many opportunities exist, as well. This study attempts to apply a multidisciplinary approach to ISF adoption evaluation through the lens of individuals that have adopted CLs and are willing to discuss the prospect of a new technology, since a "qual-quant-itative" - a mixture of both quantitative and qualitative data collection and analysis - can broaden the understanding of this subject, not only in the formative stages of a project, but for monitoring and evaluation (Langford and Panter-Brick, 2013; Cole et al. 2015).

The author served as the water and sanitation coordinator for the region of BDT-N and formed relationships with the families involved in this study through Peace Corps colleagues including one volunteer that served in Valle de Riscó during the initial project phase described earlier. Valle de Riscó was one of the original 30-some communities in the CL campaign during the Mid-2000s through the Peace Corps, USAID and the Panamanian National Environment Authority. Funding was provided for all CLs with the participants providing the manual labor and organization. Since then, Peace Corps has moved away from large infrastructure projects and providing full funding in favor of self-funded or crowd-sourced projects.

In the past decade and a half Valle de Riscó has developed into the area's hub becoming the entrance to many other more rural communities in the area and being home to about 1500 people. As large as this community was by a rural standard, it still contains the familiar kinship structure of a community like Drigari. As mentioned previously, Drigari was primarily composed of two families living in tight clusters around each other. Valle de Riscó could be considered as a town of clusters in the same manner. The five participating families, then, were really just two large families that can trace back their kin to two different patriarchs. 


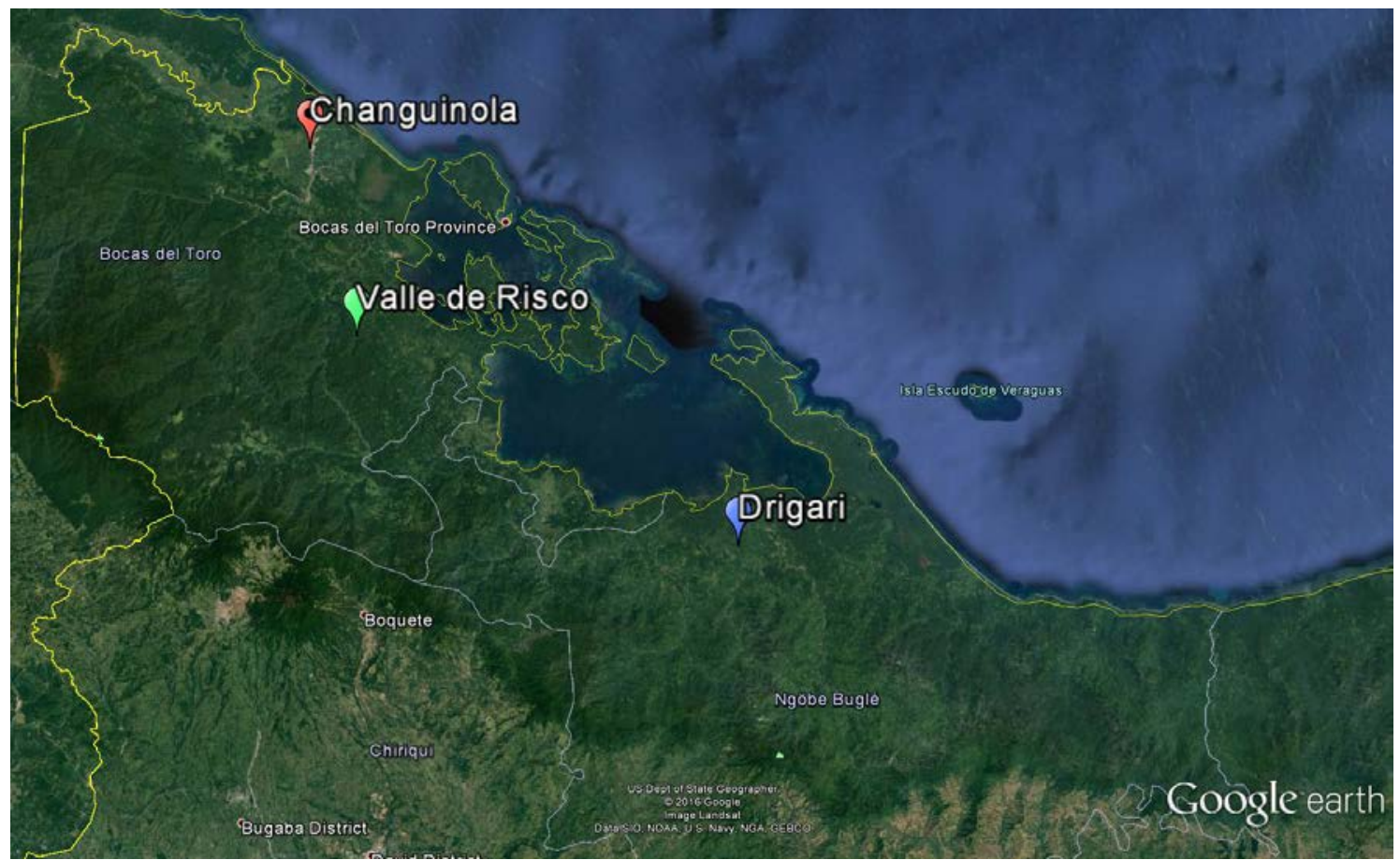

Figure 19 - Map of Key Research Areas: Red-Changuinola, the location of the experiment; Green-Valle De Riscó, qualitative data collection site; Blue-Drigari, ferrocement composting latrine site (Map is reproduced from Google Earth with Google (C) 2016 per Fair Use Licensing and Google's Guidelines: https://www.google.com/permissions/geoguidelines.html)

Valle de Riscó is approximately 35 minutes away by small bus to the much more urbanized city-center of Almirante - the port to the tourist destination of Bocas Del Toro and one of the main departure points of Chiquita Bananas' supply fleets. The cost of a ride into town is only a fraction of that of the community of Drigari highlighted before allowing access and fluidity to economic prospects and goods. Many of the families in Valle have one or more household members working outside the community, this is evident in the incomes reported to the National Census Institute of Panamá. In 2010,100\% of the residents of Drigari made less than $\$ 175$ per month, whereas $56 \%$ of those living in Valle de Riscó made at least that amount, with almost $20 \%$ making between $\$ 400$ and $\$ 800$ per month.

Some of this income difference could be explained by the accessibility to cities like Changuinola and Almirante, both former Banana towns but now urban centers. Also, many individuals were, or are still, receiving some benefits from AES, the company overseeing operation and administration of the controversial Changuinola Dam. This creates an almost peri-urban community, where income is dispersed heterogeneously and rural households have close ties to a more urban lifestyle.

Many households were observed to own some type of ISF including flush toilets and pit latrines, yet others had none at all, according to some residents. Five families have habitually operated and maintained CLs for more than a decade after receiving initial construction and training from Peace Corps Volunteers. Three of these five families were 
asked to participate in the complementary technical investigation, as well. Initial interactions with the families were informal and general in the scope of conversation taking place throughout February 2016. The formal interviews were conducted during the end of August 2016 after several more meetings and casual encounters.

The interviews were conducted with key informants decided by the family to be the household leader, and knew the details associated with the CL project, the operation and maintenance of it, and had knowledge of previous Peace Corps volunteers. Informed consent was received from all participants prior to any formal questioning. There has been considerable interaction between the community and Peace Corps volunteers either directly within or indirectly around the surrounding area of Valle de Riscó and this had considerable influence on the participants of this study.

The author found it difficult to parse the true opinion of the respondent from the "right" answer they might have believed would bring them another project despite the disclosure prior to beginning their interview. The author observed this kind of bias in informal conversations with non-users during the preliminary stages of the ethnographic study. Future studies could approach the perspectives of both persistent users and non-users. Also, EcoSan as a whole is a novel and obscure technology to many rural communities, so ABS was targeted towards current users since the foundation of such a technology already existed. All interviews were conducted in Spanish by the author and had contributing remarks from other family members in Spanish or Ngäbere. The full list of questions and topics is available in the Appendix and was developed with insights from previous studies (Kaiser, 2006; Mehl, 2008; Wilbur, 2013). The main objectives of the interviews were to determine the following:

- The current situation with the household's CL

- User motivations and suggestions towards CL improvement

- Potential adoption of new methods, i.e. ABS

\section{Chapter 5: Results and Discussion}

\section{0: Intrinsic Ammonia-Based Sanitation in Urine-Diverting Composting Latrines: The Effect of Ash Amendment on Ammonia Concentration}

The current study set out to determine the effectiveness of ABS through the use readily available materials such as the intrinsic ammonia found in urine and wood-ash from traditional hearths found in Panamá and many other places in the world. The hypothesis that increased ash amendment would yield higher $\mathrm{pH}$ values was informed by the myriad of studies on the efficacy of ABS through bench-scale modeling of the process (Pecson et al., 2007; Nordin, 2009; Fidjeland, 2015). The corresponding postulation was that matrices exhibiting high alkaline $\mathrm{pH}$ ( $\mathrm{pH}$ greater than 7, ideally approaching values greater than 9) would yield higher uncharged ammonia readings, (uncharged ammonia, or $\mathrm{NH}_{3}$, being the principal agent of pathogen inactivation through exposure to this toxic species of ammonia). There were many findings that deviated from the hypothesis drawn from the previous studies and the ammonia concentration and inactivation models therein. 
Certain findings were consistent with the literature, like that the groups that received more alkaline amendment $(\mathrm{ash})$ produced more basic $(\mathrm{pH}<7)$ readings. An unforeseen outcome was that the $\mathrm{C}+\mathrm{U}+\mathrm{A}_{75 \%}$ group, receiving $75 \%$ ash by volume of compost - the most of any group - was hypothesized to outperform the other less alkaline groups, especially the control group that was unamended, yet only slightly did so. Full results can be seen in Tables 2 and 3. This group designated by the number " 5 " in Table 3, averaged a $\mathrm{pH}$ of 9.77, the highest of all the groups, but had an average uncharged ammonia concentration of 348 mg- $\mathrm{NH}_{3}-\mathrm{N} / \mathrm{L}$, not far from the intrinsic uncharged ammonia found in the control group, group 1. Uncharged ammonia concentration is positively correlated with Ascaris ova inactivation (McKinley, 2012; Nordin, 2007; Fidjeland, 2015; Trimmer 2015). Table 2 presents biweekly $\mathrm{NH}_{3}$ concentrations of each individual matrix grouped by control or treatment regime. The highlighted rows in Table 2 represent matrices that experienced total pathogen inactivation after 12 weeks. Figure 20 provides a graphically representation of uncharged ammonia production over the course of the 12 weeks by treatment group, or the average of each of the three latrine matrices distinguished by their matrix composition.

Table 2 - Average Matrix Properties and Projected Inactivation Times; Each Matrix is designated with either $A, B$, or $C$ to identify which latrine it originated from. The numbers following represent each treatment group i.e. 1: Compost Control, 2: Compost and Urine, 3: Compost and Urine with 25\% by Volume Ash Amendment, 4: Compost and Urine with 50\% Ash, 5: Compost and Urine with 75\% Ash, 6: Urine Control; Highlighted rows represent no presence of pathogens after 12 weeks

\begin{tabular}{|c|c|c|c|c|r|r|r|r|}
\hline Matrix & $\begin{array}{c}\text { Inactiva } \\
\text { tion } \\
\text { Yes/N } \\
\text { o) }\end{array}$ & $\begin{array}{c}\text { Average } \\
\text { Sample } \\
\text { Temp. }\end{array}$ & $\mathrm{pH}$ & $\begin{array}{c}\text { Ash \% } \\
\text { By } \\
\text { Volume }\end{array}$ & $\begin{array}{c}\text { Moisture } \\
\text { Content } \\
(\%)\end{array}$ & $\begin{array}{c}\text { Unionized } \\
\text { Ammonia } \\
\text { (mgNH3- } \\
\text { N/L) }\end{array}$ & $\begin{array}{c}\text { Total } \\
\text { Ammonia } \\
\text { (mgNH3/ } \\
\text { L) }\end{array}$ & $\begin{array}{c}\text { Calculated } \\
\text { Time to } \\
\text { Inactivate } \\
\text { (Days) }\end{array}$ \\
\hline A1 & No & 30.0 & 8.5 & 0.0 & 37.8 & 17.4 & 80.6 & 2107.8 \\
B1 & No & 31.0 & 9.4 & 0.0 & 39.0 & 71.2 & 114.7 & 362.8 \\
C1 & No & 30.2 & 8.6 & 0.0 & 47.1 & 9.2 & 78.8 & 2795.3 \\
\hline A2 & No & 31.9 & 9.0 & 0.0 & 45.8 & 2550.2 & 5821.4 & 31.1 \\
B2 & No & 30.8 & 9.1 & 0.0 & 58.7 & 2135.0 & 5064.3 & 30.8 \\
C2 (-) & Yes & 30.8 & 8.9 & 0.0 & 52.2 & 2779.1 & 6235.7 & 34.4 \\
\hline A3 & No & 29.9 & 9.3 & 25.0 & 44.0 & 3089.6 & 4715.7 & 25.8 \\
B3 (-) & Yes & 30.8 & 9.0 & 25.0 & 45.1 & 2035.9 & 4328.6 & 40.6 \\
C3 & No & 30.5 & 9.3 & 25.0 & 37.5 & 2187.2 & 3529.3 & 29.3 \\
\hline A4 (-) & Yes & 31.1 & 9.5 & 50.0 & 41.4 & 3042.7 & 4060.7 & 18.4 \\
B4 & No & 31.8 & 9.4 & 50.0 & 45.2 & 2258.5 & 3214.3 & 26.4 \\
C4 (-) & Yes & 30.5 & 8.9 & 50.0 & 42.0 & 2896.5 & 5878.6 & 28.3 \\
\hline A5 & No & 30.0 & 9.8 & 75.0 & 34.0 & 164.8 & 185.1 & 149.1 \\
B5 (-) & Yes & 30.3 & 9.7 & 75.0 & 37.3 & 475.1 & 565.0 & 63.7 \\
C5 & No & 31.2 & 9.9 & 75.0 & 36.7 & 400.5 & 458.6 & 62.9 \\
\hline A6 & N/A & 31.5 & 8.7 & N/A & N/A & 2253.9 & 7592.9 & 31.1 \\
B6 & N/A & 32.1 & 8.7 & N/A & N/A & 1262.6 & 4917.1 & 47.7 \\
C6 & N/A & 30.4 & 8.6 & N/A & N/A & 1283.3 & 5437.1 & 55.5 \\
\hline
\end{tabular}


The discrepancy between the $\mathrm{pH}$ and corresponding $\mathrm{NH}_{3}$ values in Group $\mathrm{A}_{0.75}$ could be explained by the lack of mixing and the resulting moisture content upon ash amendment. Perhaps the combination of a lowered moisture content and heterogeneous distribution of aqueous $\mathrm{NH}_{3}$ produced a highly volatile concentration and inhibited movement of hydroxide ions (Nordin, 2010). Also, of note is the ammonia production performance of the $\mathrm{C}+\mathrm{U}$ Group (Compost and Urine), the first treatment group using entirely the intrinsic $\mathrm{pH}$ of the urine and compost as no ash was added. Figure 21 demonstrates total ammonia production by treatment group, or the combined concentrations of both relevant ammonia species - the ammonium ion, $\mathrm{NH}_{4}{ }^{+}$and uncharged ammonia, $\mathrm{NH}_{3}$ - as a counterpart to Figure 20. Comparing the two figures, show that ash, or $\mathrm{pH}$ did play an important role in determining whether the ammonia species would be $\mathrm{NH}_{4}{ }^{+}$or $\mathrm{NH}_{3}$, as seen by the performance of the urine control in producing total ammonia, where it did very well, versus uncharged ammonia, where it was third from last.

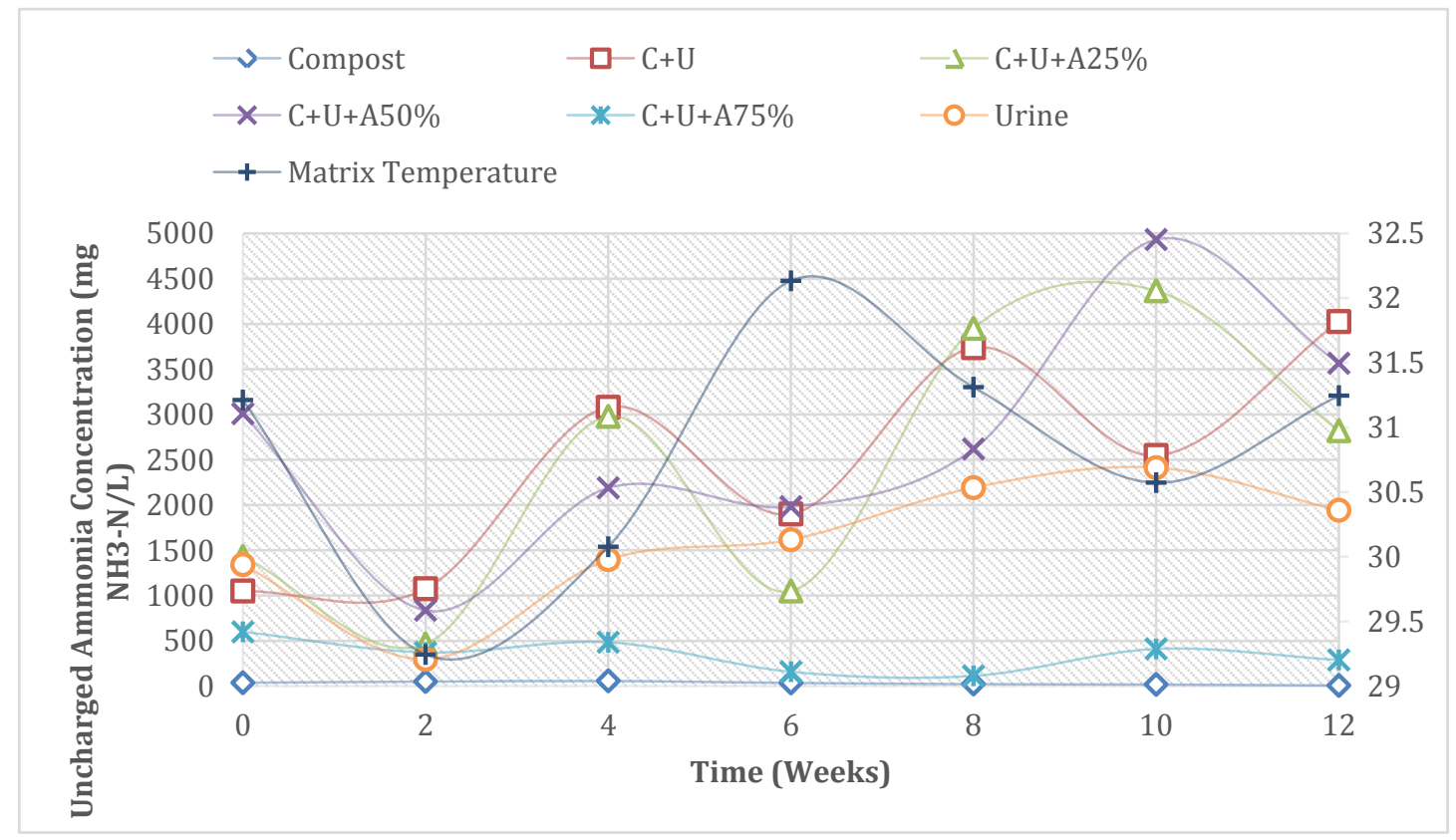

Figure 20 - Un-ionized Ammonia Concentration by Treatment Group; Compost Control (C), Compost with Urine $(C+U)$, Compost, Urine and 25\% By Volume Ash Amendment $\left(C+U+A_{25 \%}\right)$, Compost, Urine and 50\% By Volume Ash Amendment ( $\left.C+U+A_{50 \%}\right)$, Compost, Urine and $75 \%$ By Volume Ash Amendment ( $\left.C+U+A_{75 \%}\right)$, Urine Control (U), Matrix Temperature is presented on a secondary axis at Degrees Celsius

These two findings suggest that for ABS treatment a lack of a desiccant or cover material is not inhibitory as is the case for both composting and alkaline desiccation - two widely used EcoSan methods. Although aerobic decomposition can occur when carbon-nitrogen ratios are within the proper bounds through the use of sawdust, and similarly alkalization and desiccation can be achieved when ash amendment is 1-2 cups, both of these suggested dry materials are only seasonally or conditionally available, difficult or unpleasant to collect, 
and not locally abundant at all as some respondents answered herein and in the study by Wilbur (2013) and Trimmer (2015). Sawdust availability is dependent on the success of sawyers and on an optimistic rate of deforestation, while ash is less and less widely found due to the positive change towards the use of propane and improved cook stoves in light of the correlated effects open fires have on pulmonary disease and also the former phenomenon of deforestation that causes families to search for wood further and further away. If neither process can explicitly improve health outcomes or even be found to eliminate pathogens or the vector from human excreta then more commonly available and practical dry materials like grass - which in BDT-Ñ is cleared by machete-wielding men and women weekly, if not daily - should be promoted to diminish smells and create the biological barrier to fend off vectors.

These findings have real-world implications as seen by the trends in Panamá. Both deforestation and population growth can lead to diminishing levels of fuelwood. The increasing levels of accessibility to marketplaces, making gas a far more common fuel source, compound this. In 2000, nearly $98 \%$ of families in the CNB claimed to use firewood as their main source of cooking fuel, compared to $94 \%$ in 2010 , still a fairly high figure. In BDT, however, only 33\% used firewood dropping to 30\% ten years later. Neither region decreased its firewood use significantly, yet a starker distinction could be made between a difficult to access area and a more accessible area similarly to the argument between access to improved water and sanitation that was made previously. That is to say that communities and subsequently EcoSan latrine users will have less ash available, which has been commented on by users in BDT-N and in other parts of the world as a stressor and frequently mentioned complaint or disadvantage (Trimmer, 2015; Wilbur, 2013, Kaiser, 2006). 


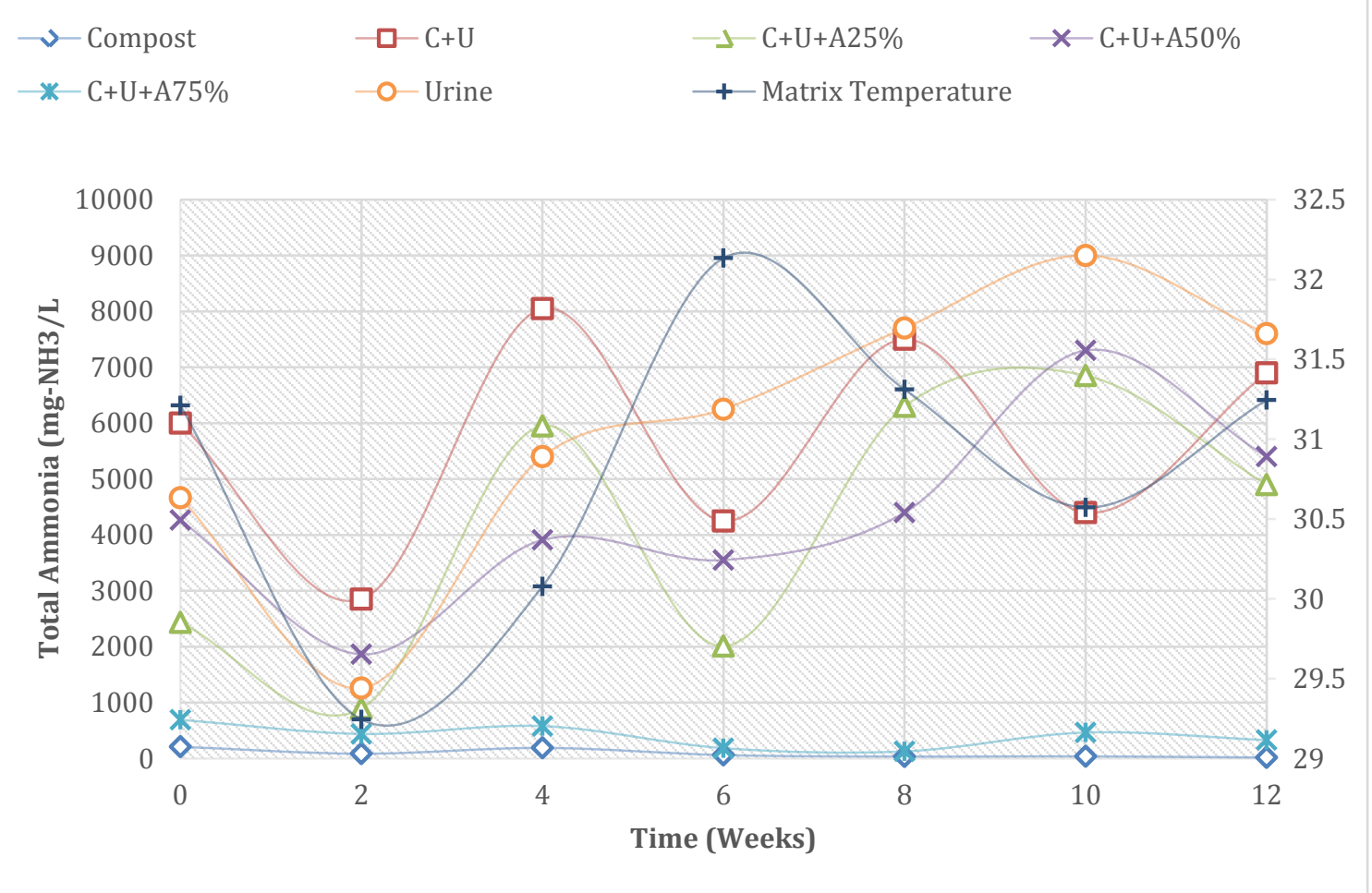

Figure 21 - Total Ammonia Concentration by Treatment Group; Compost Control (C), Compost with Urine $(C+U)$, Compost, Urine and $25 \%$ By Volume Ash Amendment $\left(C+U+A_{25 \%}\right)$, Compost, Urine and 50\% By Volume Ash Amendment ( $\left.C+U+A_{50 \%}\right)$, Compost, Urine and $75 \%$ By Volume Ash Amendment $\left(C+U+A_{75 \%}\right)$, Urine Control (U), Matrix Temperature is presented on a secondary axis at Degrees Celsius

\section{1: Intrinsic Ammonia-Based Sanitation in Urine-Diverting Composting Latrines: Pathogen Inactivation and Microbiological Results}

Results from the microbiological testing have more compelling and complicated interpretations. Testing was performed at a local clinic laboratory microscopically. The clinic performs routine stool sample analysis and for this reason, viability or log reduction determination was not possible. Thus, the initial samples showed either presence or absence of Ascaris ova. Samples taken at the end of the 12-week experimental period showed that only five of the 12 treatment matrices had no presence of viable Ascaris ova. These results are presented in Figures 22 and 23, with each individual matrix accounted for. Dashed lines represent treatment groups that experienced total pathogen inactivation and the blue field represents the calculated threshold value of ammonia concentration needed over the 12-week period. This value was determined by taking a representative composite matrix from the averages of all treatment groups using the method developed by Fidjeland (2015). 


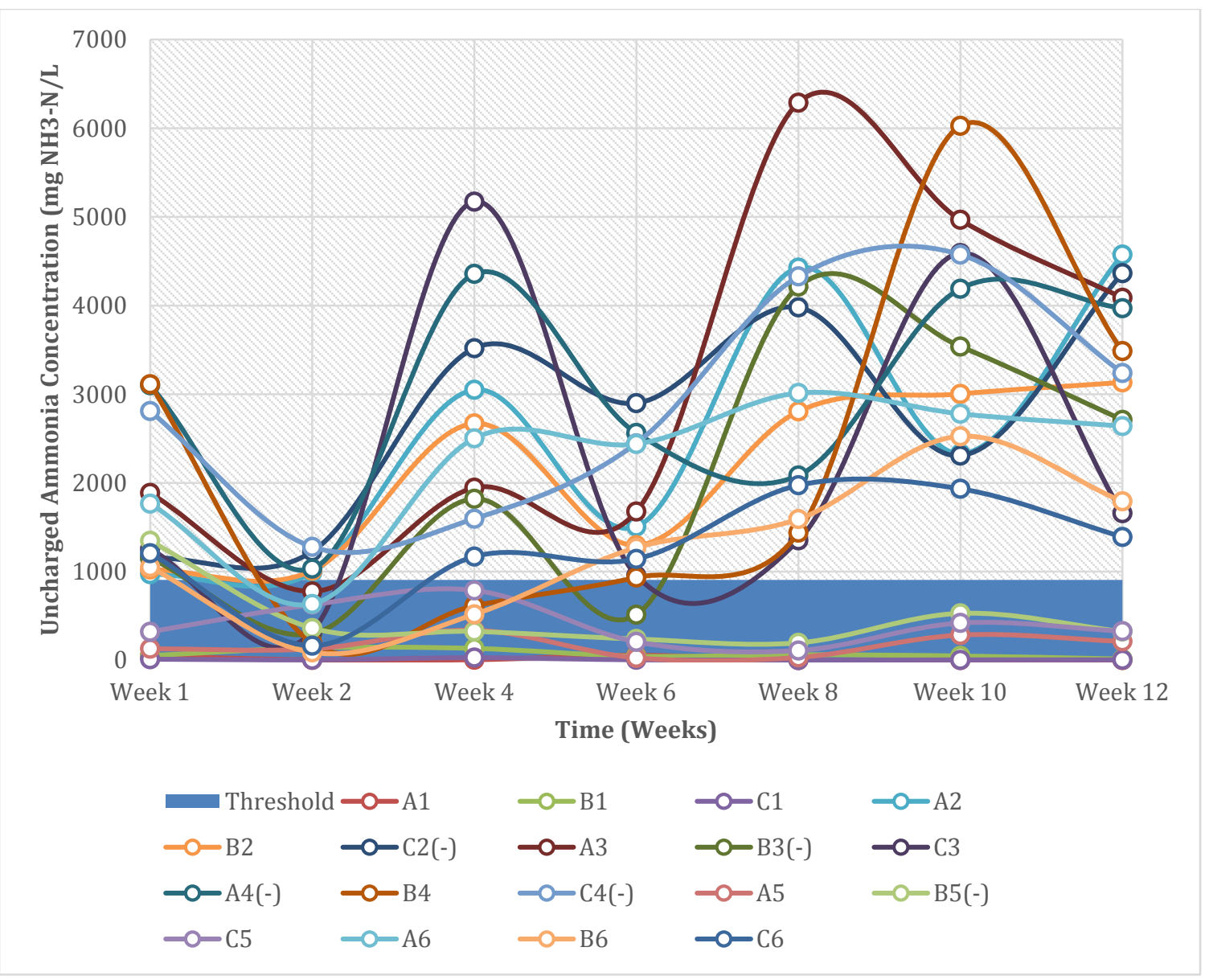

Figure 22- Un-ionized Ammonia Concentration by Individual Matrix (mg NH3-N/L); Threshold represents the calculated necessary un-ionized ammonia concentration to achieve pathogen inactivation in 12 weeks 


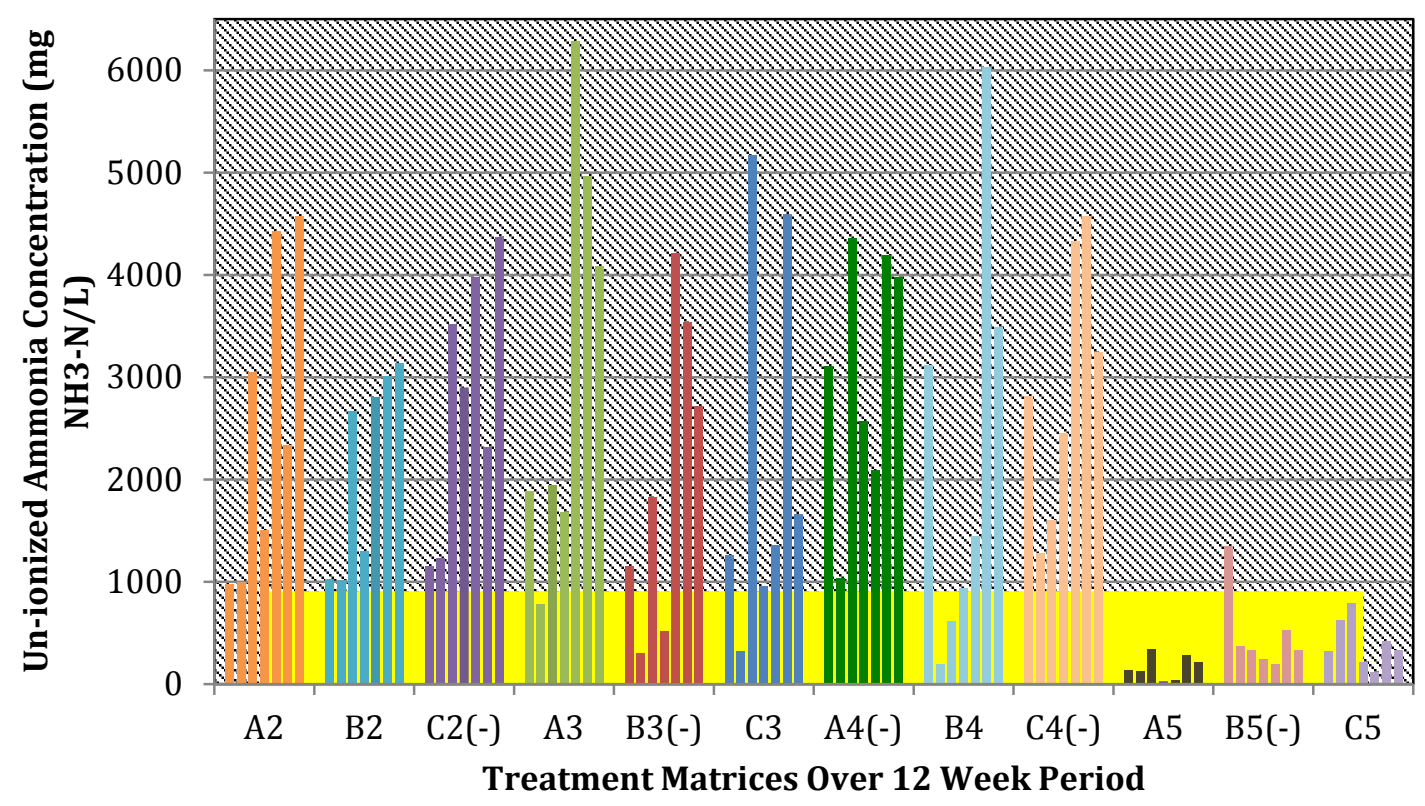

Figure 23 - Un-ionized Ammonia Concentration by Individual Treatment Matrix; The

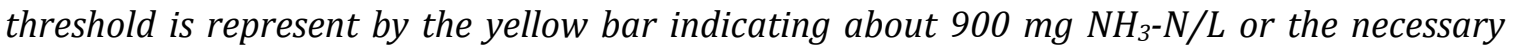
uncharged ammonia concentration to achieve pathogen inactivation in 12 weeks

As the data imply, there is not an obvious correlation that could be drawn between ammonia concentration and pathogen inactivation. There are several matrices that outperformed or were in-line with their more successful counterparts only to yield a positive reading. Most notably matrix $\mathrm{B} 5$, which had readings near the absolute bottom of the groups, yet was still able to produce a negative result in the microbiological test. Unfortunately, no other studies have investigated effectiveness of ABS treatment on real CLs, only in laboratory trials. This once again shows the need for more studies on effectiveness since efficacy studies can sometimes not take into account the variability that can take place in an uncontrolled environment like those conditions found in the field.

\section{2: Temperature Fluctuation}

One possible explanation for the discrepancy in negative and positive results could be the effects of ambient temperature fluctuation, which have a direct influence on matrix temperature and ultimately, ammonia concentration (Nordin, 2009). Temperature variation is discussed by Niwagaba (2009) as a possible effect on the speed of inactivation, yet McKinley et. al. (2012) suggests the opposite, that a sustained temperature and therefore ammonia concentration is critical. Temperatures fluctuated between a higher range than in previous studies, and can explain the high $\mathrm{NH}_{3}$ concentrations found in many of the matrices. Figure 24 shows that average sample temperature was consistently higher than the average ambient temperature, yet cannot express any of the fluctuations in sample temperature as they were drawn consistently between mid-morning and mid-afternoon. Figure 25 demonstrates a correlation between the temperatures measured from each matrix sample and the ambient temperature. The relationship other studies, namely Nordin 
(2009) have posited can be seen in both Figures 26 and 27, which depict matrix temperatures against uncharged ammonia concentrations and total ammonia concentrations, respectively. A second order polynomial regression seems to emerge from Figures 26 and 27 that should be further studied in the field. This means that raising temperature in the field caused the ammonia concentration to reach an optimal point around 31 degrees Celsius. Variable or fluctuating temperature has not been studied thoroughly in either an efficacy or effectiveness study, rather stable temperatures at varying levels were more the focus of Pecson (2007) or Nordin (2009). Volatilization might be much more likely at these temperatures and could possibly explain the reason for a nonlinear relationship in ammonia production when temperatures become higher.

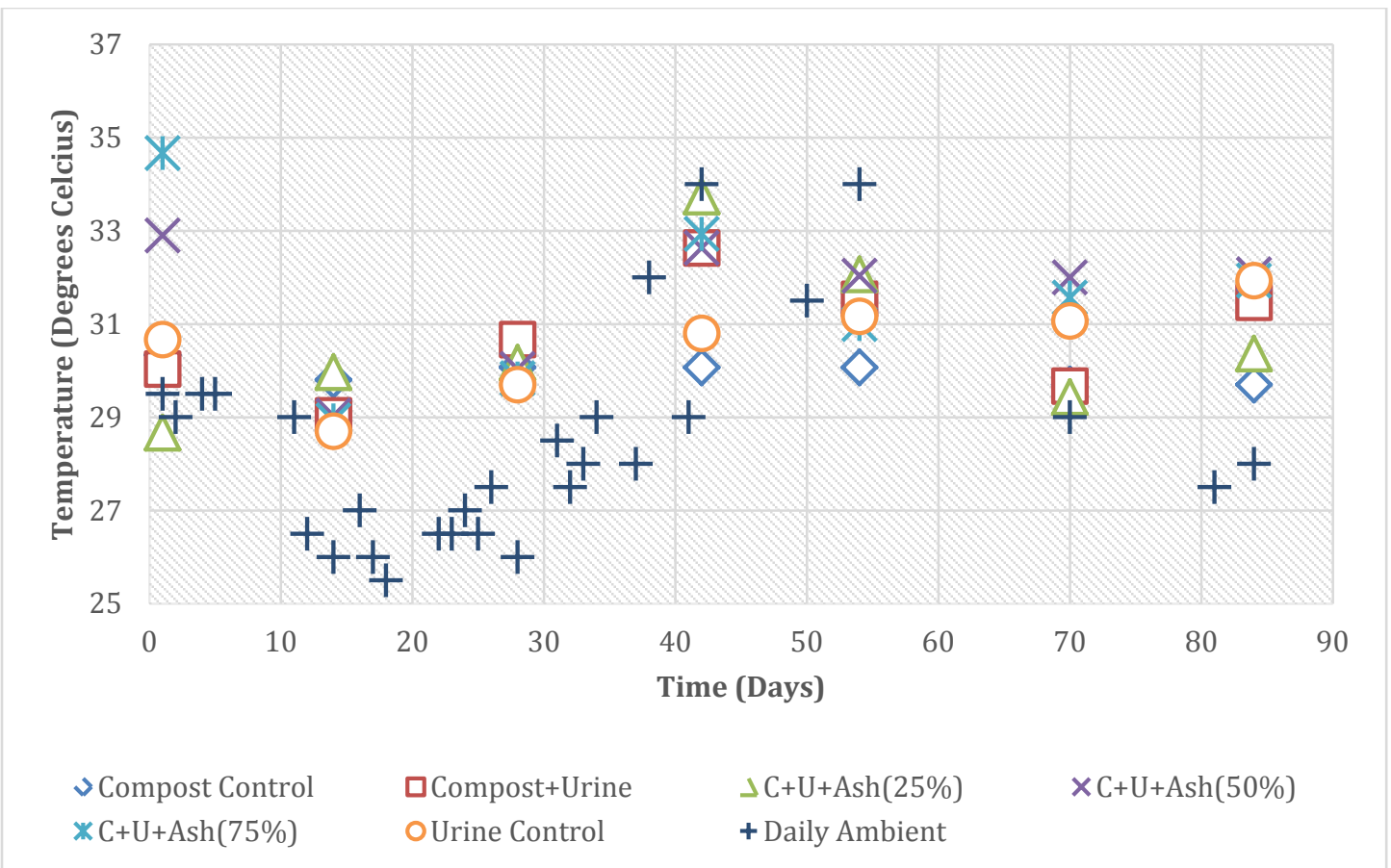

Figure 24 - Average Matrix Temperatures alongside Average Daily Ambient Temperatures 


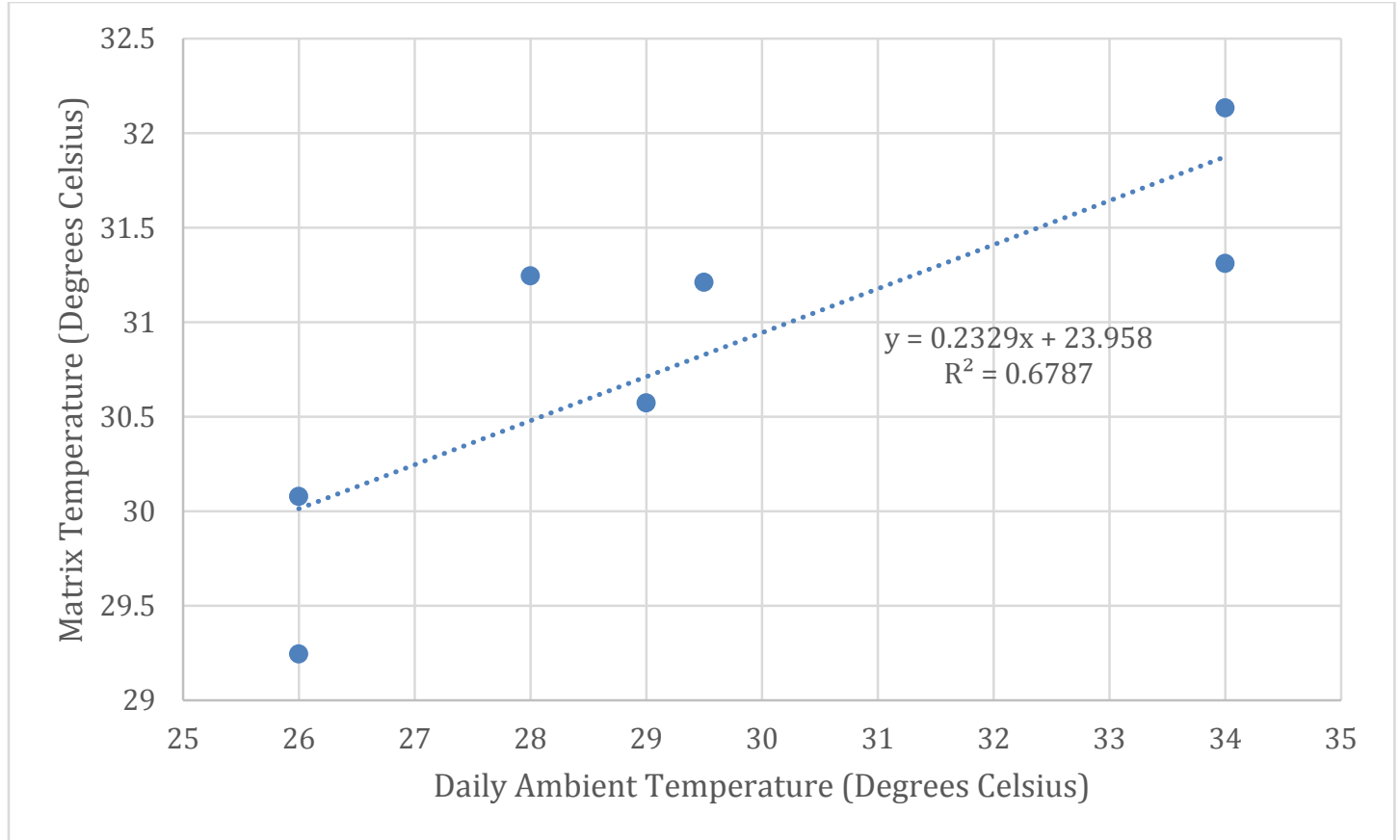

Figure 25 - Average Matrix Temperatures vs. Average Daily Ambient Temperatures

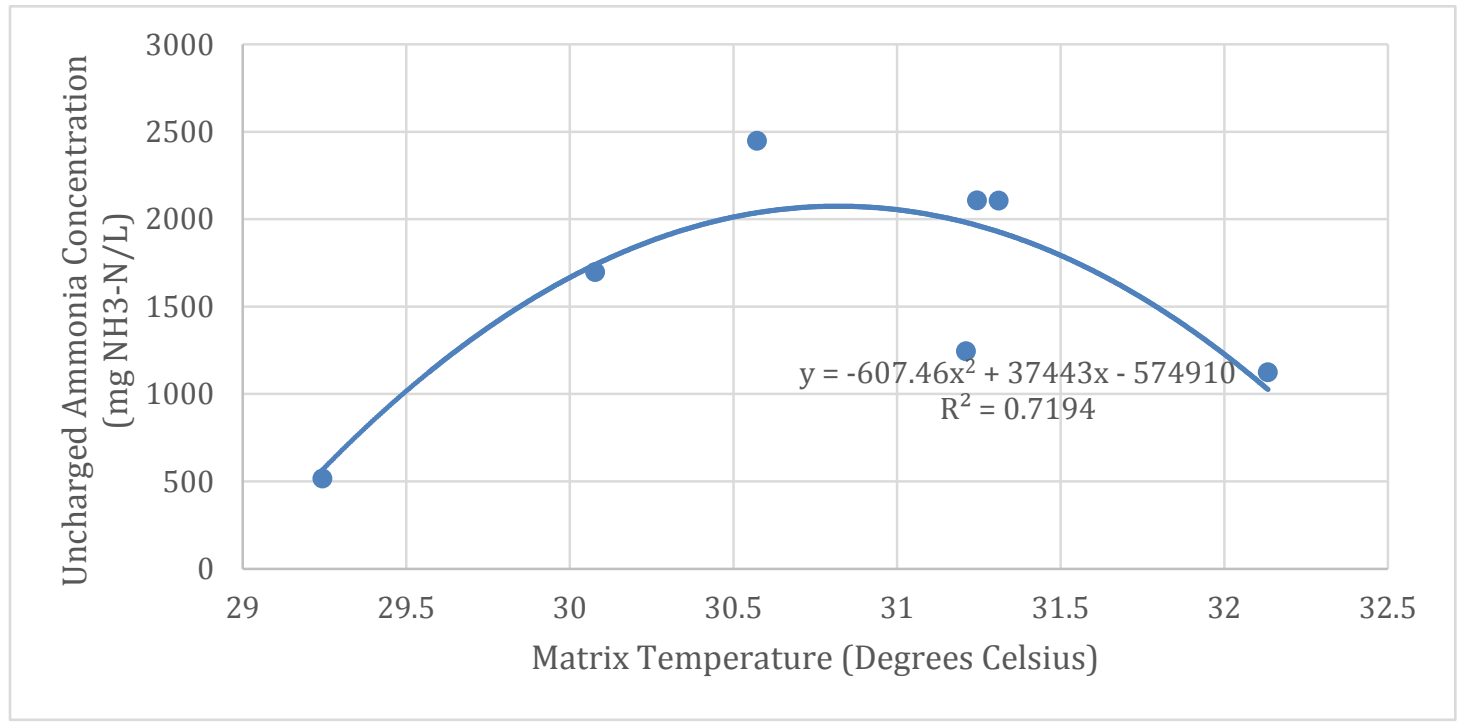

Figure 26 - Matrix Temperatures vs. Uncharged Ammonia Concentration 


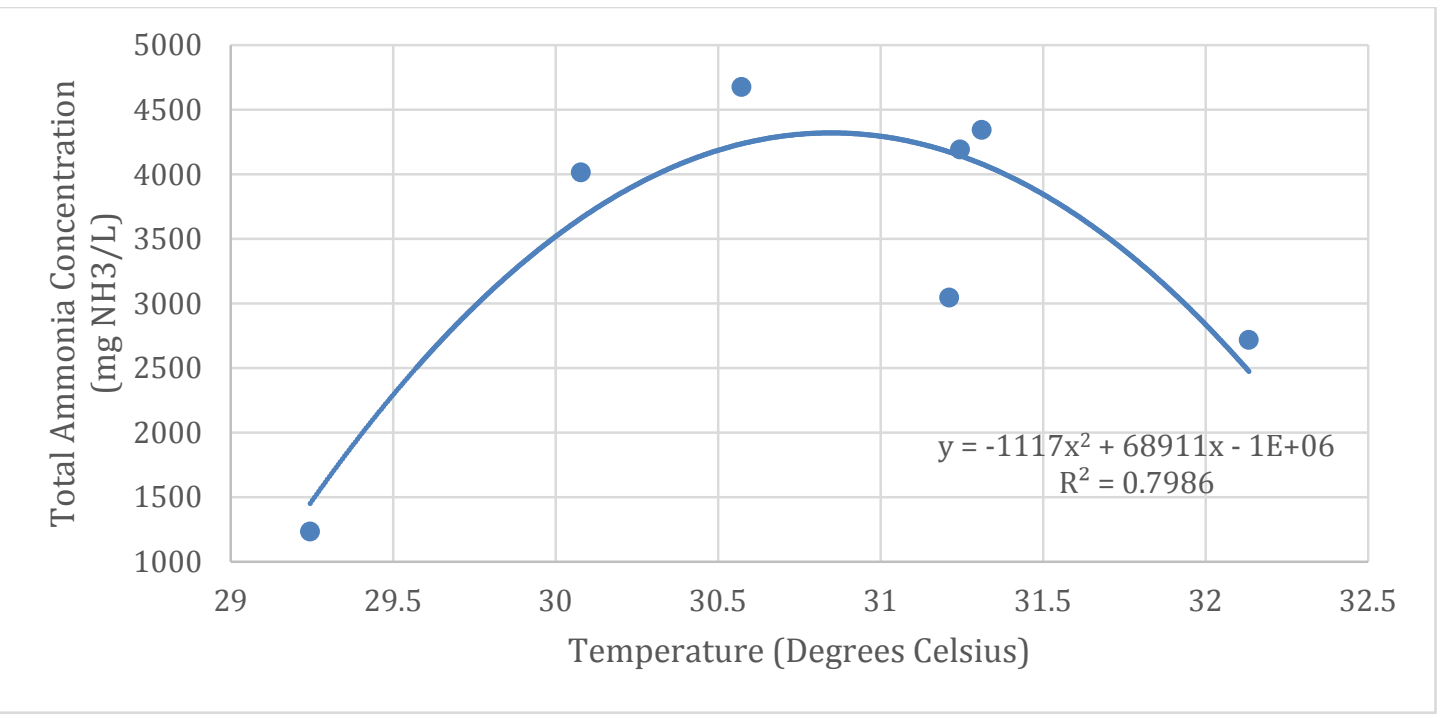

Figure 27 - Matrix Temperatures vs. Total Ammonia Concentrations

\section{3: Qualitative Data: First Impressions of Urine Storage and its Use in Ammonia-Based Sanitation Systems in Rural Panamá}

Households that had adopted CL use for the past 12-14 years were asked to participate in this study to fill in some gaps in the literature on EcoSan and provide preliminary knowledge on the still experimental ABS process. The researcher used open coding in the in vivo method, when possible, to develop common ideas and differences into overarching themes. The respondents were all very eager to participate since, as they expressed, they had a positive experience with Peace Corps and had been part of similar monitoring and evaluation efforts in the past. On first approaching one household to discuss the motives and methods of the study, one of the respondents upon hearing that CLs were to be evaluated promptly threw down the task at hand and marched the author over to her latrine and said, "6 months and six months, what more do you want? It's easy" (indicating to each chamber the time allotted for compost to be produced per the original training sessions).

That is to say that drawing questions out of those interviewed was not difficult or awkward with respect to this taboo subject. This was the case in the author's first few months in Drigari, yet families here were quick to drop the courtesy of speaking about feces and urine around a stranger. The author's familiarity with the culture of the families and novice knowledge of the Ngäbere language facilitated this. Families found the whole study interesting and for lack of a better term, humorous, which facilitated conversations about their opinions on the subject.

All of the participants accurately described the "story" of how they had acquired a CL, including dates, figures and key actors in the initial project. The idea of a "change agent" emerged as a common subject, pointing to the confidence the Peace Corps Volunteer (PCV) evoked about the use of CLs. A few mentioned that the PCV convinced them on the basis of smell and lack of pests since they had been using pit latrines. Also, the pit latrines were set 
away from their homes on a hillside that was sometimes difficult to reach. The case was made, also, that privacy was becoming an issue with respect to open stream defecation since more and more families were building homes in close proximity to each other. Another thing to note was the value-added aspect of the CL - its ability to produce an agricultural fertilizer motivated many of the families that have small farms, grow crops nearby or produce cacao. Also, one of the five participating families had actually constructed their CL through their own funding, labor and initiative. As mentioned previously, the cost of one CL in BDT-Ñ is $\sim \$ 400$ or almost double the monthly income of a typical household.

Respondents cited CLs as being cost-prohibitive for a reason, since others hadn't built their own initially or since. Otherwise, when they were asked, "why don't others have a CL?" respondents said others didn't want them or weren't interested, in a way derogating those that didn't have a CL. Claiming someone isn't "interested" in these contexts has led the author to believe that the opinion-holder typically is referring to a status issue since its inferred "others" are lazy and don't want to take an initiative, are set in their ways, or can't, for lack of an advantage the speaker, indeed has over the "others." Otherwise, the matter-offact response was that the budget didn't account for other users besides the ones that were chosen, a conclusion tinged with stoicism and resignation, sentiments that are often cited as part of the cultural framework in some Ngäbe communities (Wilbur, 2013).

These participating families weren't necessarily the extraordinarily "well-off" or affluent, or more educated than others in Valle de Riscó from the observations of the author. Through the story told of how they came to own a CL - along with comments like those above - they explained that the Peace Corps Volunteer or foreman on the project, or another influential individual or "change agent" had a personal connection with them and found their interest would warrant participation in this project. Many times the most motivated were similarly "rewarded" in these manner in the author's own experiences in his own community of Drigari. Community's lacking these types of influencers might not have had enough understanding of the scope and requirements of the project or frankly how CLs even worked or what they were good for.

When questioned about their prolonged use of CLs, a common sentiment was that they have become accustomed to its use through its convenience and now the CL is their "only option" and as just as someone raised in a more urban setting would conclude, "where else are we to go?" However, this didn't mean that all families would continue using a CL unequivocally only that they might not choose to return to the practice of open defecation. For instance, one family determined that the CL is only a temporary solution until the government installs a flush toilet for their home - this being the preferred option since visitors aren't always knowledgeable on the operation of a CL. Another respondent suggested that they wouldn't refuse a government handout if the opportunity came, yet admitted that they'd "have to know what its impact would be on the watershed."

Questions relating to current and future use of CLs always carried with them the subjects of convenience, observed behavior change or potential for user adaptability and customization, multi-sensory aesthetics (i.e. smell, feel or comfort), and an overall demonstration of initiative. Examples of initiative or drive could be seen in the improvements performed by some users like auxiliary washing stations or "bathrooms" connected to the original CL; replacing a broken seat or increasing the size of the urine- 
diversion pipes; always having a desiccant available as one would have soap to wash clothes or themselves; or building their own CL without outside funding or technical assistance as was the case of this respondent:

"I built it with my own resources. This was in 2005. I built it because I saw they had built others and saw that it was good. That's why I took my own initiative to build one like the others."

This theme of an initiative, drive, ownership, personal investment or just in general, an intrinsic motivation for continuing ISF use should not be surprising since these five families effectively self-selected themselves by exhibiting these traits. That is to say that those seemingly perfunctory seminars in the initial stages of the CL project may not have generated an interest that wasn't there but afforded an opportunity to individuals that already had the resources or initiative to undertake an improved sanitation method more labor-intensive or complex than a simple pit latrine. This respondent describes the opportunity presented by a PCV named Ian,

"We saw some of the first families using their composting latrines so we were interested. To obtain the latrine we had to work together. He paid for all the materials except for the wood, which we provided. "

That being said, issues still arise that could facilitate users like these to have more of their needs met, mainly revolving around maintenance and operation. As in Wilbur's study (2013), concerns about the use and availability of desiccant were expressed as the main difficulties, and all of the users from this study were surprised to learn that other desiccants could be used. One respondent mentioned that the household must, at times, purchase sawdust from others since it isn't readily found, and another commented on the changing times and the dearth of ash accompanying the increased use of gas (propane) stoves.

The difficulty around the need for toilet paper was also brought up and was proposed to be an influential barrier on large-scale adoption of EcoSan ISFs. One participant said, "I think that a bidet might help to get other people to want to have latrines, as well." The use of a bidet as shown in Figures 7, 9 and 11 could alleviate these concerns and has shown, at least anecdotally, to increase interest and revitalized formerly abandoned or unused CL projects. Thus, a more costly project might be worthwhile, linking this to a case in Cambodia where users counterintuitively were willing to pay much more for a flush toilet than accept a subsidized pit latrine (Clouet, 2009).

An idea evident in the preceding chapters calling upon the business/social marketing model to sanitation promotion was desirability. Appropriate technologies and human-centered design make this a principle tenet of their approach alongside viability, feasibility and sustainability. Desirability could be described more simply by affordability or whether or not the price point is acceptable or even possible by the user/buyer. When questioned about the respondents' willingness to pay (WTP), some merely calculated the list of materials and associated labor that another CL would cost to construct - not necessarily did it carry an intrinsic value.

Others were not able to determine any sort of price since they were not privy to how much these materials might cost, so juxtaposing other objects that had a fixed price to the CL 
showed that, at that point in their experience with a CL it was worth more than $\$ 500$. These objects were common household items that many families have in their possession or are very aware of their value i.e.: a cellphone, a large cooking pot, and a gasoline generator. Here are two examples of how participants rationalized their answers:

"Maybe, it would have to be more expensive because the price of materials would have gone up as it does. I would choose a latrine over a cellular phone. Despite the utility of a new pot, I would still want to receive a latrine. It would serve me better than a generator, also."

"We'd want a latrine over a cellphone. Now it's a bit more difficult compared to the pot, but as it was a big investment, the pot - one could acquire it themselves at some later time - but the latrine is much more urgent. That's also good (the generator), but the latrine is free to maintain, the generator would require combustible fuel to use."

The WTP was addressed, as well, to compare with the ABS technology since one of the main efforts of the author's design was to drastically lower the price to the comfort of a single household. In contrast to money, time had not the same level of importance, with respondents answering by explaining how long they think it would take from inception to implementation and some saying that they could wait indefinitely.

All families used their compost in some manner, either in the yards around the house or much further away in one their farmland. Wilbur (2013) found that one of the biggest advantages CLs held in their operation was the production of fertilizer. Here and throughout the other topics discussed, users elicited the agricultural value of the compost as quite important to their initial and continued interest in CLs in both Wilbur's study and the one here. A very interesting account was brought up with respect to humanure compost being used on cacao, one of the most important, if not, only cash crop the community produced. An excerpt from one respondent describes this account:

"We have a little plantation around the house and we use it around there. It appears to me that when the project came we had a great expectation to use the organic compost the latrine provides as a resource on our cacao. However, after some time came the Cooperative that prohibited the use of the compost on our cacao and this affected many as we are all producers here. What we eat, you see, is not necessarily organic [laughter]. We know if it isn't cacao you could use it, but not for the sale with the Cooperative. But, it's a shame because it works."

Very soon after the CL implementation project, an influential cooperative that focuses on the purchase and exporting of cacao produced by its members throughout the BDT-N region, threatened to pull back from certain communities that had received and were using compost harvested from their CLs to fertilize their cacao trees. The respondent in question explained further that the reason behind this was the questionable diet of the cacao farmers, claiming that the foods they were eating were not, in fact, organic and thus their compost could not be so either. During the author's literature review, there was no supporting evidence to this claim, but should be addressed to possibly revitalize the promotion of CLs in agriculturally prominent communities. 
To verify the knowledge of the pathogen inactivation aspects of CLs, the researcher asked users about their feelings towards the possible presence of pathogens in their compost and what the effects of this could be on their family's health, if any. There were negative connotations to the potential disease-carrying organism, however, many trusted the change agent, or whomever initially trained families on the operation of CLs. All believed that their own excreta and consequently their compost would be pathogen-free, but all agreed that they would discontinue using it if this was known. This uncertainty could be also understood as a lack of feedback - a concept important to the effective operation and adoption of many technologies. Many appropriate technologies designed for developing communities do not exhibit any sort of feedback since it'd require excessive training and in some cases expensive equipment. Instead relying on the trainings and knowledge of the extension agent, government worker, etc. to instill confidence in imperceptible effects of interventions like water treatment with chlorine or pathogen inactivation in ISFs. These effects are obviously difficult to make obvious, creating all the more reason to make certain that effectiveness of any intervention is possible in many conditions.

Because of the expressed interest in the agricultural value, the researcher introduced urine as another potential source for plant nutrients. The author asked users how urine compared in terms of disgust to compost and raw excrement. The majority of the respondents made favorable comments to its use and were intrigued to the validity of the claim that it is a considered a better fertilizer than compost and more available. Some were more familiar with the idea of handling stored urine since they were either botanical healers or were exposed to the idea as an alternative to pesticides. Compared to compost, however, many courteously stated that they would not choose to handle it without receiving proper guidance, first, since like compost, in the beginning, they are unfamiliar with it. Not all were sold on the idea, but if an "authority like the Cooperative" could profess the virtues of its use and its acceptance on the products they produce, they might be convinced.

One of the main objectives of these interviews was to gain some understanding on the potential of ABS through the initial impressions of a proposed design that was introduced to participants in piecemeal. After receiving insight on urine storage; integral to the implementation of an economical model of ABS, the author asked users their thoughts on an experimental method that would utilize urine as a necessary function of its operation. The main concern, justifiably, was the smell associated with stale urine that many were familiar with. But, as in other instances, they mentioned that first a demonstration would be necessary to gauge their level of acceptance.

The idea of a pilot latrine as seen in the case of Drigari, is common practice in Peace Corps Panamá projects, since literature supports the notion, that demonstration ISFs can increase project success by encouraging early adopters to come to the forefront and allow diffusion theory to be put into practice (Cole et al., 2015). Demonstration CLs were built very early on in the inception of the early 2000s project in Valle De Riscó. Drigari has yet to have fully accepted the pilot ferrocement CL described before due to it being around for barely more than a year. Once more families become aware of this option, a future study could determine if the pilot latrine program was truly viable or not.

The finer details associated with what an ISF incorporating ABS would look like and the public's opinion of such a technology and its particular facets were presented to the 
participants in a short description involving the methods, intentions and outcomes of the experimental portion of this study. Respondents were informed that the results of the study suggested that CLs could function more quickly, or would take three months rather than a year to produce "compost". This process would require the collection and storage of urine that can also be used as a fertilizer, which would later have to be mixed with the compost for the 3-month period. After this period, the reactor could be drained of excess liquids and the solids removed and applied as typical compost. Some of the implications of ABS are an $85 \%$ reduction in cost, more frequent need to harvest compost and more complex mechanism involved in proper pathogen reduction.

Respondents voiced their concerns about the complexity of the process, yet as in previous instances were confident that they could be more convinced after training sessions. Affordability was overall less important than previously considered, other factors outweighing the improved costs. That is to say that cost was described as prohibitive yet unimportant if sanitation is seen as a non-issue. One respondent stated this quite succinctly, "Of course a lower price is better for me, but the best price is zero - if someone has no money than the price doesn't matter since they can't pay anyway." A surprising outcome of the interviews was the positive reception of the seemingly increased workload where the CL would have to be emptied four times a year instead of once. Again, this respondent put it well; "We're not worried about more frequent work since it'd be less compost to harvest each time, meaning less work. We prefer three smaller meals a day than a single larger one."

Another topic to be addressed is the idea of fatalism described before. It can be extrapolated into an attitude of not of accepting forgone conclusions but waiting for the preferred outcome to manifest itself. This sentiment was expressed in many of the responses by the phrase, "si hay..." or "if it's there..." To put it in other words, this is not necessarily a passive approach, but an active opportunism that is prevalent in some communities that rely on each other for simple daily offerings or in other instances great favors.

To put it in the context of this study, when some respondents were asked about the potential system or any hypothetical, responses were overtly positive and sometimes included either insinuating or direct comments that this proposed project could benefit them despite the refrain from the informed consent form that the results would neither negatively nor positively impact the respondents. This puts into question whether an innovation is necessary or if these current ISFs should rather be improved (with bidets or secondary treatment methods) or maintained until a more acceptable technology (i.e. flush toilets) is implemented.

An interesting observation from the study in Valle de Riscó was the presence of new CLs provided by the Ministry of Health (MINSA) seemingly in direct contradiction to the previously mentioned "0/100\%" campaign promising no latrines, but rather hygienic sanitation systems for all. After further inquiry, the new CLs were provided to households that were part of the $0 / 100$ program but requested a CL over the proposed flush toilet since they had become accustomed to the rest of the families CLs and professed the potential contamination or issues with flooding that a flush toilet might suffer as a concern. 
That being said, ABS could offer the safest, quickest method for improved sanitation possible on a household, rural basis, yet offers many unresolved issues that should be studied further before implementation on a large scale, preferably with demonstration models. This was due to the findings from the technical portion of the study. For instance, a treatment group that had received no ash amendment at all was found to have eliminated all pathogens. The proposed design considered users' inputs regarding the materials and corrections that could be made to the original design like using larger diameter pipes or including a bidet. This makes the design for readily constructed in rural areas as those described throughout. Per this study's title, an interesting EcoSan opportunity lies from a common practice among these families of paying for the service of harvesting their compost as described here:

"My husband has been emptying the chamber once a year. It takes 2 people to empty the chamber for our family (although they thought it should be 6-8 months, they have a smaller family so that's what it takes a year). If my husband is not around, we pay $\$ 15$ to someone (and their helper) to empty the chamber. However, we prefers that my husband to do it so it doesn't cost any money."

Despite the negative note at the end, this commentary and action was an organic outcome from this particular rural community. In-situ CL treatment could be possible in rural communities in Panamá if following a model akin to X-Runner in Perú and SOIL in Haiti, as described before. Using the proposed model introduced in the following section could facilitate services like these and could be profitable quickly if they incorporate ferrocement technology in place of plastic containers. Also, with a CL committee or service-provider like SOIL in charge of these latrines users would not have to concern themselves with the lack of feedback mentioned before since the stakeholder would be incentivized to provide compost quickly and effectively. Yet without a stakeholder, the author must concede the suggestions of the respondents to not pursue such a technology due to factors like complexity and multisensory aesthetics, especially considering that the technical study revealed that not every matrix was effective in sanitizing the compost.

\section{4: Proposed Design}

An outcome of this multi-disciplinary study was an attempt at a pilot design for the implementation of ABS on a household level. Due to the accelerated pathogen inactivation process made possible through ABS, a significant decrease in chamber volume could be afforded. This cost savings in materials through sheer volume reduction can be further capitalized on through the incorporation of the ferrocement construction technique described in detail in Appendix A. The main cost associated with the CL design currently found in Panamá is cement and concrete block. The overwhelming majority of CLs in Panamá were constructed with either concrete block or poured concrete with a few wooden CLs built in areas less prone to flooding. In a more recent project grant proposal the cost of only the cement and concrete block accounted for $82 \%$ of the entire construction cost excluding the additional cost of sand and gravel which in total could amount to more than $\$ 300$ per latrine. Aside from the fact that very few families could be convinced to save this amount or even be able to, the economics of development already points to more affordable 
and appropriate solutions. Although few of the respondents from the interviews described an overt concern for the cost of a CL, this has been shown to be a barrier in many other parts of the world (Van Mihn et al., 2013, Hall et al., 2015).

The current vault volume recommended by the traditional CL design is just over 300 gallons or $1.16 \mathrm{~m}^{3}$. This figure is calculated to be approximately the size sufficient for a family of 8 . Indeed, from the findings of Wilbur (2013) the mean of the household size of CL users of BDT-Ñ was just slightly over that, yet the standard deviation was almost 4 , meaning that many CLs are either undersized or oversized. Calculating chamber or vault volume is difficult in the context of CLs since variables such as family size, total users, diet, desiccant use, operation and the effects of location can vary greatly. In fact, Murphy (2015) reviewed the literature on solid accumulation rates in pit latrines and found that it varied from 18 $\mathrm{L} /$ person/year to $70 \mathrm{~L} /$ person/year from sources 30-60 years old. CLs can be even more volatile since a compost volume can reduce to upwards of $70 \%$ of its original size (Riech et al., 2012; Van Ginkel et al. 1999).) Pebler (2014) found that maintaining moisture content in the range of 50\%-70\% was promoted for improved aerobic decomposition, which translates into volume reduction and increased storage, which ultimately factors into reduced costs.

The CL design featured by Hurtado (2005) along with the UDDTs described by Trimmer (2015) were half the size of the currently promoted CLs due to the difference in the recommended treatment duration. Regardless, being able to customize a technology to suit specific user needs can be very beneficial; - ferrocement allows for modification by the user herself since it is not skillful work nor labor intensive. IDE was able to construct an UDDT using concrete rings, which are very inexpensive in Cambodia and also in India at around \$2-\$4 per 3-foot ring (Clouet, 2009).

The proposed design volume was determined through an analysis of currently recommended volumes and excreta production at $\sim 130$ gallons per tank or more precisely $1.0 \mathrm{~m}^{3}$ in toto. The experience and insight from the case study in Drigari informed much of the design of this ABS model. Along with a cubic meter of storage necessary for fecal sludge storage, a 60-gallon tank will be necessary to collect and store urine that is typically diverted and lost to the soil seepage. Thus, the total storage volume would be 320 gallons, significantly less than the 520 gallons in the demonstration model in Drigari. Basic plans for the design can be seen in Figure 28. They introduce many of the concepts discussed herein and insight from other realms of EcoSan. For instance, urine storage is commonplace in many African and South American nations at this moment. Shaw (2010) presents simple and affordable urine collection methods using 20-liter jerry cans typically used for transport of gasoline in the USA, but found ubiquitously in Panamá when purchasing oil in bulk, and are, then, coveted for water storage and collection. Also, additions of waterwashing and handwashing stations could also improve adoption as discussed before.

The design calls for two half-cubic meter-sized ferrocement tanks constructed in a similar fashion to the doubly large tanks presented in Appendix A. The use of rebar as reinforcement therein is actually not a vital component of ferrocement since the steel-tocement ratio is magnitudes higher than that of reinforced concrete (Ludwig et al., 2000).) Instead, it is merely used to fortify and give shape to the form during the application of the layers of mortar, especially to tanks less than 250 gallons in volume. Some tanks 
constructed in a similar fashion make use of an exaggerated jar shape, enough so that "ferro- "or steel reinforcement is not necessary, at all. The tanks in Drigari had no tank lid per se, instead relying on the gap between the tank and the false floor as a barrier to deter vermin. A compost vault does not need to be air-tight since the biological barrier that is the desiccant provides enough protection (Jenkins, 1994). However, the ABS design depends on avoiding the volatilization of ammonia to the atmosphere because of smell and its correlation with pathogen inactivation. These lids could either be constructed in a similar fashion to the base using ferrocement methods, or a simple wooden or plastic lid that can press down on the plastic sheet that will really be providing a semi-air tight seal. This is, by far, the biggest technical barrier to the incorporation of ferrocement with ABS.

Figure 28 depicts the use of a common 55-liter plastic barrel or drum typically used to store chemicals as the urine storage container. Theoretically, ferrocement could also be used to store urine; yet positioning the urine storage tank below the diversion point but above the treatment reactors could be a challenge due to the typical upright orientation of ferrocement tanks. To reiterate, ferrocement has been proven to provide increased access to an improved water source, yet the experiment detailed in this study could not review its performance in the context of storing urine. Ferrocement has been used with septic tanks to store fecal sludge and in some other alternative sanitation methods like biogas generation due to its durability and affordability, however (Abassi et al., 2012). The urine tank should be outfitted with an overflow that begins near the bottom of the tank so as not provide a large surface area for the ammonia to volatize. Other than that, it would function as any other water storage tank including the use of valves.

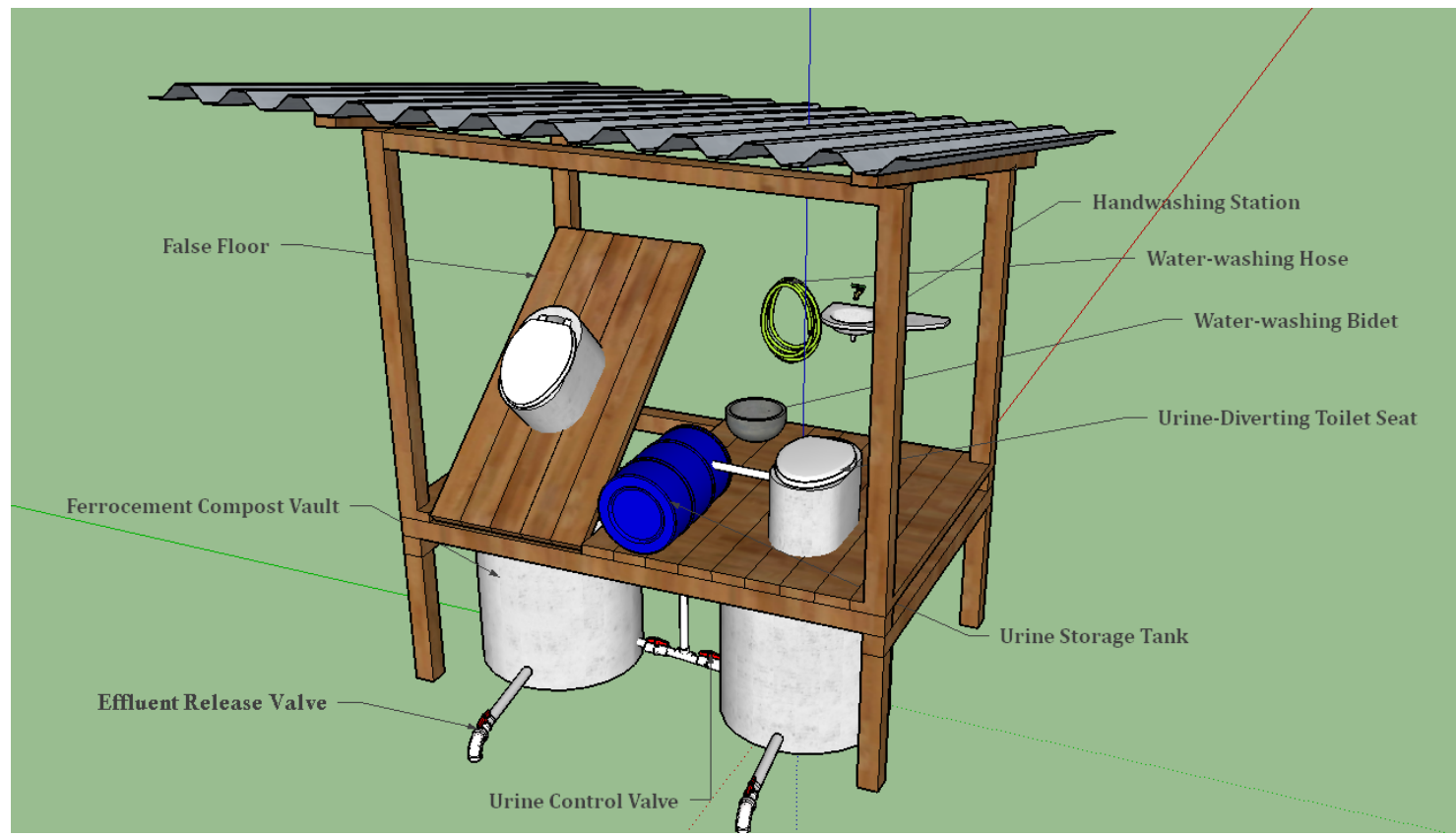

Figure 28 - Conceptual Model of ABS Latrine Design (Drawing by Author) 
The operation of the latrine would be identical to that of a traditional CL in terms of urine diversion, avoiding the entry of water and also proper desiccant use (although the carbon:nitrogen ratio is of lesser importance to ABS since aerobic decomposition is a preferable outcome yet unnecessary for pathogen inactivation). However, every three months, the tank would have to be sealed and become a reactor for the ABS process to begin. Two valves control the influent urine from entering the reactor, but once it does enter the urease in the compost will begin the ureolysis, as discussed previously, and the second chamber would have to be primed with desiccant and begin being used. Once another three months has passed, another valve controlling the effluent of the reactor would have to be opened to drain and release the leachate, preferably into a soak pit. The disposal of this nitrogen-rich effluent is key to not making ABS another contributor to eutrophication and other environmentally- detrimental anthropogenic actions.

Next, the false floor would be raised and the tank unsealed ideally after several hours so as to allow the residual ammonia gas to disperse before the compost is being shoveled off for agricultural use or to be disposed of. In the author's opinion, the contents of the ABS reactors had a non-offensive chemical smell similar to household cleaners, not desirable but distinct from either the pungent smell of stale urine or the fetid odor from raw feces. This is the complimentary social barrier, complimentary to the technical one, relating to ammonia volatilization. Indeed, this process would not simplify the already more complex EcoSan approach to ISFs compared to simpler "flush and discharge" or "drop and store" methods found in septic systems and pit latrines, respectively.

Table 3 - Materials List and Associated Costs for the ABS Latrine (Price Quotes from Panamá Suppliers)

\begin{tabular}{|c|c|r|r|}
\hline Quantity & Material & \multicolumn{1}{|c|}{ Price(\$) } & \multicolumn{1}{c|}{ Total(\$): } \\
\hline 2 & Bags of Cement & $\$ 11.25$ & $\$ 22.50$ \\
\hline 10 & Feet of Chicken Wire & $\$ 0.50$ & $\$ 5.00$ \\
\hline 3 & Bars of 1/4" Rebar & $\$ 1.50$ & $\$ 4.50$ \\
\hline 24 & 2.5 gal Bags of Sand & $\$ 0.50$ & $\$ 12.00$ \\
\hline 5 & Feet of Fabric & $\$ 0.40$ & $\$ 2.00$ \\
\hline 4 & 1-1/2" PVC Ball Valve & $\$ 7.00$ & $\$ 28.00$ \\
\hline 1 & 20' Long 1-1/2"PVC Pipe & $\$ 6.00$ & $\$ 6.00$ \\
\hline 1 & 55-gallon Plastic Drum & $\$ 60.00$ & $\$ 60.00$ \\
\hline \multicolumn{3}{|c|}{ Total: } & $\$ 140.00$ \\
\hline With Ferrocement Urine Storage: & $\$ 80.00$ \\
\hline \multicolumn{3}{|c|}{ Ferrocement Urine Storage using Local Sand: } \\
\hline
\end{tabular}

Another important takeaway is the extra costs associated with the plumbing, which typical CLs do not include. Larger diameter pipe and corresponding valves account for $40 \%$ of the total costs. Then, if a small ferrocement tank for urine storage does not prove feasible then 
the cost almost doubles. An alternative design that could bring the price down to that of a pit latrine involves crossing the urine diversion streams so that the inactive chamber slowly receives the necessary urine quantity but without any storage. This design was not further researched due to the variability of ammonia concentration and the difficulty in determining when the urine would be viable for the ABS process to take hold.

Alternatively, to facilitate adoption and lessen the labor necessary to construct such a system, while making it more mobile and possibly lucrative for entrepreneurial opportunities, two 2-120-gallon plastic tanks and one 1-55-gallon tank could replace the ferrocement tank at a significant cost (around $\$ 300$ depending on the supplier). This however, is nearly equivalent to the traditional design that uses concrete block and cement, eliminating much of the construction period and labor. Volume is shown to be a costprohibitive factor, and for that reason a urine-to-compost ratio of 1:1 urine-to-compost was used rather than the more effective 2:1 mixture recommended by Trimmer (2015). Once again, the social aspects of ISF adoption should be referred to prior to moving forward with any design.

\section{Chapter 6: Conclusion and Recommendations}

\section{0: Conclusion}

The current thesis set out to describe the sanitation situation of Bocas Del Toro-Nokribo, through the context of the people affected, current approaches to promotion and implementation of ISFs, and the implications of novel designs and technologies for ISFs. Overall, the specific case studies in BDT-N, along with the qualitative and quantitative data collected present an argument for the need for a multi-faceted approach that faces the complexities of modern and future sanitation. In more precise terms, improved sanitation not only requires technology that destroys pathogens but improves health outcomes; behavior change models that not only compel individuals into abandoning open defecation, but motivate them to do it by their own motives on their own terms with equity in mind; and designs that aren't made for an underserved population but with them.

CLs in BDT-N were found to be ineffective in treating compost and unsuccessful in being adopted by the population in question according to previous literature. Yet, many communities are without access to improved sanitation not due to either of these issues, but due to factors beyond their control like living rurally or the lack of political will. "Water is life, sanitation is dignity", declared the South African government in their white paper on water reform in 1997. Dignity is what families in rural Valle de Riscó were asking for when they addressed safety, privacy and even convenience as positive motivators in their continued use of ISFs. Many families around the world are asking for the same, in spite of the definition of improved sanitation determined by NGOs and the WHO.

The community of Drigari was presented with a possible alternative to their current practice of open defecation using local materials and the egalitarian technology of ferrocement that requires neither skilled labor nor subsidies to implement. This provides an opportunity to flood-prone, riverine communities that can be self-funded and self- 
deterministic - not merely awaiting a handout from government or non-governmental entities. Families in Valle de Riscó were able to sway local government agencies to approach sanitation in a way that they chose not from the top down, however the role of an outside influence - be it in the form of a "change agent" or a neighbor - was implicit in the success exhibited by these families. These families were motivated and sustained use of CLs for more than a decade by making them their own with simple repairs, modifications to fit their cultural preferences or by building one utterly themselves. This goes to show that simple additions like water-washing stations or bidets that can increase the cost of an intervention can be worth the investment when the stakeholder is satisfied.

New technologies like ammonia-based sanitation can be implemented on a household level or "scaled-up" only if they are done so in an appropriate manner exemplified by social business models like SOIL or X-runner that make use of consumer motivations like convenience and simplicity in their lack of maintenance rather than health and shame. ABS was proven to be effective in five of 12 treatment groups and two of three in the best performing treatment group. There was no correlation found between either ammonia concentration or $\mathrm{pH}$ with respect to pathogen inactivation of Ascaris Lumbricoides. It was determined that matrices exhibiting higher fluctuations in sample temperature were more likely to produce reduction in pathogens from their individual treatment groups. Another outcome was the effect of ash amendment on ammonia concentration production, mainly that amounts commonly recommended for use in UDDTs can be physically inhibitive to the distribution of the alkaline properties found in ash that directly influence the uncharged ammonia fraction in urine.

\section{1: Future Work}

The investigations presented herein revealed several gaps that can be addressed with future research. Primarily, a study on a fully realized prototype version of the ABS model described above or in other literature that can be used to determine user perceptions and other issues yet unknown. Ash amendment was varied in this study to determine any correlations between ash and $\mathrm{pH} /$ uncharged ammonia production, since desiccant availability is a common complaint worldwide with EcoSan latrines. Since the urine-tocompost ratio was conservative based on results from Trimmer (2015) more research into lower volumes of urine and its effects on pathogen inactivation or ammonia production could further simplify and economize the technology. Another study of interest could feature a non-urine diverting CL using ABS. Traditional CLs had no urine-diverting mechanism instead utilizing a false floor, if at all, meaning that urine and compost were combined as in the objective of ABS. This takes out any complications often seen with pipes clogging from improper desiccant placement or improper design for children or women. Berendes et al. (2015) working with compost collected from the aforementioned NGO, SOIL, found that open-air bins of compost using urine to raise moisture content to an optimal range of around $67 \%$ had complete reduction of Ascaris ova within 16 weeks. Thus, an investigation into ABS applications like these where fresh urine combines with stored urine and compost on a transient state basis that also does not provide an airtight seal should be attempted. 


\section{References:}

Abbasi, T., Tauseef, S. M., and Abbasi, S. A. (2012). A Brief History of Anaerobic Digestion and "Biogas". In Biogas Energy (pp. 11-23). Springer New York.

Bartram, J., and Cairncross, S. (2010). Hygiene, sanitation, and water: forgotten foundations of health. PLoS Med, 7(11), e1000367.

Berendes, D., Levy, K., Knee, J., Handzel, T., and Hill, V. R. (2015). Ascaris and Escherichia coli Inactivation in an Ecological Sanitation System in Port-au-Prince, Haiti. PloS one, 10(5), e0125336.

Botting, M. J., Porbeni, E. O., Joffres, M. R., Johnston, B. C., Black, R. E., and Mills, E. J. (2010). Water and sanitation infrastructure for health: The impact of foreign aid. Globalization and health, 6(1), 1.

Bourgois, P. (1988). conjugated oppression: class and ethnicity among Guaymi and Kuna banana workers. American ethnologist, 328-348.

Cairncross, S., and Feachem, R. (1993). Environmental health engineering in the tropics: an introductory text (No. Ed. 2). John Wiley and Sons Ltd..

Campbell, S. J., Savage, G. B., Gray, D. J., Atkinson, J. A. M., Magalhaes, R. J. S., Nery, S. V., ... and Williams, G. M. (2014). Water, sanitation, and hygiene (WASH): a critical component for sustainable soil-transmitted helminth and schistosomiasis control. PLoS Negl Trop Dis, 8(4), e2651. 
Cheng, J. J., Schuster-Wallace, C. J., Watt, S., Newbold, B. K., and Mente, A. (2012). An ecological quantification of the relationships between water, sanitation and infant, child, and maternal mortality. Environmental Health, 11(1), 1.

Clouet, B. (2009) IDE Sanitation marketing pilot project. Retrieved October 1, 2016, from http://www.youtube.com/watch?v=zloOePIhQzc

Cole, B., DeGabriele, J., Ho, G., and Anda, M. (2015). Exploring the utility of diffusion theory to evaluate social marketing approaches to improve urban sanitation in Malawi. Journal of Water Sanitation and Hygiene for Development, 5(2), 289-300.

Condit, R., Robinson, W. D., Ibáñez, R., Aguilar, S., Sanjur, A., Martínez, R., ... and Wright, S. J. (2001). The Status of the Panamá Canal Watershed and Its Biodiversity at the Beginning of the 21st Century Long-term ecological studies reveal a diverse flora and fauna near the Panamá Canal, harbored within a corridor of forest stretching from the Caribbean to the Pacific, but deforestation, land degradation, erosion, and overhunting remain threats. BioScience, 51(5), 389-398.

Coville, A., and Orozco, V. (2014). Moving from efficacy to effectiveness: using behavioural economics to improve the impact of WASH interventions. Waterlines, 33(1), 26-34.

Cumming, O., Elliott, M., Overbo, A., and Bartram, J. (2014). Does global progress on sanitation really lag behind water? An analysis of global progress on community-and household-level access to safe water and sanitation. PLoS One, 9(12), e114699.

del Rosario, F. (2011). This Land Is Our Land: The Ngöbe Struggle for Land. Unpublished Independent Study Project. SIT Graduate Institute.

Dreibelbis, R., Greene, L. E., Freeman, M. C., Saboori, S., Chase, R. P., and Rheingans, R. (2013). Water, sanitation, and primary school attendance: A multi-level assessment of determinants of household-reported absence in Kenya. International Journal of Educational Development, 33(5), 457-465.

Eisenberg, J. N., Scott, J. C., and Porco, T. (2007). Integrating disease control strategies: balancing water sanitation and hygiene interventions to reduce diarrheal disease burden. American Journal of Public Health, 97(5), 846-852.

Endale, Y. T., Yirsaw, B. D., and Asfaw, S. L. (2012). Pathogen reduction efficiency of onsite treatment processes in eco-sanitation system. Waste Management and Research, $0734242 X 11432190$.

Evans, B. E., and Bartram, J. (2005). The sanitation challenge: Turning commitment into reality (pp. 1-32). World Health Organization.

Evans, B. E., Colin, C., Jones, H., and Robinson, A. (2009). Sustainability and equity aspects of total sanitation programmes - A study of recent WaterAid-supported programmes in three countries: global synthesis report. Report. WaterAid, London. 
Exley, J. L., Liseka, B., Cumming, O., and Ensink, J. H. J. (2015). The sanitation ladder, what constitutes an improved form of sanitation?. Environmental science and technology, 49(2), 1086-1094.

Feachem, R., Bradley, D. J., Garelick, H., and Mara, D. D. (1983). Ascaris and ascariasis. Sanitation and disease: health aspects of excreta and wastewater management. World Bank: Washington: World Bank, 391.

Fewtrell, L., and Colford, J. M. (2004). Water, sanitation and hygiene: interventions and diarrhoea. A systematic review and meta-analysis. The International Bank for Reconstruction and Development/The World Bank. Washington, DC, 20133.

Fewtrell, L., Kaufmann, R. B., Kay, D., Enanoria, W., Haller, L., and Colford, J. M. (2005). Water, sanitation, and hygiene interventions to reduce diarrhoea in less developed countries: a systematic review and meta-analysis. The Lancet infectious diseases, 5(1), 4252 .

Fidjeland, J. (2015). Sanitisation of faecal sludge by ammonia. Acta Universitatis agriculturae Sueciae

(Vol. 2015, No. 45).

Fidjeland, J., Magri, M. E., Jönsson, H., Albihn, A., and Vinnerås, B. (2013). The potential for self-sanitisation of faecal sludge by intrinsic ammonia. Water research, 47(16), 6014-6023.

Freeman, M. C., Greene, L. E., Dreibelbis, R., Saboori, S., Muga, R., Brumback, B., and Rheingans, R. (2012). Assessing the impact of a school-based water treatment, hygiene and sanitation programme on pupil absence in Nyanza Province, Kenya: a cluster-randomized trial. Tropical Medicine and International Health, 17(3), 380-391.

Fry, D., Mideksa, D., Ambelu, A., Feyisa, Y., Abaire, B., Cunliffe, K., and Freeman, M. C. (2015). Adoption and sustained use of the arborloo in rural Ethiopia: a cross-sectional study. Journal of Water Sanitation and Hygiene for Development, 5(3), 412-425.

Gibson, D.A., (2014). Inactivation of Ascaris in double-vault urine-diverting composting latrines in

Panamá: methods and environmental health engineering field applications. Master's Thesis, University of South Florida, Civil and Environmental Engineering, Tampa, Florida. Retrieved September 5, 2016, from http://scholarcommons.usf.edu/etd/5224

Gomes, M. C. R. L., Moura, E. A. F., Pedro, J. P. B., Bezerra, M. M., and Brito, O. S. (2015). Sustainability of a sanitation program in flooded areas of the Brazilian Amazon. Journal of Water Sanitation and Hygiene for Development,5(2), 261-270.

Hall, R. P., Vance, E. A., Van Houweling, E., and Huang, W. (2015). Willingness to pay for VIP latrines in rural Senegal. Journal of Water Sanitation and Hygiene for Development, 5(4), 586-593.

Halpenny, C. M., Paller, C., Koski, K. G., Valdés, V. E., and Scott, M. E. (2013). Regional, 
household and individual factors that influence soil transmitted helminth reinfection dynamics in preschool children from rural indigenous Panamá. PLoS Negl Trop Dis, 7(2), e2070.

Hanchett, S., Khan, M. H., Krieger, L., \& Kullmann, C. (2011). Sustainability of sanitation in rural Bangladesh. In The future of water sanitation and hygiene: Innovation, adaptation and engagement in a changing world. Loughborough, UK: 35th WEDC International conference.

Heppleston, M. J. (2009). Beyond the pilot project: a review of the diffusion of ecological sanitation toilets (Doctoral dissertation, Faculty of Health Sciences-Simon Fraser University).

Hill, G. B., Baldwin, S. A., and Vinnerås, B. (2013). Composting toilets a misnomer: excessive ammonia from urine inhibits microbial activity yet is insufficient in sanitizing the end-product. Journal of environmental management, 119, 29-35.

Hoffmann, H. (2012). Construction of bench style double vault urine diversion toilet and alternatives. Rotaria del Peru SAC, Lima, Peru. Retrieved September 15, 2016, from http://www.susana.org/langen/library?view=ccbktypeitemandtype=2andid=1495

Hurtado, D. (2005). Compost Latrines in Rural Panamá: Design, Construction, and Evaluation of

Pathogen Removal. Unpublished Master's Thesis. Retrieved on September 15, 2016 from http://cee.eng.usf.edu/peacecorps/5\%20\%20Resources/Theses/Sanitation/2005Hurtado.pdf.

Instituto Nacional de Estadística de Censo. (2000). Retrieved October 10 2016, from http://estadisticas.contraloria.gob.pa/inec/cgibin/RpWebEngine.exe/Portal?andBASE=LP2 000andMAIN=WebServerMain_censos.inl

Instituto Nacional de Estadística de Censo. (2010). Retrieved October 10 2016, from http://estadisticas.contraloria.gob.pa/inec/cgibin/RpWebEngine.exe/Portal?andBASE=LP2 010andMAIN=WebServerMain_censos.inl

Jandreau, C. (2012). Land Rights, Cultural Hybridization, and Self-determination of First Peoples: A Case Study Among the Ngöbe of Western Panamá. Independent Study Project (ISP) Collection. Paper 1321. Retrieved September 26, 2016, from http://digitalcollections.sit.edu/isp_collection/1321

Jenkins, J. (1994). The Humanure Handbook: A Guide to Composting Human Manure. Jenkins Publishing, Grove City, PA.

Jenkins, M. W., and Scott, B. (2007). Behavioral indicators of household decision-making and demand for sanitation and potential gains from social marketing in Ghana. Social science and medicine, 64(12), 2427-2442.

Jensen, P. K. M., Phuc, P. D., Knudsen, L. G., Dalsgaard, A., \& Konradsen, F. (2008). Hygiene versus fertiliser: the use of human excreta in agriculture-a Vietnamese 
example. International journal of hygiene and environmental health, 211(3), 432-439.

Joshi, A., \& Amadi, C. (2013). Impact of water, sanitation, and hygiene interventions on improving health outcomes among school children. Journal of environmental and public health, 2013.

Kaiser, J. (2006). An Analysis of the Use of Desiccant as a Method of Pathogen Removal in Compost Latrines in Rural Panamá. Unpublished Master's Report. Retrieved September 1, 2016 from http://usfmi.weebly.com/thesesreports.html

Kim, D. G., Saggar, S., and Roudier, P. (2012). The effect of nitrification inhibitors on soil ammonia emissions in nitrogen managed soils: a meta-analysis. Nutrient Cycling in Agroecosystems, 93(1), 51-64.

Kvarnström, E., McConville, J., Bracken, P., Johansson, M., and Fogde, M. (2011). The sanitation ladder-a need for a revamp?. Journal of Water Sanitation and Hygiene for Development, 1(1), 3-12.

Langergraber, G., and Muellegger, E. (2005). Ecological Sanitation-a way to solve global sanitation problems?. Environment international, 31(3), 433-444.

Langford, M., Bartram, J., and Roaf, V. (2013). The human right to sanitation. The Human Right to Water: Theory, Practice and Prospects.

Langford, R., and Panter-Brick, C. (2013). A health equity critique of social marketing: where interventions have impact but insufficient reach. Social science and medicine, 83, 133-141.

Ludwig, A., Anaya Garduño, M., Rivera Olivar, D., Williams, G., Santos, V., Lagos, F. S., ... and Athié Lambarri, M. (2000). Water storage, tanks, cisterns, aquifers, and ponds (No. 628.13 L948). Sociedad Mexicana de la Ciencia del Suelo, Chapingo (México). Colegio de Postgraduados, Chapingo (México). Universidad Autónoma Chapingo, Chapingo (México).

Mara, D., Lane, J., Scott, B., and Trouba, D. (2010). Sanitation and health. PLoS Med, 7(11), e1000363.

Marshall, L., and Kaminsky, J. (2016). When behavior change fails: evidence for building WASH strategies on existing motivations. Journal of Water Sanitation and Hygiene for Development, washdev2016148.

McCullough, D. (2001). The path between the seas: the creation of the Panamá Canal, 18701914. Simon and Schuster.

McKinley, J. W., Parzen, R. E., and Guzmán, Á. M. (2012). Ammonia inactivation of Ascaris ova in ecological compost by using urine and ash. Applied and environmental microbiology, 78(15), 5133-5137.

Mehl, J. (2008). Pathogen Destruction and Aerobic Decomposition in Composting Latrines: 
A

Study from Rural Panamá. Unpublished Master's Report. Retrieved September 16, 2016 from http://usfmi.weebly.com/thesesreports.html

Mehta, L., and Movik, S. (2010). The dynamics and sustainability of Community-Led Total Sanitation (CLTS): mapping challenges and pathways.

Midkiff, J. B. (2013). Post-project Assessment of Pit Latrines in Rural Panamá. Unpublished Master's Report. Retrieved September 12, 2016, from http://digitalcommons.mtu.edu/etds/692

Miller, K., Chang, E., and Johnson, N. (2001). Defining common ground for the Mesoamerican Biological Corridor. Washington, DC: World Resources Institute.

Ministry of Public Works. (2014). Cuadro 333-19. LONGITUD DE LA RED VIAL EN LA REPÚBLICA, SEGÚN PROVINCIA, COMARCA INDÍGENA Y TIPO DE SUPERFICIE: AL 31 DE DICIEMBRE DE LOS AÑOS 2013-1. Panamá City, Panamá

Murphy, C. M. (2015). Solids Accumulation Rates of Latrines at Rural Schools in Nimba County, Liberia. Unpublished Master's Report. Retrieved September 6, 2016, from http://scholarcommons.usf.edu/etd/5545

Myers, J. (2013). Ecological sanitation: a sustainable dream or reality?: exploring complexity of transitions to more sustainable sanitation practices: a case-study of Burmi Tola, India. Master Thesis Series in Environmental Studies and Sustainability Science.

Myers, N., Mittermeier, R. A., Mittermeier, C. G., da Fonseca, G. A., and Kent, J. (2000). Biodiversity hotspots for conservation priorities. Nature, 403(6772), 853-858.

Nawab, B., Nyborg, I. L., Esser, K. B., and Jenssen, P. D. (2006). Cultural preferences in designing ecological sanitation systems in North West Frontier Province, Pakistan. Journal of Environmental Psychology, 26(3), 236-246.

Niwagaba, C., Nalubega, M., Vinnerås, B., Sundberg, C., and Jönsson, H. (2009). Bench-scale composting of source-separated human faeces for sanitation. Waste management, 29(2), 585-589.

Nordin, A. (2007). Ammonia Based Sanitation Technology: Safe Plant Nutrient Recovery from Source Separated Human Excreta (Doctoral dissertation, Department of Biometry and Engineering, Swedish University of Agricultural Sciences).

Nordin, A., Nyberg, K., and Vinnerås, B. (2009). Inactivation of Ascaris eggs in sourceseparated urine and feces by ammonia at ambient temperatures. Applied and environmental microbiology, 75(3), 662-667.

O'Reilly, K., and Louis, E. (2014). The toilet tripod: Understanding successful sanitation in rural India. Health and place, 29, 43-51. 
Panamá Canal Authority. (2015). Panamá Canal Authority. Annual Report 2015. Panamá City, Panamá. Retrieved September 22, 2016, from http://www.acp.gob.pa/eng/general/reporte-anual/index.html

Pebler, P. T. (2015). Double vault composting latrines in rural Paraguay: Feasible construction and optimal use. Unpublished Master's Report. Retrieved September 2, 2016, from http://digitalcommons.mtu.edu/etds/892

Pecson, B. M., Barrios, J. A., Jiménez, B. E., and Nelson, K. L. (2007). The effects of temperature, $\mathrm{pH}$, and ammonia concentration on the inactivation of Ascaris eggs in sewage sludge. Water research, 41(13), 2893-2902.

Pradyumna, A., Prahlad, I. M., and Ganesh, C. K. (2015). Moving beyond sanitation's diarrhoea fixation. The Lancet Global Health, 3(1), e16.

Prüss-Ustün, A., Bartram, J., Clasen, T., Colford, J. M., Cumming, O., Curtis, V., ... and Freeman, M. C. (2014). Burden of disease from inadequate water, sanitation and hygiene in low-and middle-income settings: a retrospective analysis of data from 145 countries. Tropical Medicine and International Health, 19(8), 894-905.

Redclift, M. R. "'Urban bias and rural poverty: A Latin American perspective." The Journal of Development Studies 20.3 (1984): 123-138.

Redlinger, T., Graham, J., Corella-Barud, V., \& Avitia, R. (2001). Survival of fecal coliforms in dry-composting toilets. Applied and environmental microbiology, 67(9), 4036-4040.

Riboli-Sasco, E., Leslie, J., Felix, L., Head, R., Car, J., and Gunn, L.H. (2015). Effectiveness of Communication Strategies Embedded in Social Marketing Programs on Health Behaviors and Related Health and Welfare Outcomes in Low and Middle Income Countries (Protocol). Campbell Systematic Reviews, 11(3).

Rieck, C., von Münch, E., and Hoffmann, H. (2012). Technology review of urine-diverting dry toilets (UDDTs)-Overview on design, management, maintenance and costs. Deutsche Gesellschaft fuer Internationale Zusammenarbeit (GIZ) GmbH, Eschborn, Germany.

Rosengarden, C. L. (2007). Land Management Strategies and Fuelwood Collection in the Indigenous Ngäbe Village of Hato Horcón, La Comarca Ngäbe-Buglé, Panamá (Doctoral dissertation, Michigan Technological University).

Runk, J. V. (2012). Indigenous land and environmental conflicts in Panamá: neoliberal multiculturalism, changing legislation, and human rights.Journal of Latin American Geography, 11(2), 21-47.

Russel, K., Tilmans, S., Kramer, S., Sklar, R., Tillias, D., and Davis, J. (2015). User perceptions of and willingness to pay for household container-based sanitation services: experience from Cap Haitien, Haiti. Environment and urbanization, 0956247815596522.

Shaw, R. (2010). Use of Human Urine as Crop Fertilizer in Mali, West Africa (Master's thesis). 
Retrieved September 27, 2016 from http://cee.eng.usf.edu/peacecorps/5\%20\%20Resources/Theses/Sanitation/2010Shaw.pdf.

Shayo, A. J. (2003, April). Acceptance of Ecosan concepts in Tanzania-a case study of piloting ecological sanitation, Majumbasita, Dar Es Salaam. In 2nd International Symposium on Ecological Sanitation.

Sommer, M., Kjellén, M., and Pensulo, C. (2013). Girls' and women's unmet needs for menstrual hygiene management (MHM): The interactions between MHM and sanitation systems in low-income countries. Journal of Water Sanitation and Hygiene for Development, 3(3), 283-297.

Sossou, S. K., Sou, M., Konate, Y., Maiga, A. H., and Funamizu, N. (2016). Inactivation kinetics of indicator microorganisms during urea treatment for sanitizing finished compost from composting toilet. Journal of Water Sanitation and Hygiene for Development, washdev2016090.

Sparkman, D., and Sturzenegger, G. (2016). Fostering Water and Sanitation Markets in Latin America and the Caribbean: How the Public Sector Can Support the Private Sector to Bridge Coverage Gaps and Improve Service Quality for Low-Income Populations.

Stewart, T.D. (1942). Persistence of the African type of tooth pointing in Panamá. American Anthropologist, 44(2), 328-330.

Strassnig, C. (2010). Rediscovering the Camino real of Panamá: Archaeology and heritage tourism potentials. Journal of Latin American Geography, 9(2), 159-168.

Strunz, E. C., Addiss, D. G., Stocks, M. E., Ogden, S., Utzinger, J., and Freeman, M. C. (2014). Water, sanitation, hygiene, and soil-transmitted helminth infection: a systematic review and meta-analysis. PLoS Med, 11(3), e1001620.

Thaler, R.H., and Sunstein, C.R.. (2008). Nudge: Improving Decisions about Health, Wealth, and Happiness. New Haven, CT: Yale University Press.

The World Bank. (2015). Panamá. Data. Retrieved September 29 2016, from http://data.worldbank.org/country/Panamá

Tilley, E., Bieri, S., and Kohler, P. (2013). Sanitation in developing countries: a review through a gender lens. Journal of Water Sanitation and Hygiene for Development, 3(3), 298314.

Tilmans, S., Russel, K., Sklar, R., Page, L., Kramer, S., and Davis, J. (2015). Container-based sanitation: assessing costs and effectiveness of excreta management in Cap Haitien, Haiti. Environment and urbanization, 27(1), 89-104.

Trimmer, J. T. (2015). Ecological Sanitation in Uganda: Promotion through Demonstration Facilities and Potential for Ascaris Reduction by Free Ammonia Inactivation Using Stored Urine. Unpublished Master's Thesis. Retrieved September 4, 2016, from http://scholarcommons.usf.edu/etd/5834 
Trimmer, J. T., Nakyanjo, N., Ssekubugu, R., Sklar, M., Mihelcic, J. R., and Ergas, S. J. (2016). Estimation of Ascaris lumbricoides egg inactivation by free ammonia treatment of ashamended UDDT vault products using stored urine in Uganda. Journal of Water Sanitation and Hygiene for Development, washdev2016111.

General Assembly of the United Nations. (2010). Resolution No. A/RES/64/292. Resolutions 64th Session Retrieved September 29, 2016. From http://www.un.org/en/ga/64/resolutions.shtml

United Nations. (2014). Objetivo de Desarrollo del Milenio, IV Informe de Panamá 2014. Sistema de las Naciones Unidas. Retrieved September 3, 2016, from www.onu.org.pa/media/documentos/odm-cuarto-informe-2014.pdf

van der Hoek, W., Evans, B. E., Bjerre, J., Calopietro, M., and Konradsen, F. (2010). Measuring progress in sanitation. Retrieved September 3, 2016, from eprints.whiterose.ac.uk

Van Ginkel, J. T., Raats, P. A., and Van Haneghem, I. A. (1999). Bulk density and porosity distributions in a compost pile. Netherlands Journal of Agricultural Science, 47(2), 105-122.

Van Minh, H., Nguyen-Viet, H., Thanh, N. H., and Yang, J. C. (2013). Assessing willingness to pay for improved sanitation in rural Vietnam. Environmental health and preventive medicine, 18(4), 275-284.

Whaley, L., and Webster, J. (2011). The effectiveness and sustainability of two demanddriven sanitation and hygiene approaches in Zimbabwe. Journal of Water Sanitation and Hygiene for Development, 1(1), 20-36.

WHO/UNICEF Joint Water Supply, Sanitation Monitoring Programme, and World Health Organization. (2014). Progress on drinking water and sanitation: 2014 update. World Health Organization.

Wichuk, K. M., and McCartney, D. (2010). Compost stability and maturity evaluation-a literature review A paper submitted to the Journal of Environmental Engineering and Science. Canadian Journal of Civil Engineering, 37(11), 1505-1523.

Wilbur, P.A. (2014). An evaluation of the use of composting latrines and the perceptions of excrement

in Ngäbe communities in Panamá. Master's Thesis, University of South Florida, Civil and Environmental Engineering, Tampa, Florida. Retrieved September 27, 2016, from http://scholarcommons.usf.edu/etd/5331/

World Health Organization, and UNICEF. (2013). Progress on sanitation and drinking-water. World Health Organization.

World Health Organization. (2003). Guidelines for safe recreational water environments: Coastal and fresh waters (Vol. 1). World Health Organization. 
World Health Organization. (2006). Guidelines for the Safe Use of Wastewater, Excreta and Greywater: Excreta and greywater use in agriculture (Vol. 4). World Health Organization.

United Children's Fund. (2015). 2015 Update and MDG Assessment. Retrieved September 10, 2016, from

files.unicef.org/.../Progress_on_Sanitation_and_Drinking_Water_2015_Update_pdf

Young, P. D. (1970). Notes on the ethnohistorical evidence for structural continuity in Guaymí society. Ethnohistory, 11-29.

Young, P. D. (1985). Guaymí socionatural adaptations. The Botany and Natural History of Panamá, 357-365.

\section{Appendices:}

\section{Appendix A: Ferrocement Composting Latrine Construction Guide}

Table 4 - Materials List

\begin{tabular}{|c|c|r|r|}
\hline Quantity & Material & Price(\$) & Total(\$): \\
\hline 3 & Bags of Cement & $\$ 11.25$ & $\$ 33.75$ \\
\hline 30 & Feet of Chicken Wire & $\$ 0.50$ & $\$ 15.00$ \\
\hline 5 & Bars of 1/4" Rebar & $\$ 1.50$ & $\$ 7.50$ \\
\hline 36 & 2.5 gal Bags of Sand & $\$ 0.50$ & $\$ 18.00$ \\
\hline 13 & Feet of Fabric & $\$ 0.40$ & $\$ 5.20$ \\
\hline \multicolumn{3}{|c|}{ Total: } & $\$ 79.45$ \\
\hline & IF you have your own sand: & $\$ 61.45$ \\
\hline
\end{tabular}

\section{Step One:}


Prior to preparing the site, all of the materials described in Table 1 should be at hand. Next, a 46-inch diameter circle should be drawn out into the soil. A 23-inch piece of string could be tied to a stake and inserted into the proposed center of the circle and then used to circumscribe the circle into the ground. The site of the base slab could be set in place or moved after setting has occurred.

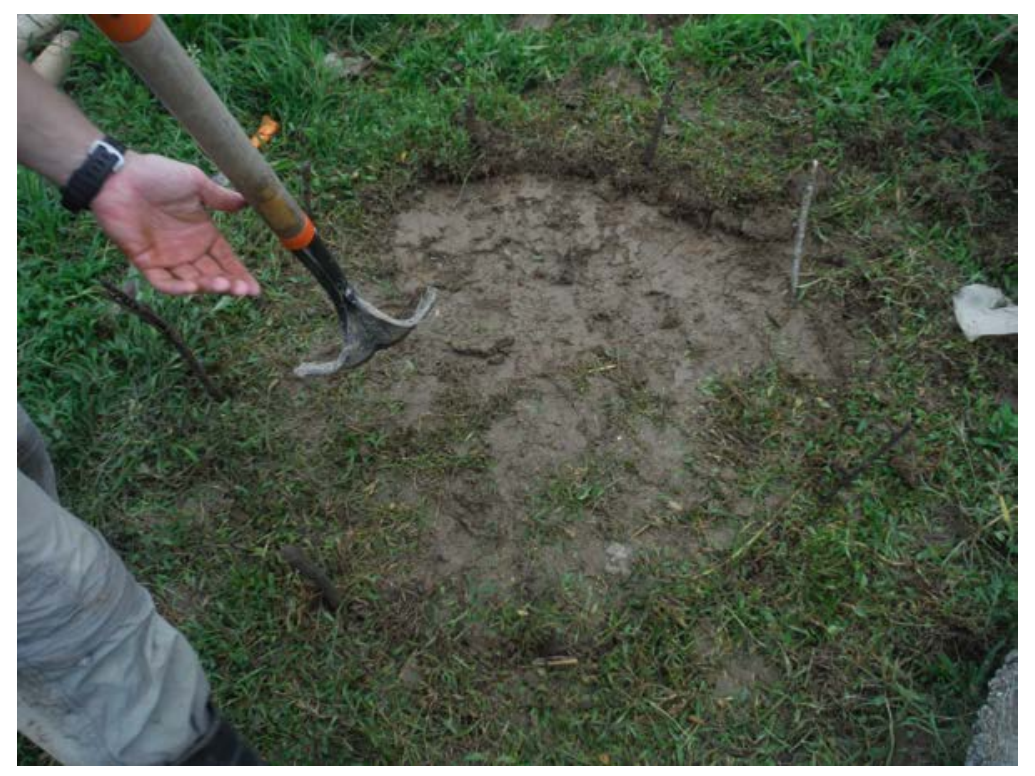

Figure 29 - Clearing final work site (Photograph by Author)

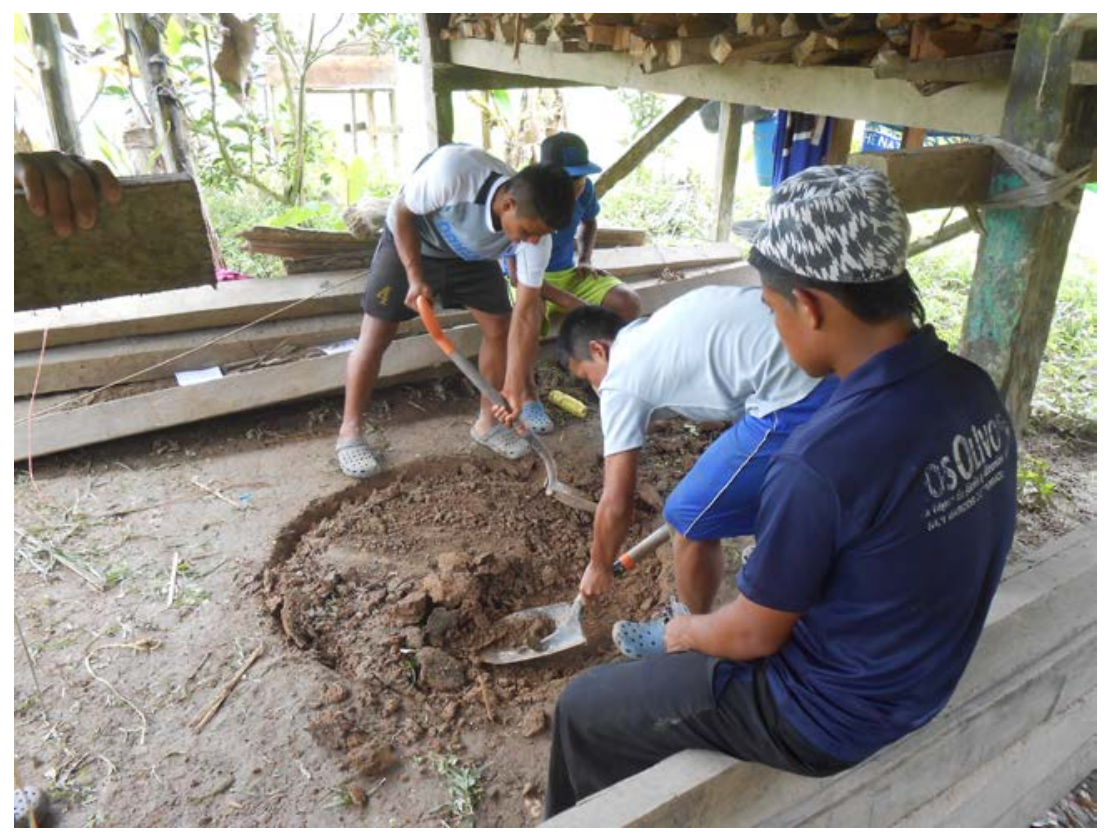

Figure 30 - Excavating circular slab depth (Photograph by Author) 


\section{Step Two:}

Next, the circle should be excavated to a depth of about three inches using a shovel and pick. Care should be taken to ensure that the hole is slightly convex forming a very gradual domelike mound with less than a $1 / 2$ inch difference between center and circumference.

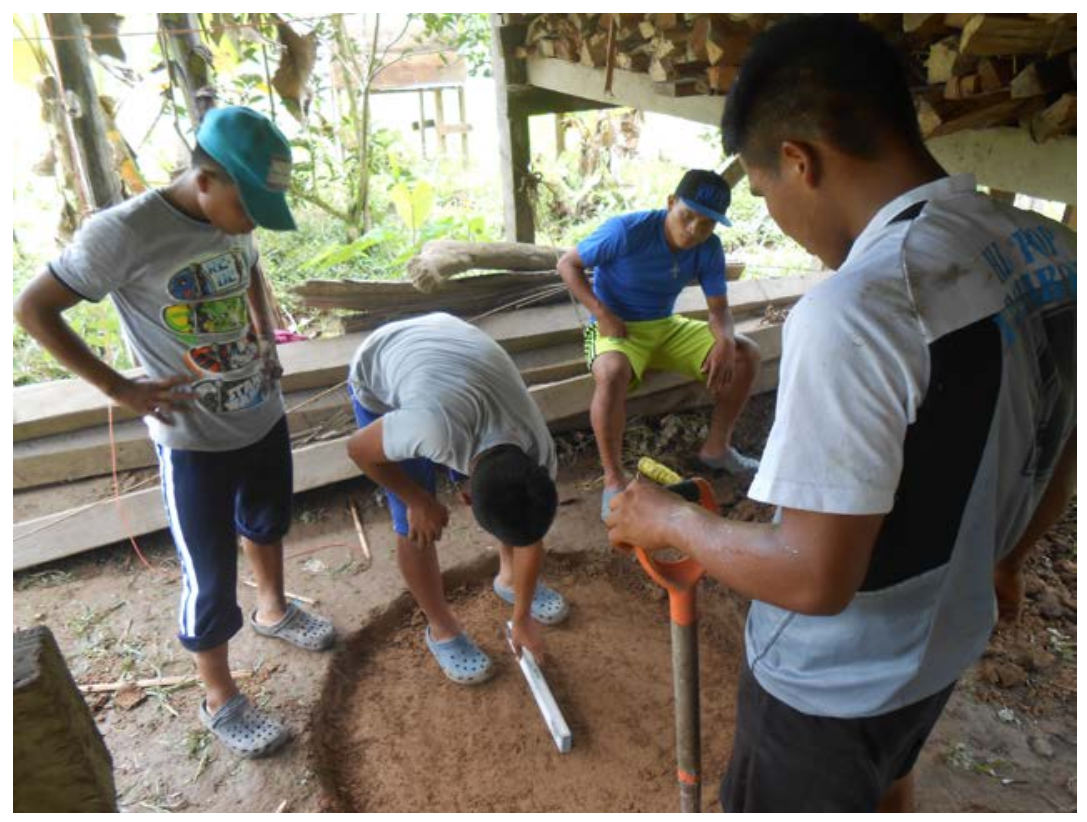

Figure 31 - Leveling the work site (Photograph by Author)

\section{Step Three:}

After leveling, the entire surface should be covered with a plastic or sturdy cloth cover to ensure that the base slab can be removed after setting or to ensure that moisture is not withdrawn from the base to the ground if building in place. 


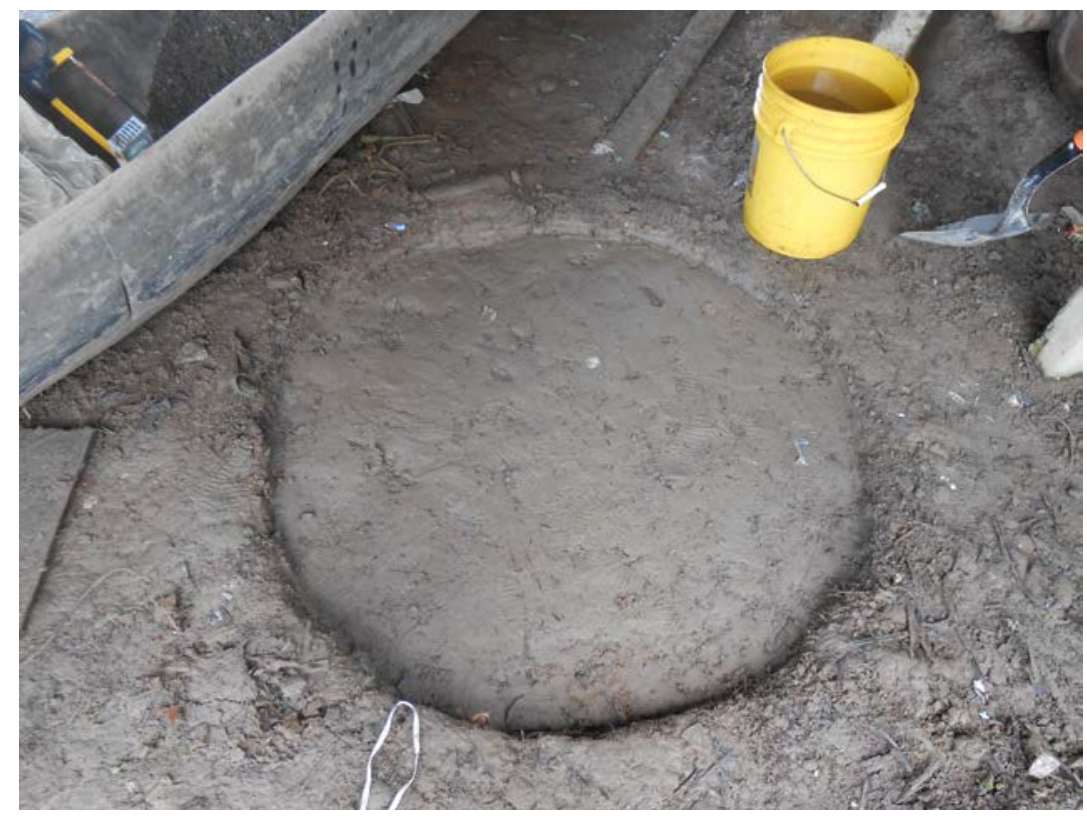

Figure 32 - The foundation of the Circular Slab (Photograph by Author)

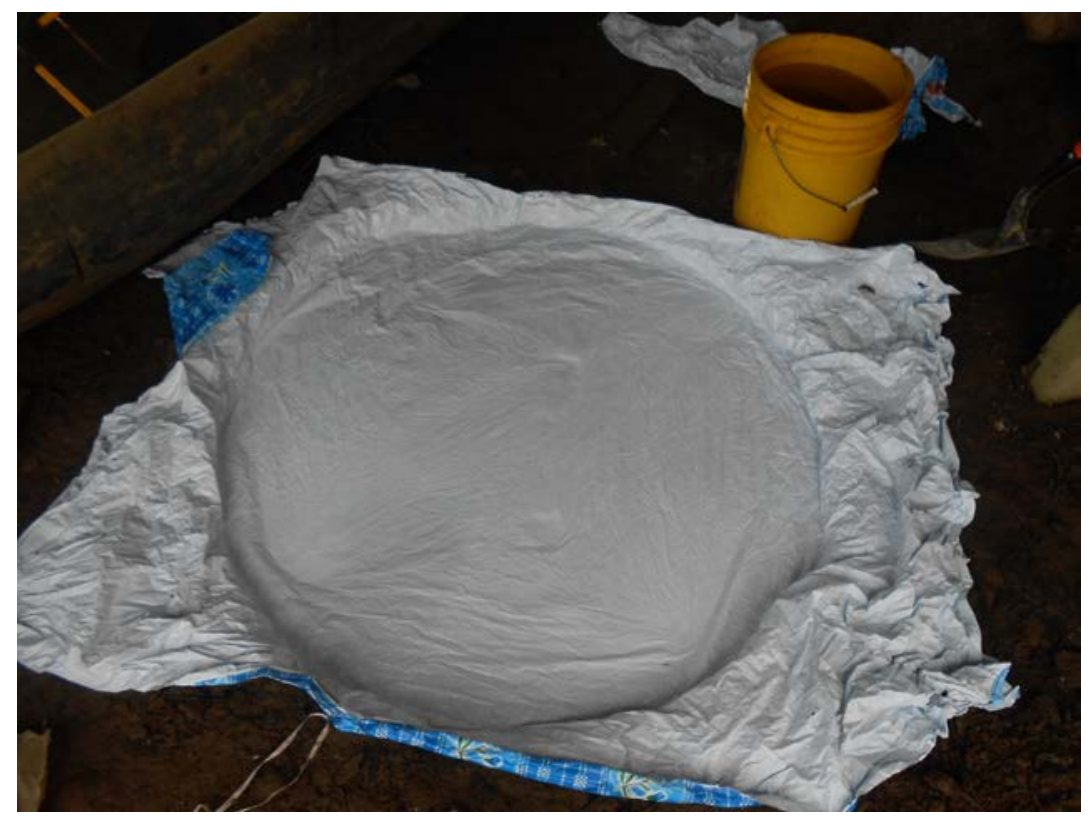

Figure 33 - Preparing the ground-form for concrete pour (Photograph by Author)

\section{Step Four:}

Using the $1 / 4$-inch rebar from the materials list create six L-bars by bending the rebar to $90^{\circ}$. These should radiate from the center and do not necessarily have to come together in the center. Leave at least six inches on the leg sticking up vertically as this portion will be tied 
into the rest of the reinforcement formwork and about 10 inches on the leg to be cemented into the base. Then, the light-gauge hexagonal wire sheets known, colloquially, as "chicken wire", cover this. This wire can overlap the circle since it can be bent up into the rest of the framework later on. The L-bars should be slightly elevated off the plastic sheeting, at least $1 / 2$-inch above the bottom using small pieces of gravel by adjusting them after concrete placement.

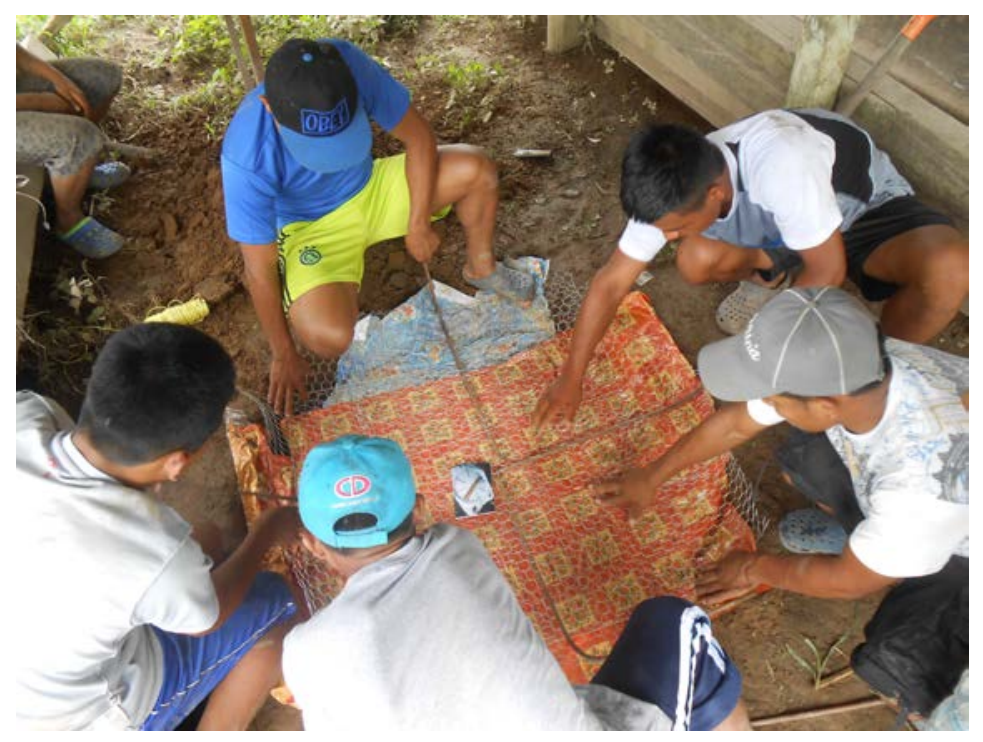

Figure 34 - Placing hexagonal wire reinforcement and 1/2" rebar (Photograph by Author)

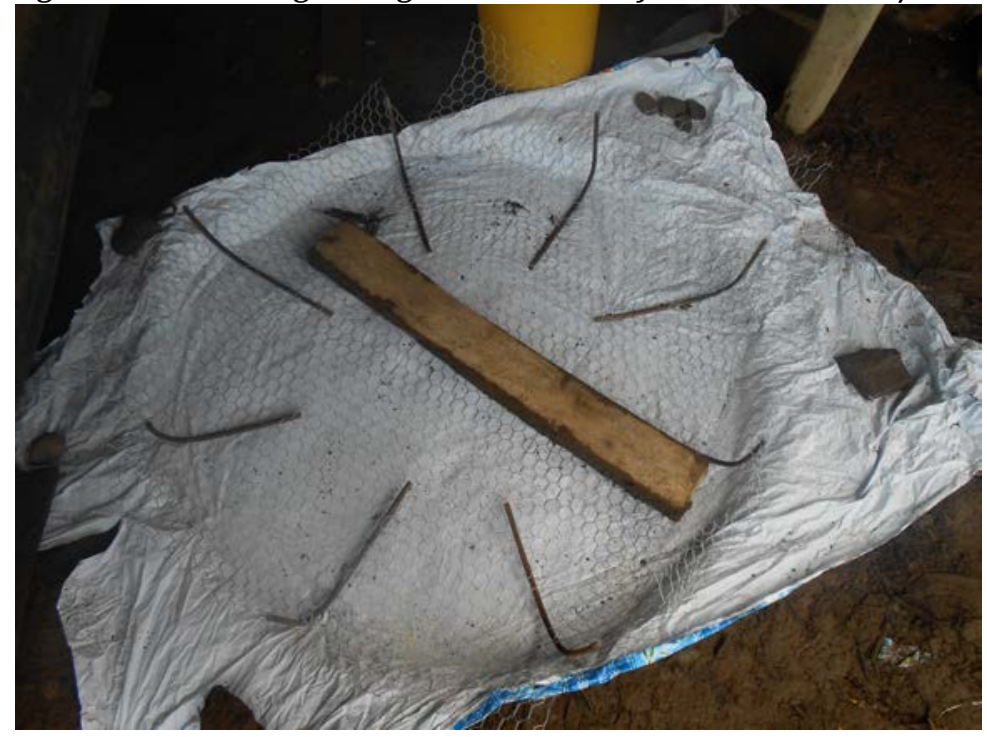

Figure 35 - Preparing ferro-reinforcement and rebar "spokes" for the slab (Photograph by Author)

\section{Step Five:}


With the base slab reinforcement in place, the pre-filtered sand and gravel can be mixed with the cement using a consistent measuring device or technique coming out to a $6: 1$ aggregate:cement ratio. The gravel should not be larger than half the depth of the slab, or rather, 1-inch. Once the dry mix is uniform, water can be added until an ice cream-like consistency is achieved and by not adding more than the equivalent original cement volume, that is to say, not more than a 1:1 cement:water ratio aiming more towards a 2:1 cement:water ratio.

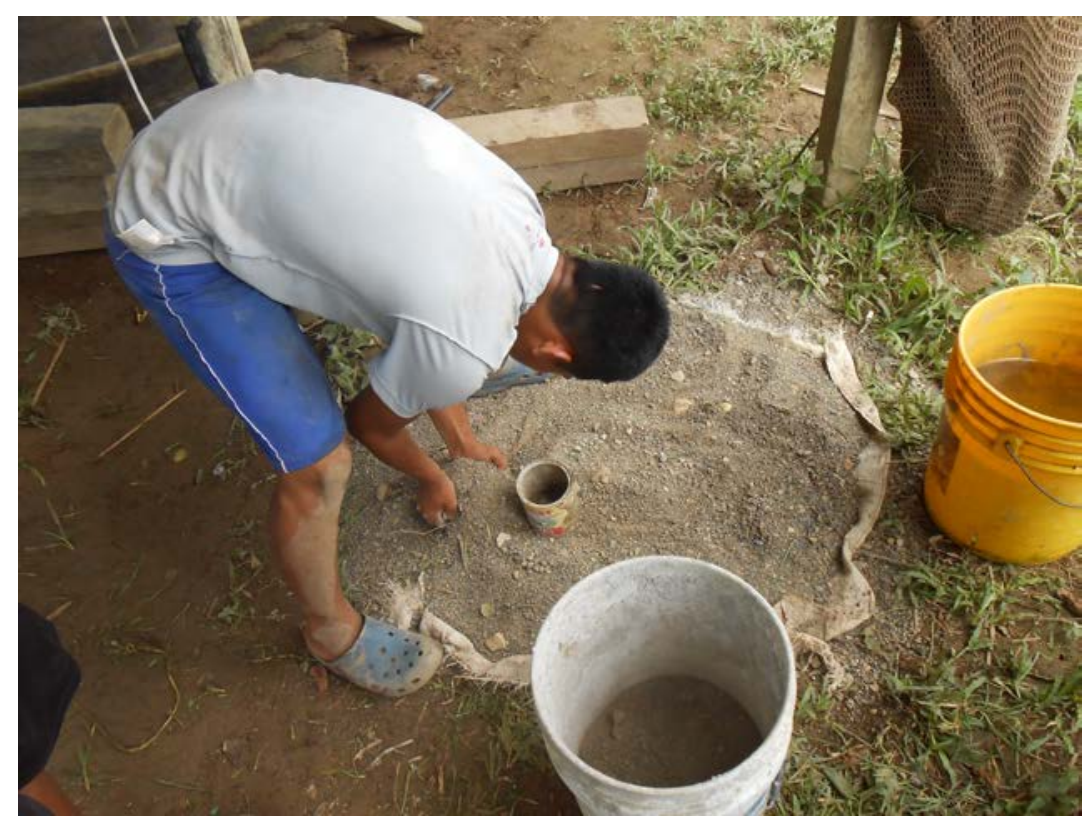

Figure 36 - Preparing fine aggregate concrete mix (Photograph by Author) 


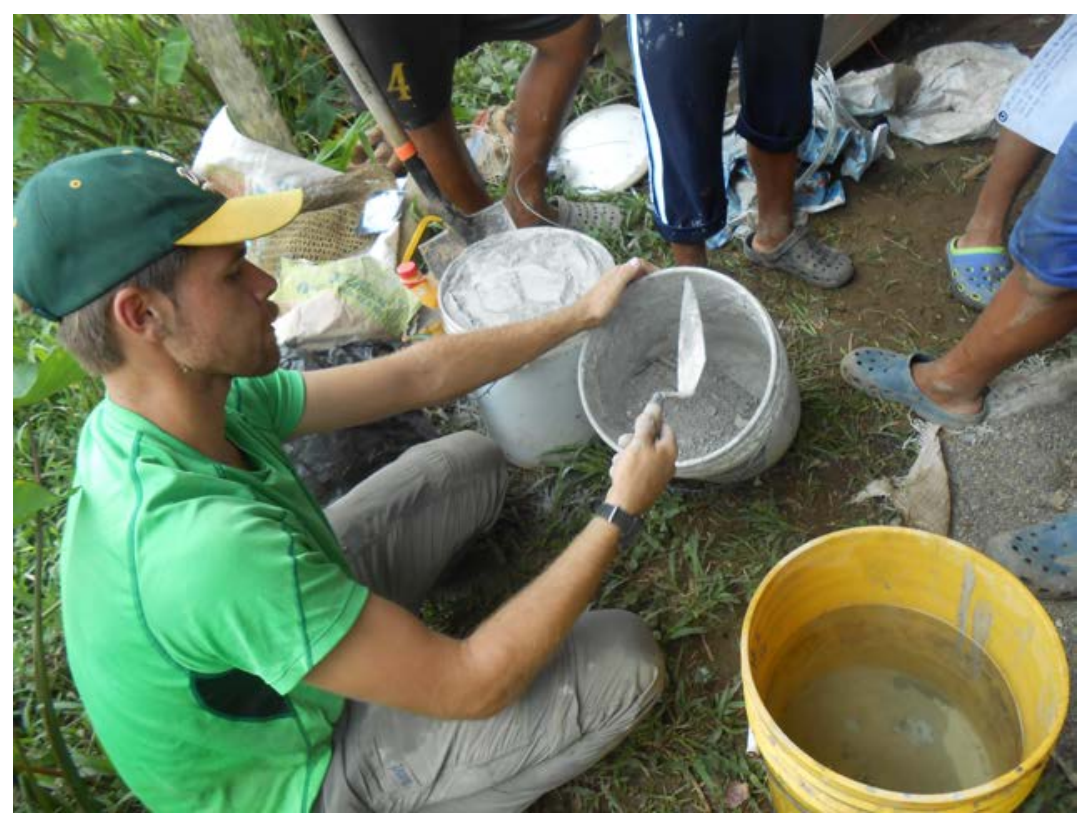

Figure 37 - Mixing cement and fine river aggregate in 5-gallon buckets (Photograph by Author)

\section{Step Six:}

With the mortar mixed, it can be placed into the center of the base and pushed out radially using a trowel or piece of screed board. Attention should be placed on making sure the rebar is not exposed on the bottom, but fully covered by concrete. The chicken wire should also be fully covered by the concrete. Once set, the base slab should be allowed to cure for at least two weeks by maintaining always wetting the surface of the slab till it becomes a dark grey color, or by completely flooding the slab before moving or continuing construction. 


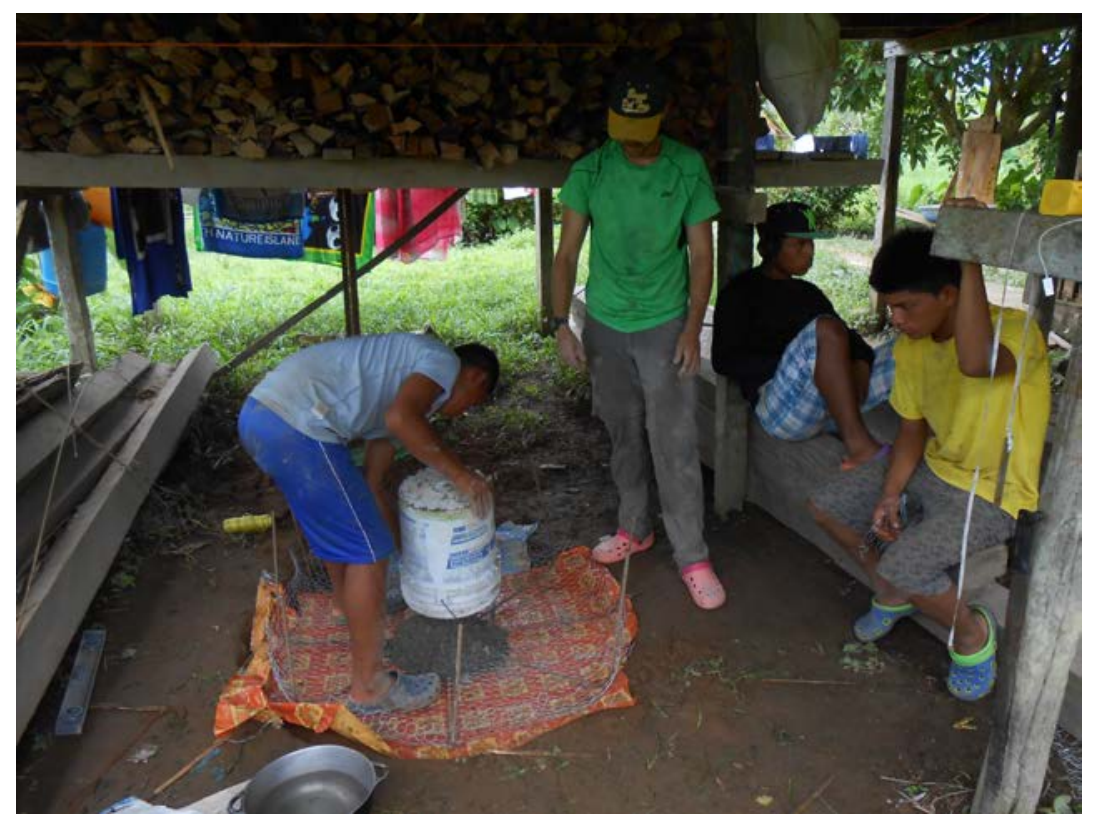

Figure 38 - Pouring mortar into ground-form (Photograph by Author)

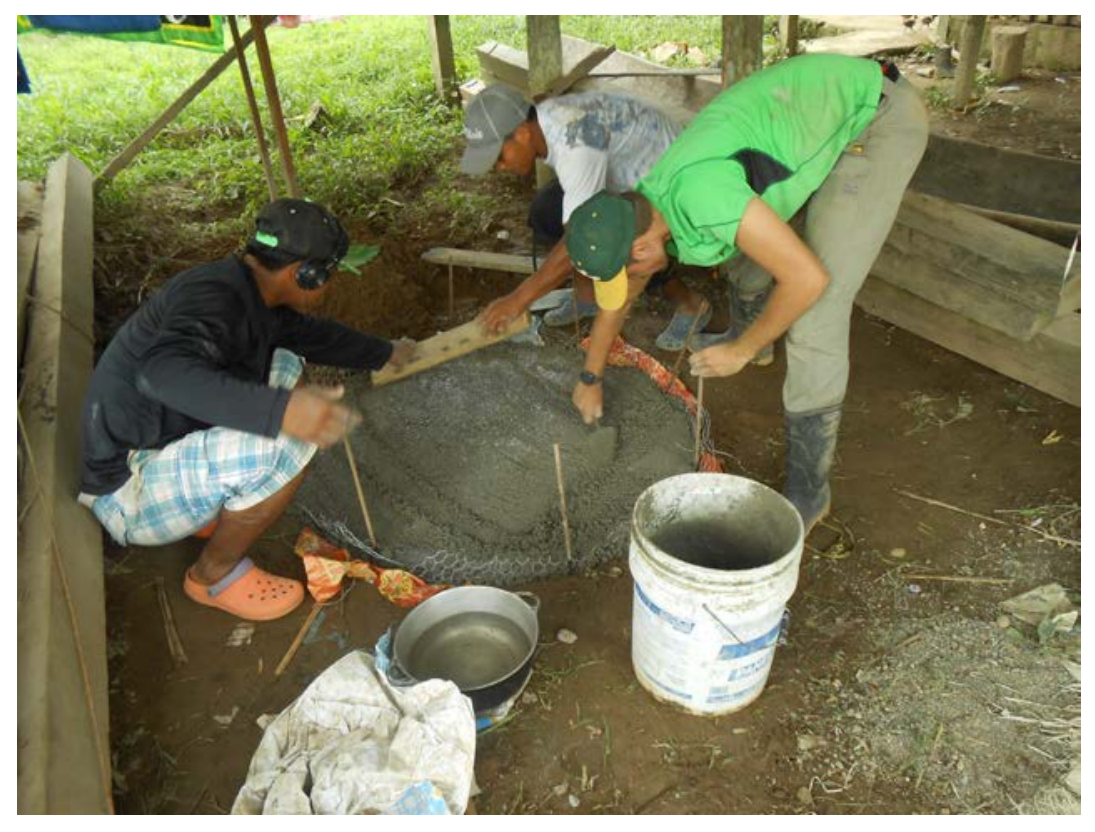

Figure 39 - Using screed board to level concrete thickness uniformly (Photograph by Author) 


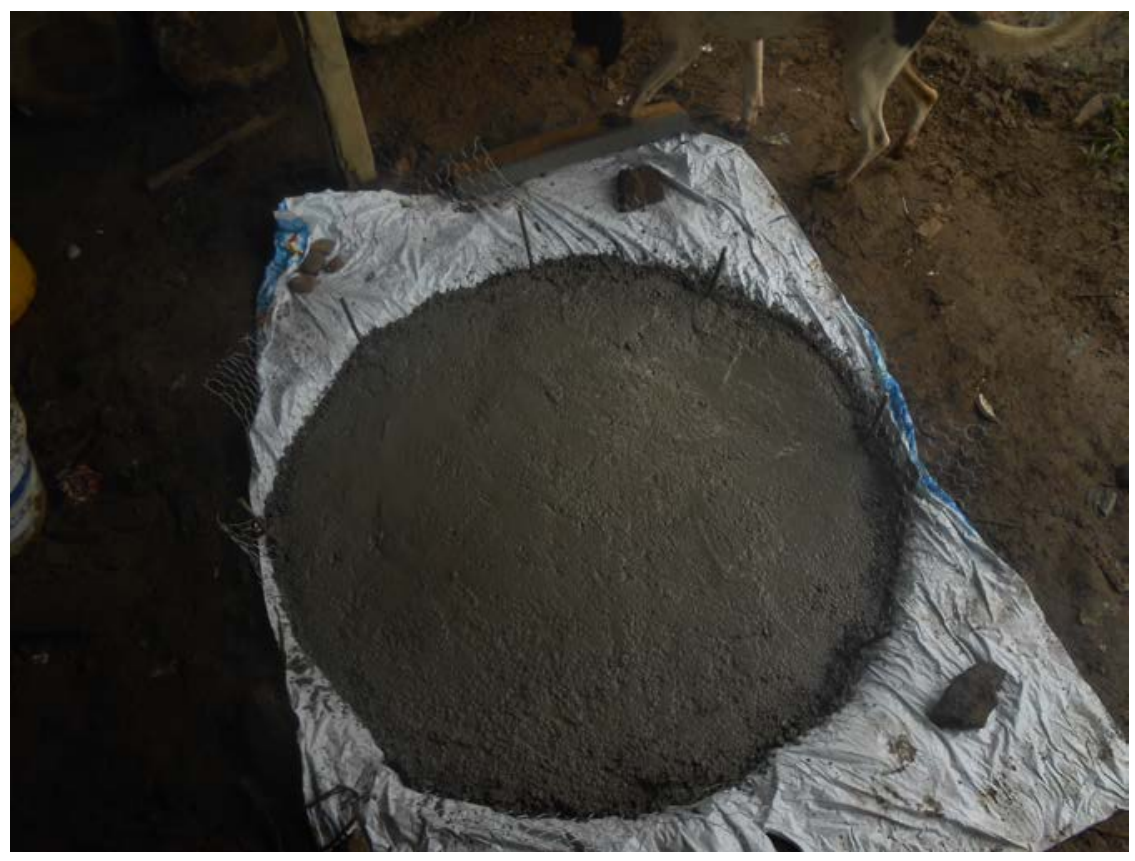

Figure 40 - Allowing slab to set (Photograph by Author)

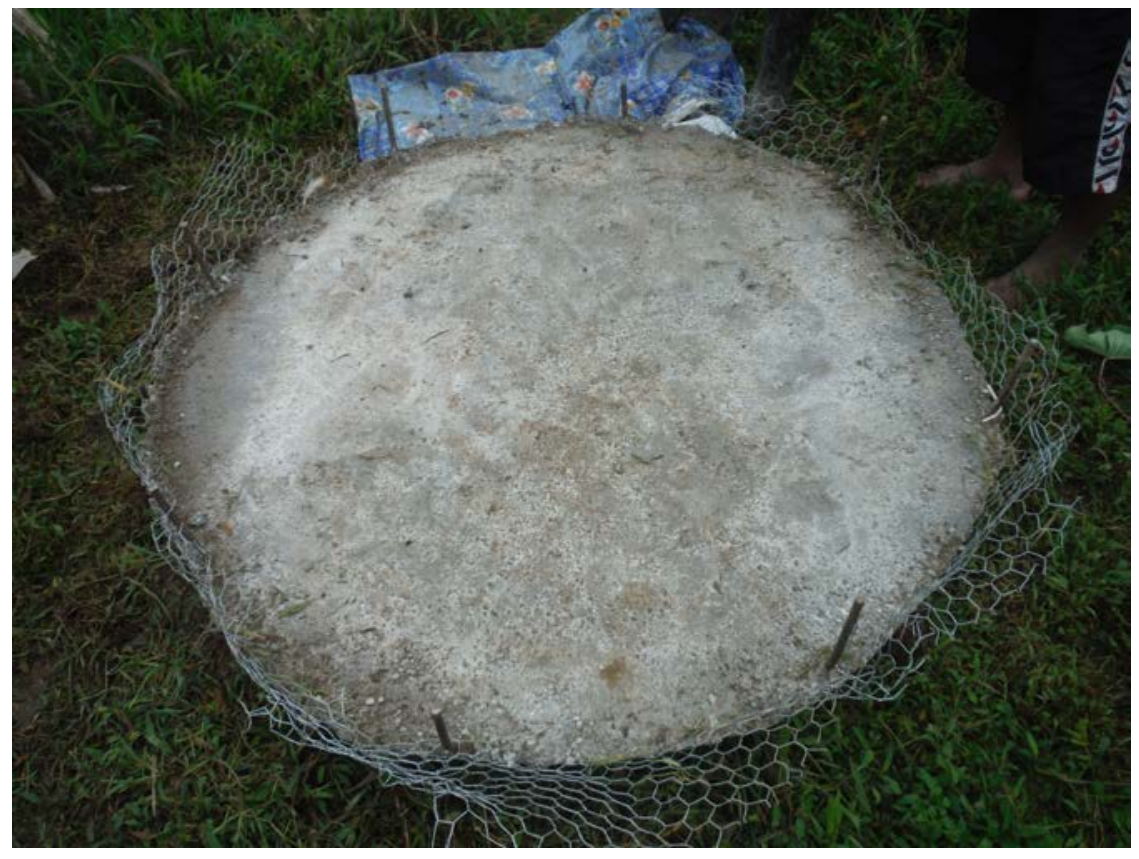

Figure 41 - Completed circular slab after allowed to cure (Photograph by Author) 


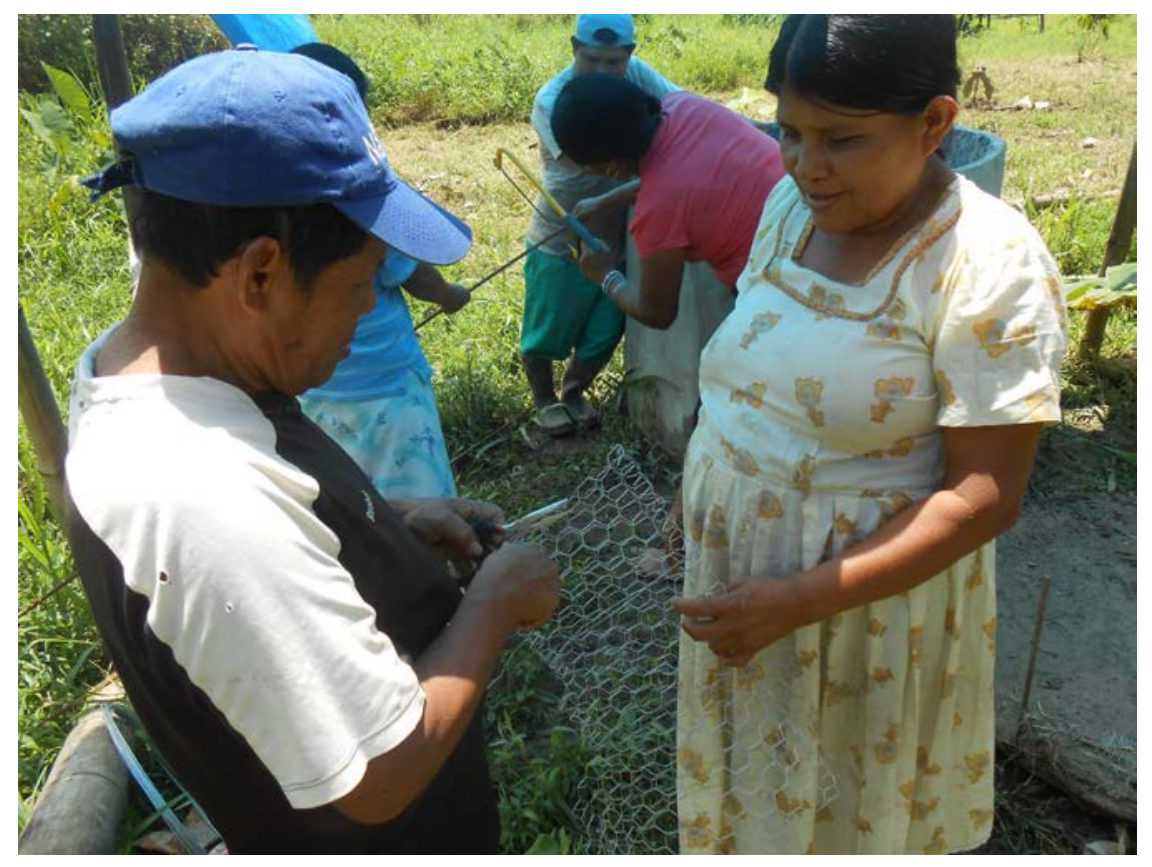

Figure 42 - Preparing materials for ferrocement construction (Photograph by Author)

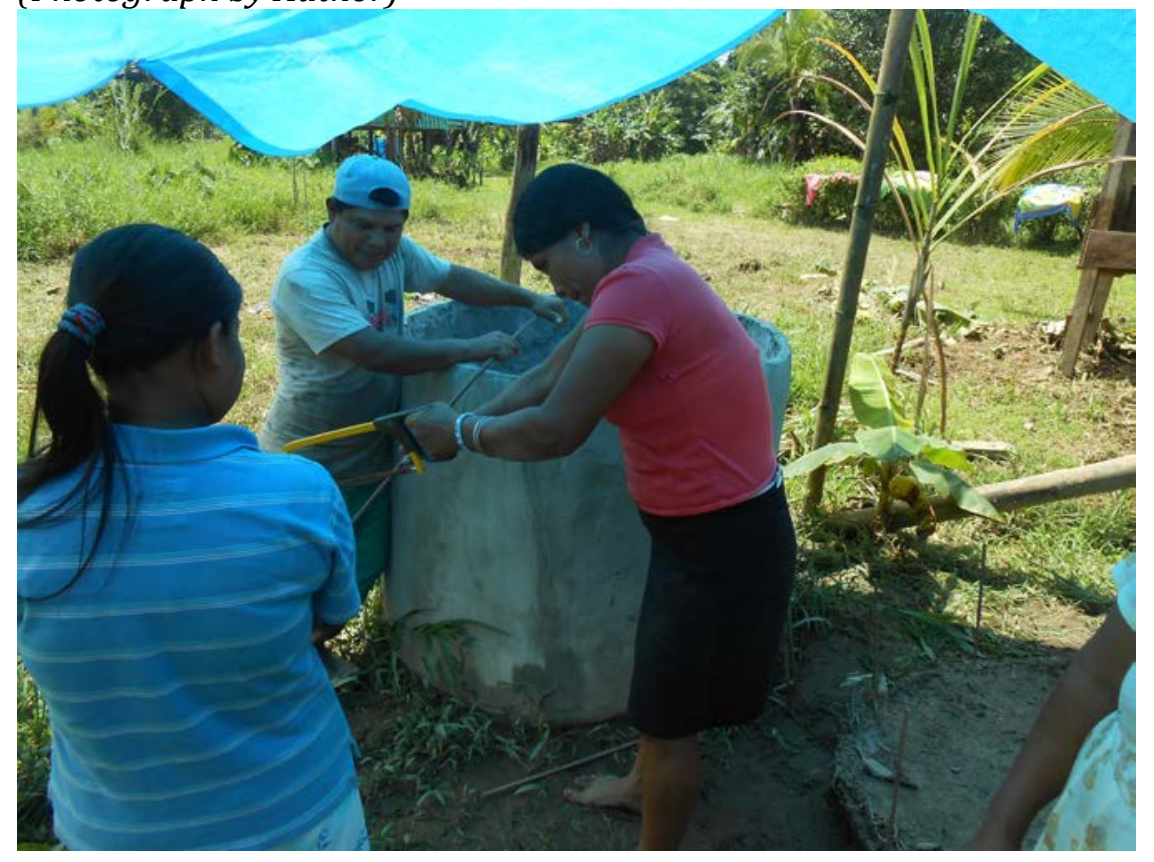

Figure 43 - Cutting rebar to be tied into tank walls (Photograph by Author) 


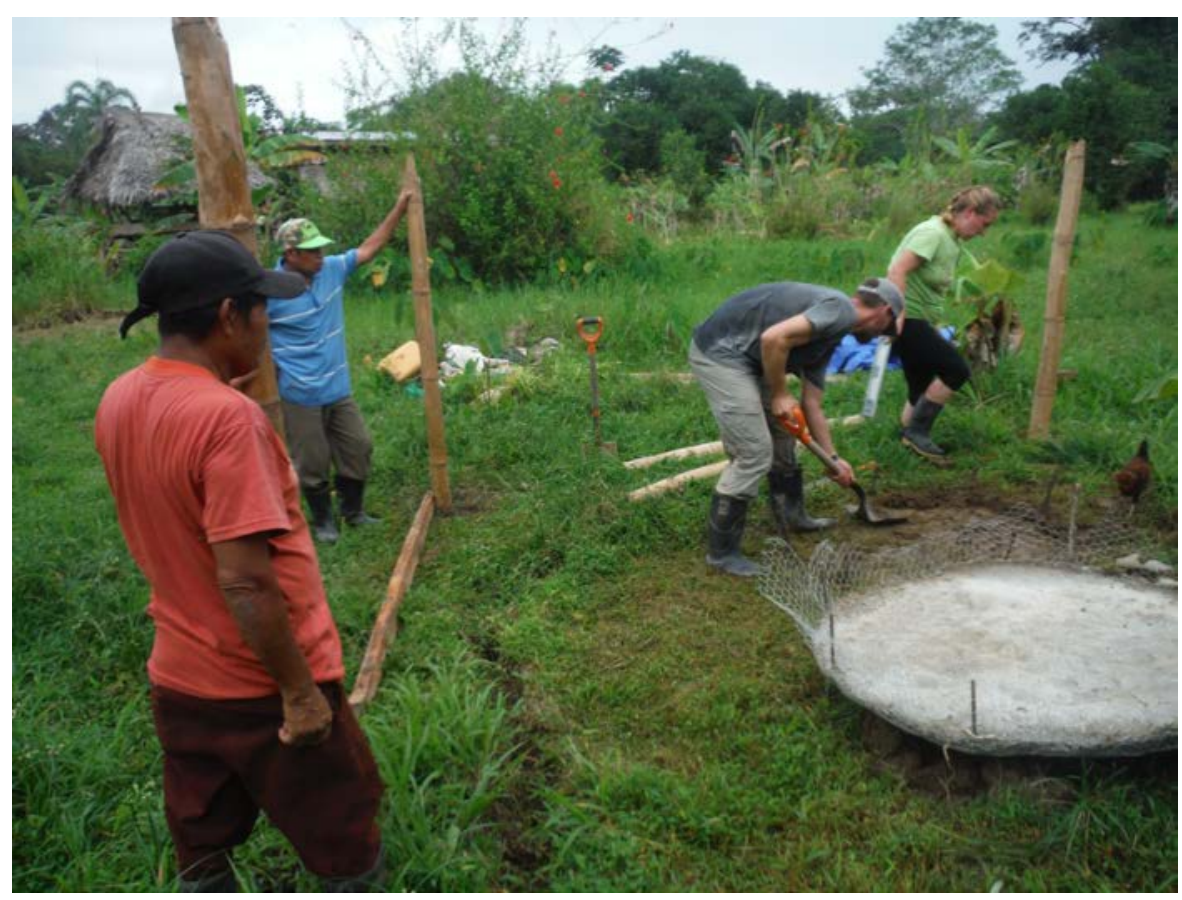

Figure 44 - Preparing the final tank site (Photograph by Author)

\section{Step Seven:}

With the base slab at considerable strength it can be moved to its final site. The area around the final site should be cleared and dug in so every portion of the bottom side of the slab is in contact with the ground. A makeshift shelter can be put together to protect the tank from the elements during the construction over the course of the next few days. It is important that a manner, by which individuals can enter and leave the inside of the tank is made, either a simple ladder, or by pulling themselves out from the top.

Then, around 13 feet of chicken wire that will eventually become the single cylindrical wall of the ferrocement tank should be cut. Next, six lengths of three feet long $1 / 2$-inch rebar should be cut that will be spaced out at two foot intervals on the long length of chicken wire. Begin 1-1/2 feet in from either side to ensure that there is one foot of overlap when the cylinder is put together. Tie each piece of the three-foot-long rebar at, at least, three points onto the chicken wire. Try to remove any kinks, or flatten the tie-ons before moving the wall into its final position. 


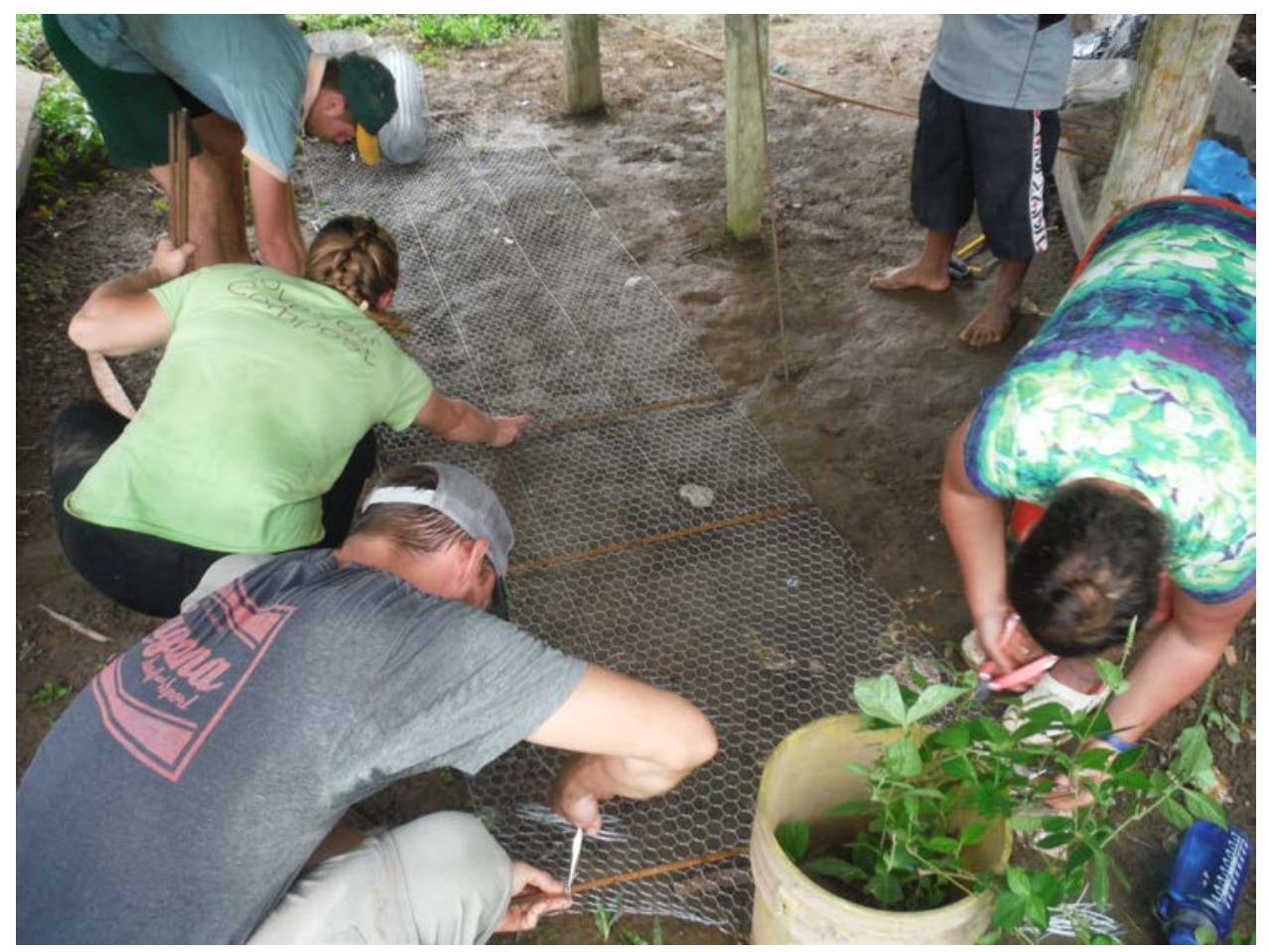

Figure 45 - Tying in rebar to wire cage (Photograph by Author)

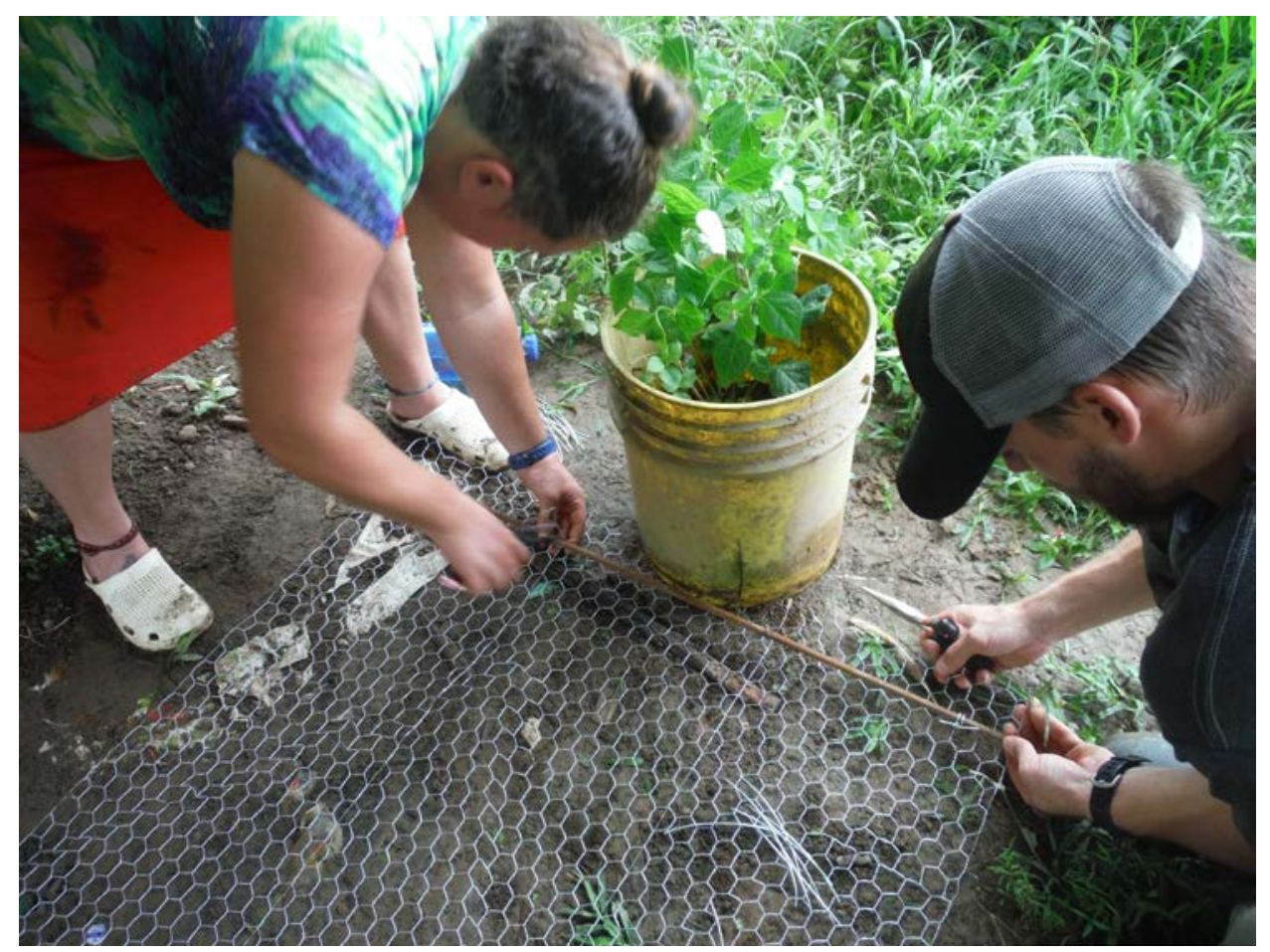

Figure 46 - Light-gauge wire used to construct the wall reinforcement cage 
(Photograph by Author)

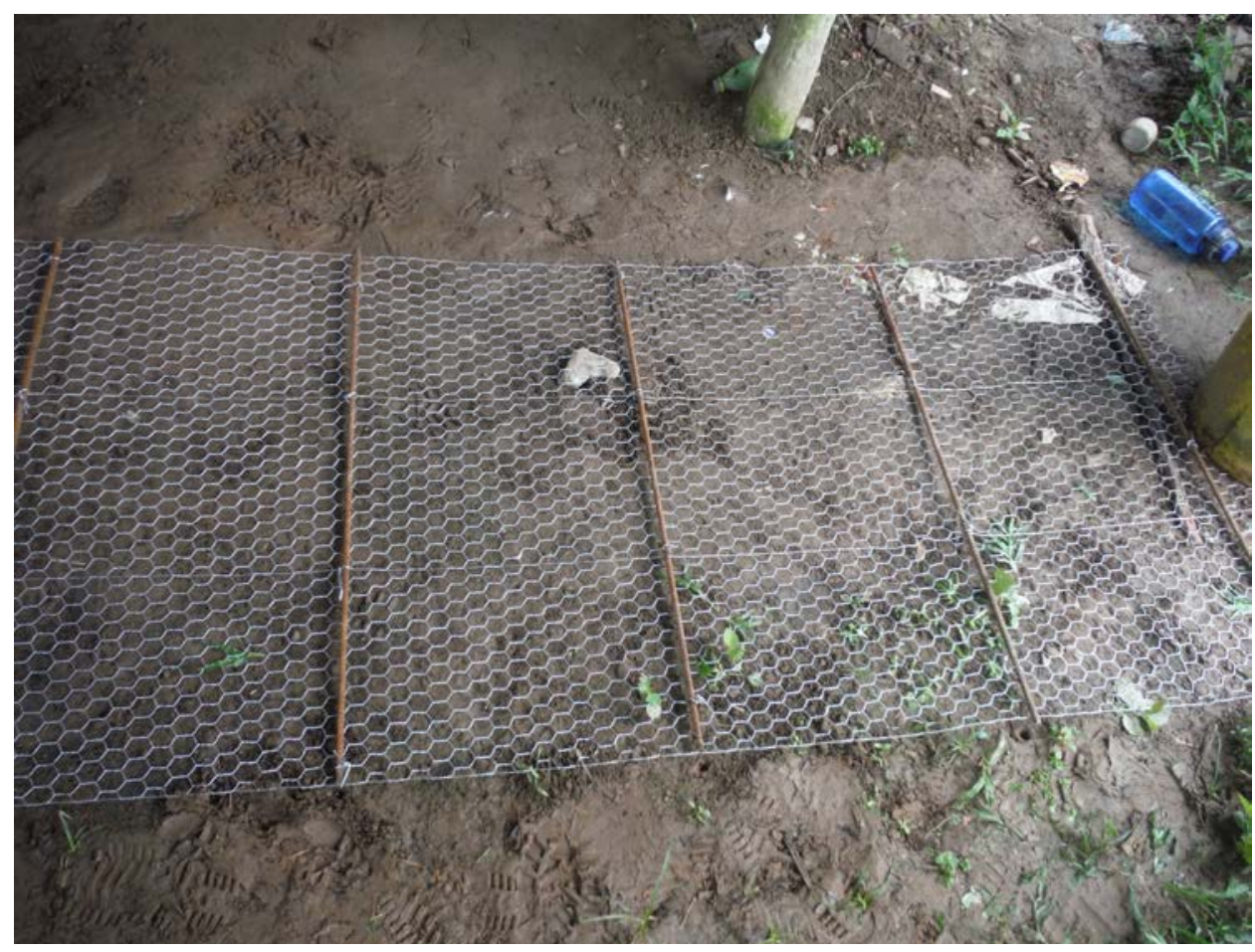

Figure 47 - Completed wall reinforcement cage (Photograph by Author)

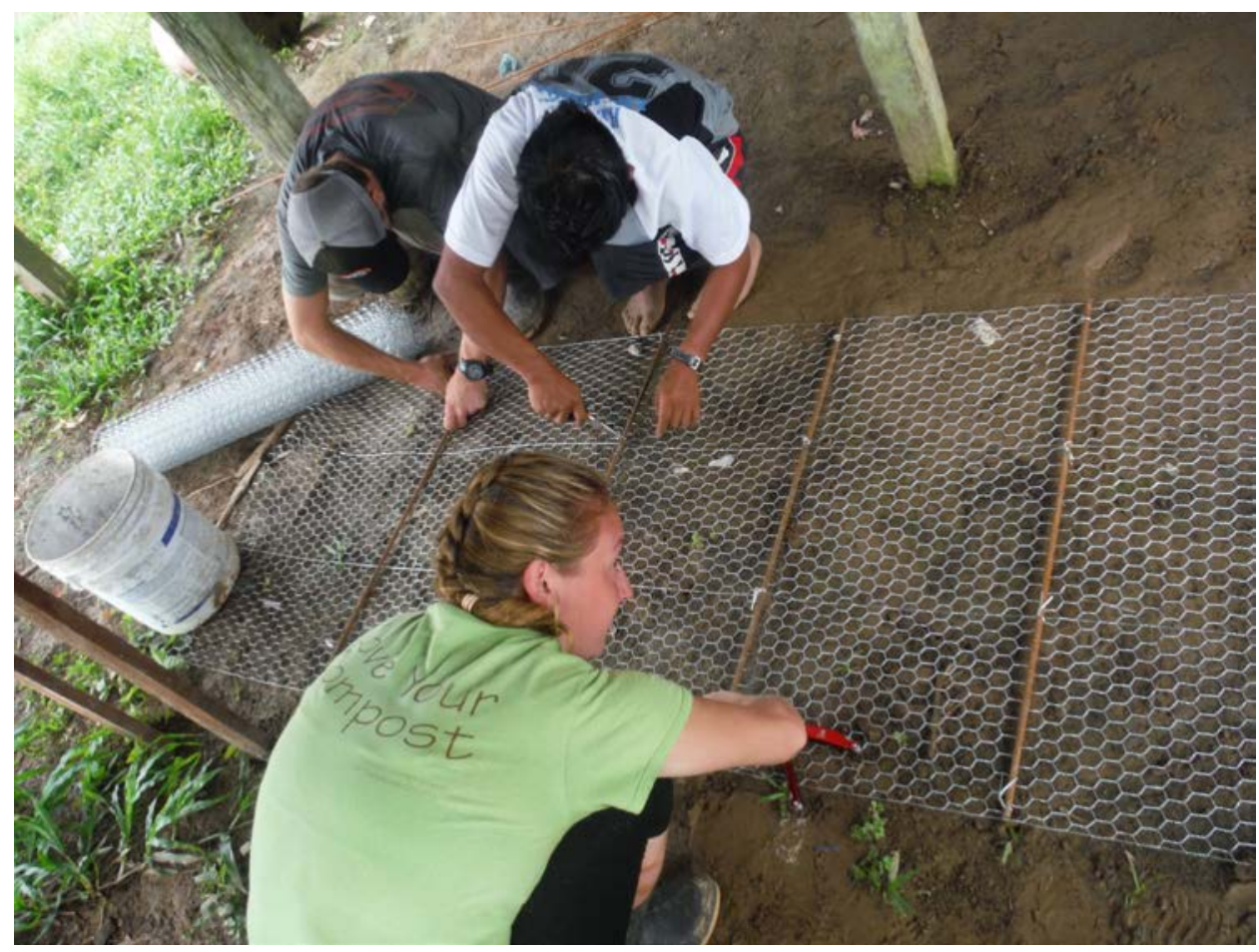


Figure 48 - Removing kinks out of wall reinforcement cage (Photograph by Author)

\section{Step Eight:}

Once the entire wall is inspected and complete, it can be moved into place above the base and tied into the six vertical legs of rebar left exposed in the base slab. To strengthen the reinforcement frame and account for potential hoop stress, two rings of $1 / 2$-inch rebar should be placed around the perimeter of the cylindrical wire "cage" just formed and tied-in at one foot from the bottom and at the very top of the tank. At this point, the wire cage is complete and an equivalent length of purple cloth can be wrapped around this frame and affixed tightly to itself to act as a surface for the mortar to adhere to.

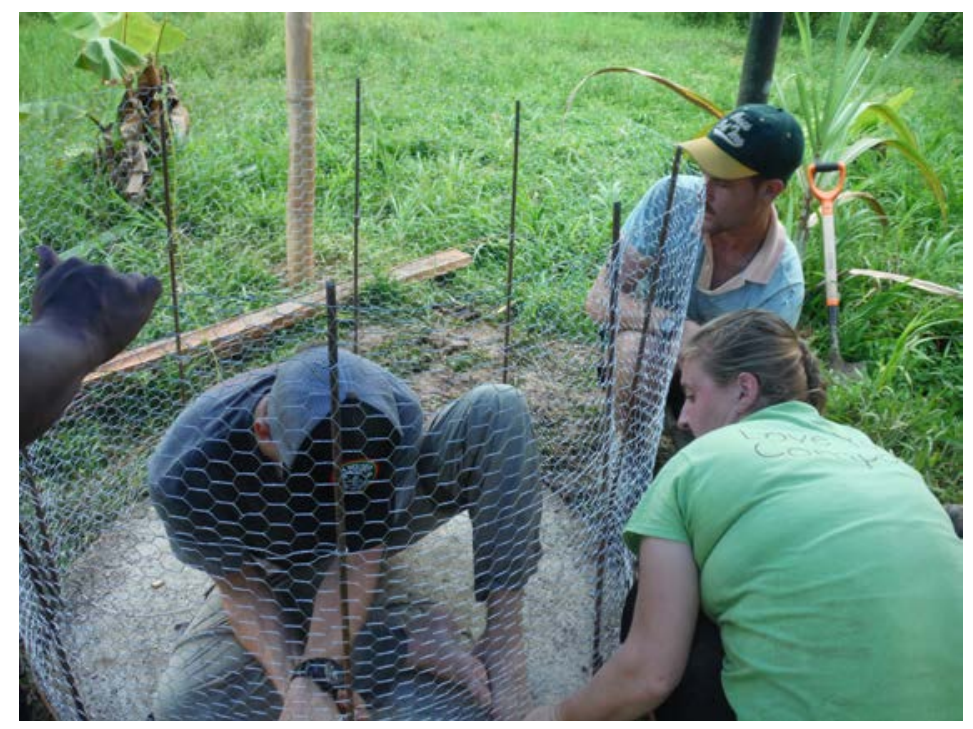

Figure 49 - Connecting wall reinforcement to exposed slab reinforcement "spokes" (Photograph by Author)

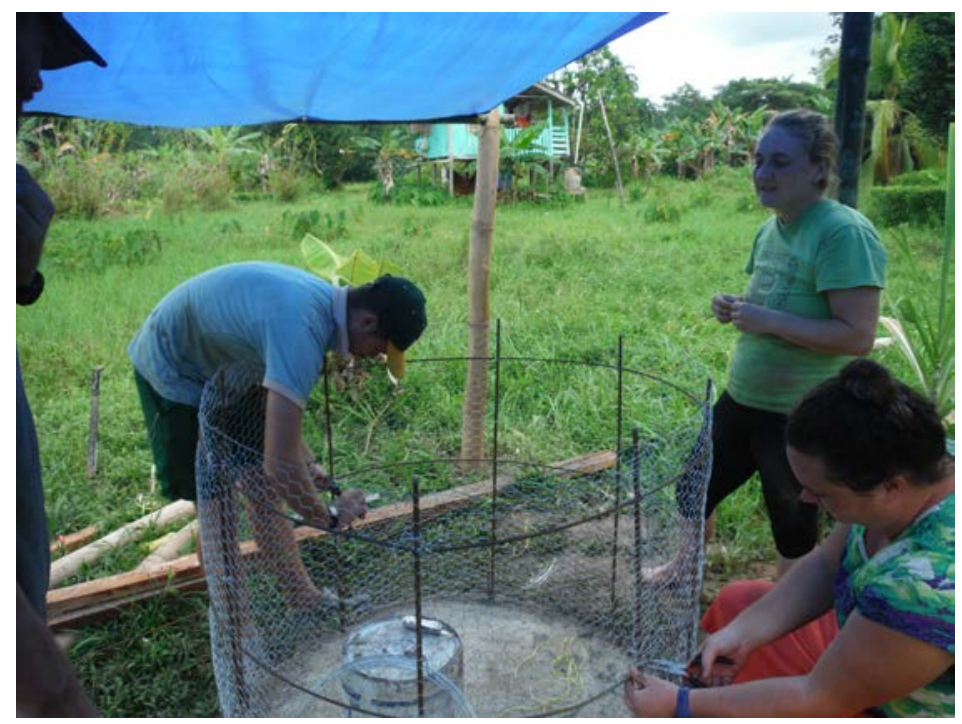


Figure 50 - Connecting two rebar rings to compensate for outward hoop stresses (Photograph by Author)

\section{Step Nine:}

At this point, a mortar mix should be made in a similar fashion to the one described in Step Five. However, this mix should use only fine sand and no gravel. Also, the ratio should be 3:1 sand:cement rather than 6:1. Similarly, the cement:water ratio should be no more than 1:1 and aiming for 2:1 to achieve an ice cream-like consistency once again. The technique of plastering the mortar onto the cloth backing is simple and takes only a few hours to master. A small amount should be place onto a trowel and pushed onto the cloth and wire cage starting from the bottom and working up. The first coat does not need to cover the wire, in fact, if the hexagonal shape can be seen in this layer but is homogenously filled, meaning no holes, the next coat will adhere easier.

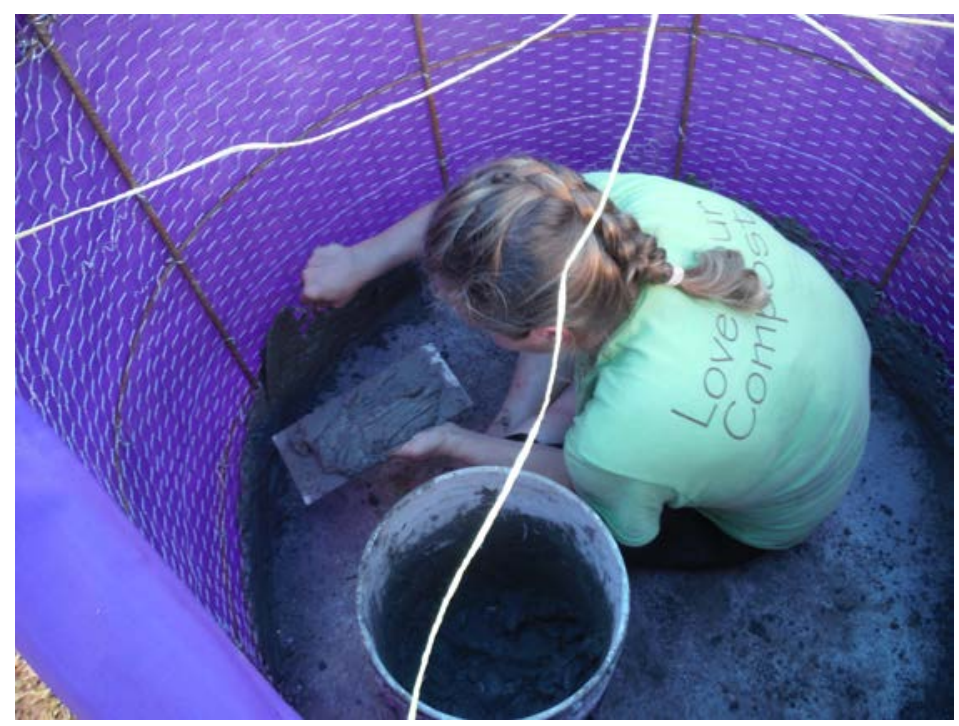

Figure 51 - Purple cloth used as outward form to promote mortar adhesion (Photograph by Author)

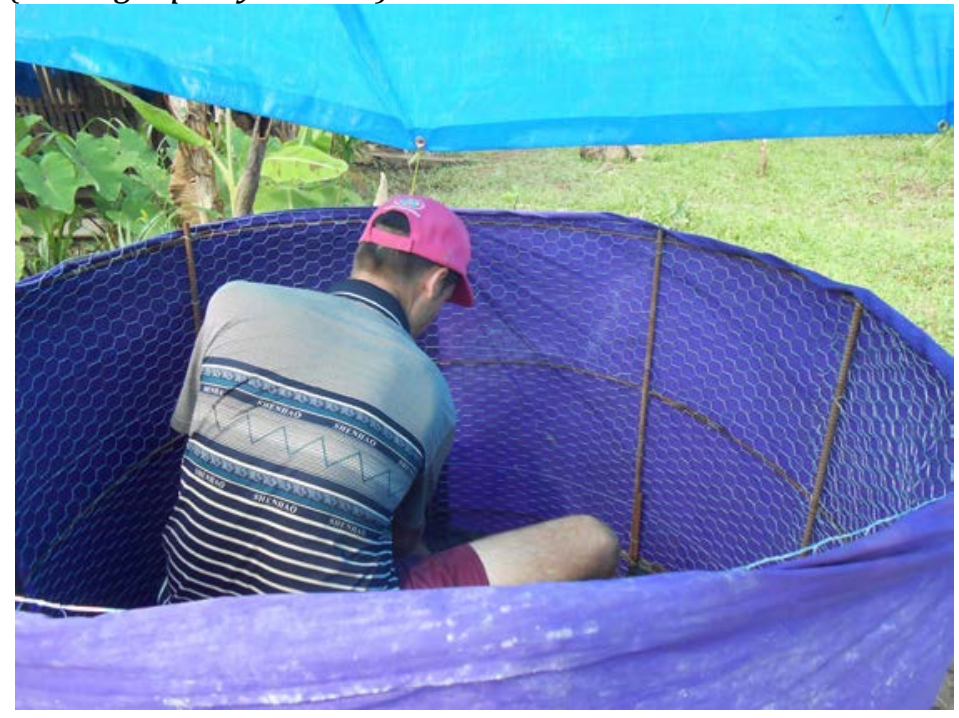


Figure 52 - Continuing the first inside mortar layer

(Photograph by Author)

\section{Step Ten:}

Once the first layer has cured for at least two days with constant moisturizing, the cloth can be removed and the first outside layer or second coat can be begun. Make sure to wet any surface before applying a second coat throughout the plastering process. The same technique and materials should be used for the layer, except one does not need to work from the bottom up, instead a single layer can be done at any arc of the cylinder as long as it is uniform with no holes in the layer. As soon as this layer is finished, but typically the next day, another inside coat can be begun without disturbing the outside layer. These layers are much easier to complete since the surface is porous and adherence is high and can be done by sections rather than in a spiral. The ultimate thickness of the tank should be around 1-1/2 to two inches. If there is no concern for water infiltration the tank is complete. In the present case flooding was the main cause for selecting this method and therefore, a fourth water-proofing layer was added being nothing more than a rich cement-sand mortar at a ratio of $1: 1$ and using the water-proofing admixture Sika-1 throughout.

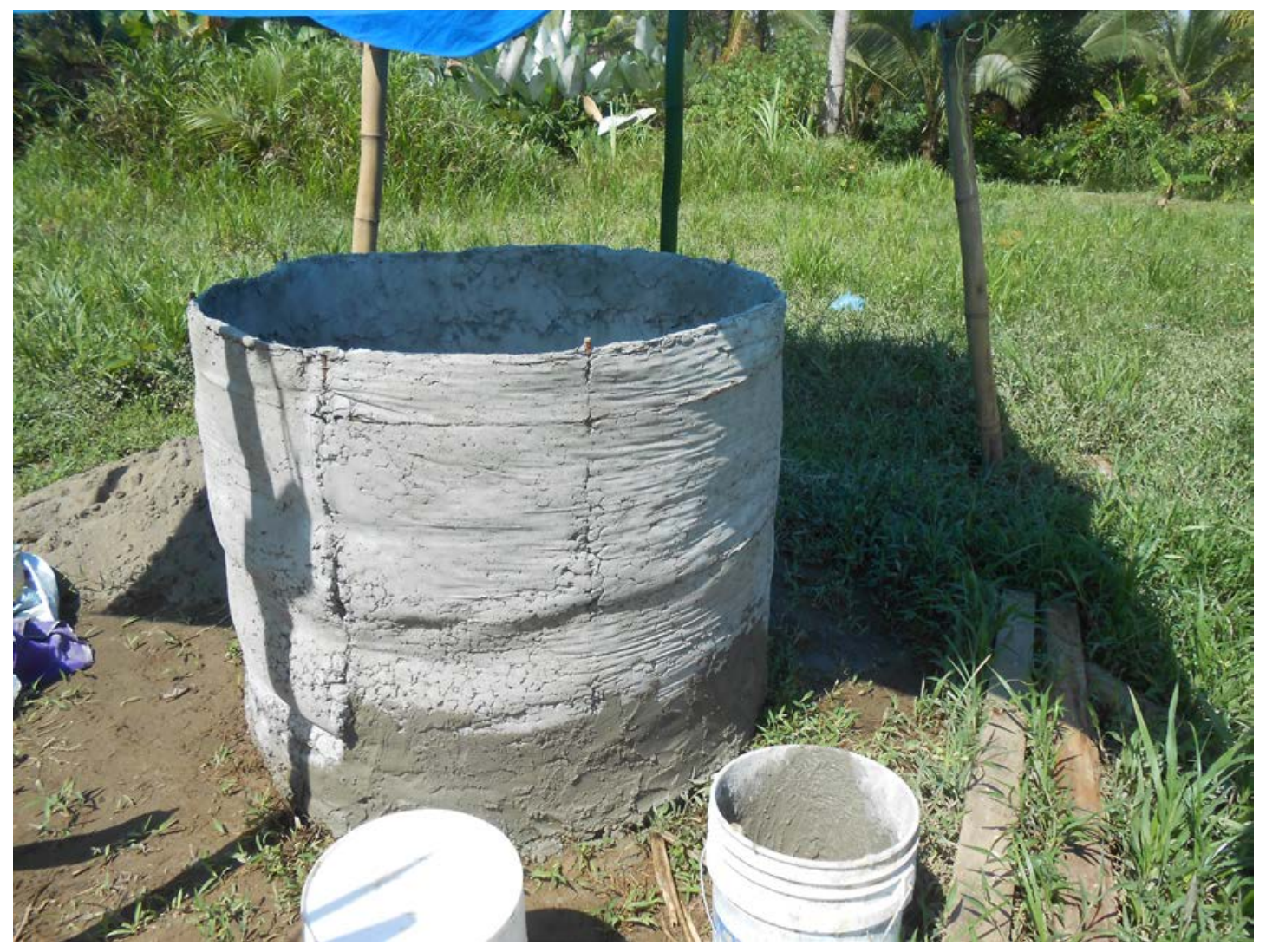

Figure 53 - The second coat of mortar on the outside layer after cloth removal (Photograph by Author) 


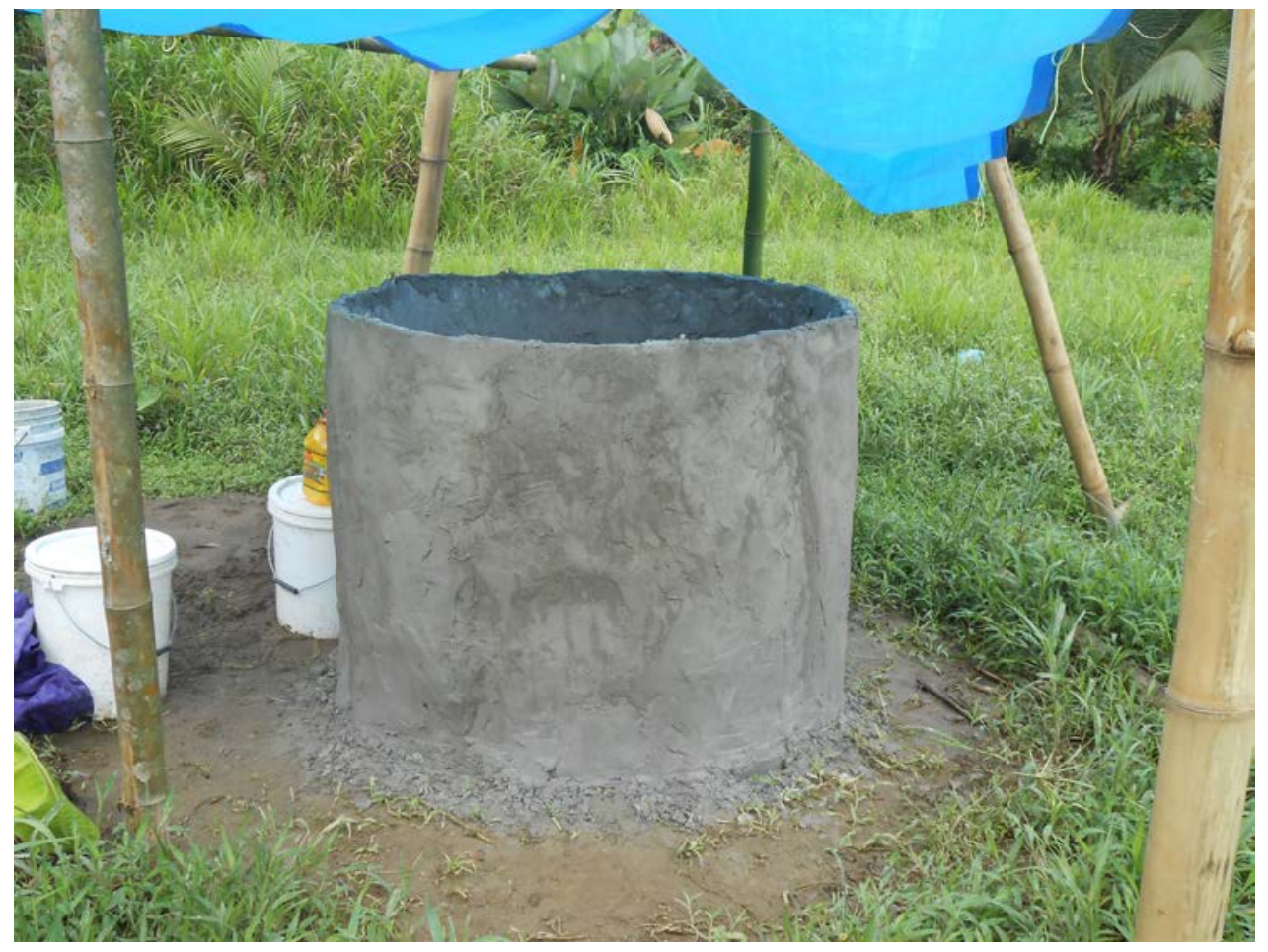

Figure 54 - Second layer completed and curing (Photograph by Author)

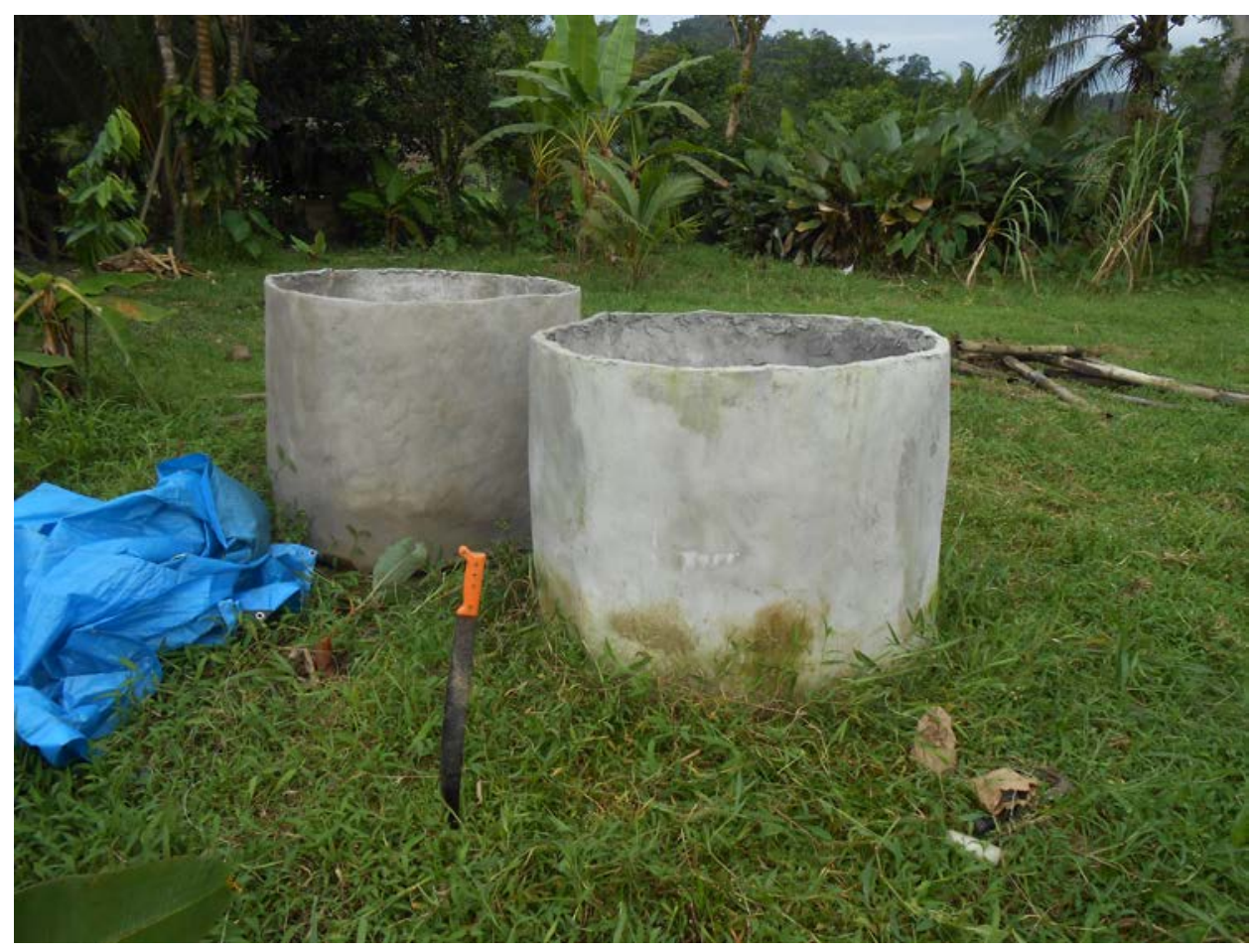




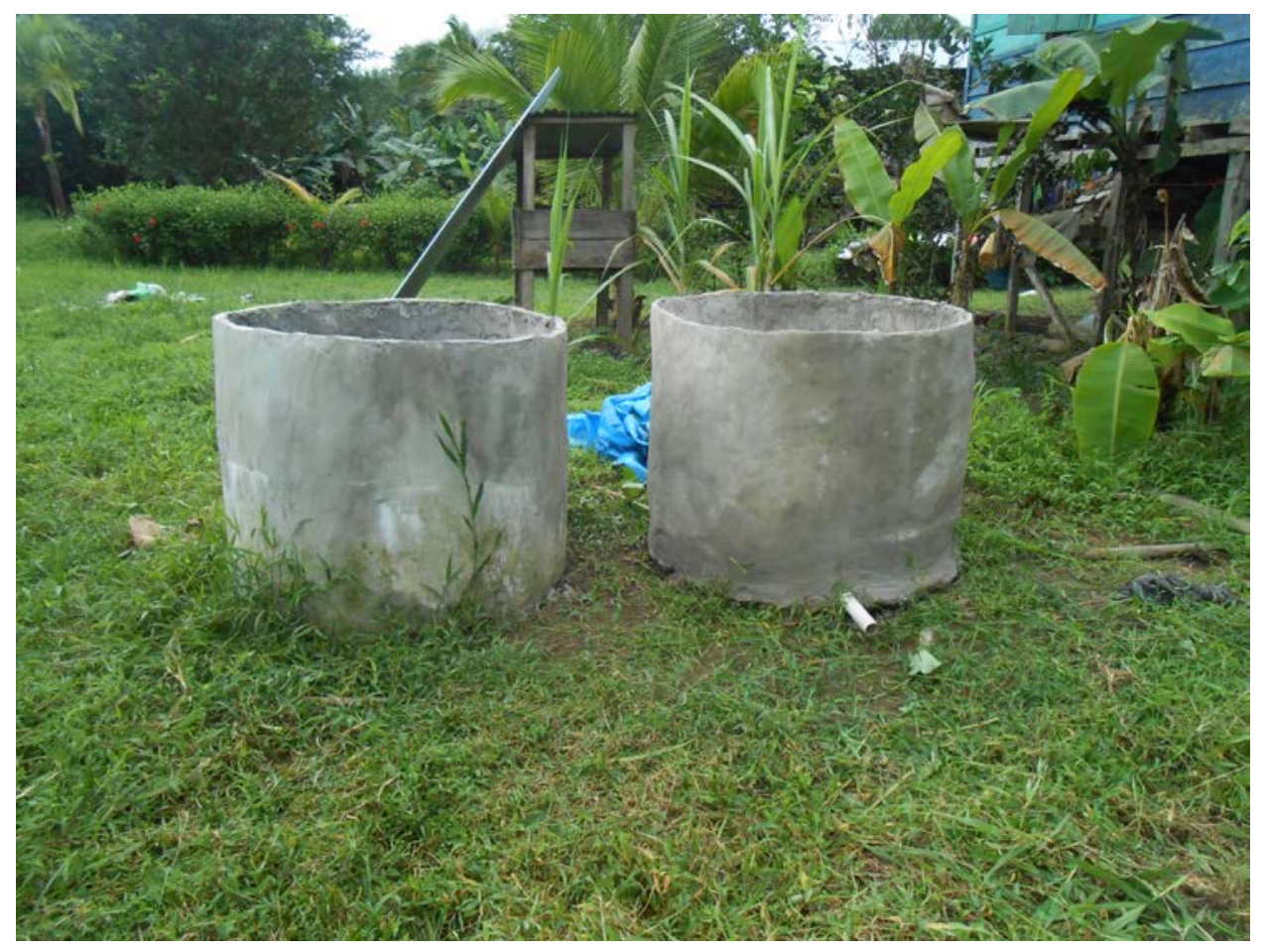

Figure 56 - The tank were set off by 1.5 feet; note the effluent pipe visible on the right tank in case of potential flood infiltration (Photograph by Author)

\section{Step Eleven:}

With both tanks completed in a similar fashion, the superstructure can be constructed. There is absolutely no right way to construct the enclosure or privacy shelter that makes up the latrine. The figures below present local construction methods that are utilized traditionally and passed on within the community. This further ensures that the beneficiaries are fully participating and customizing the structure as they see fit, with the tanks being the only "introduced" technology, which itself is very low skill, requiring only a single worker to complete one in, at most, six work days. The need for a way to remove the compost without compromising water-tightness was resolved by constructing a false floor that is hinged like a door. A stable middle platform was made to house the water-washing station or the bidet. Other methods can be used including building in a removable hatch or door at the bottom of the tank if inundation is not a concern. 


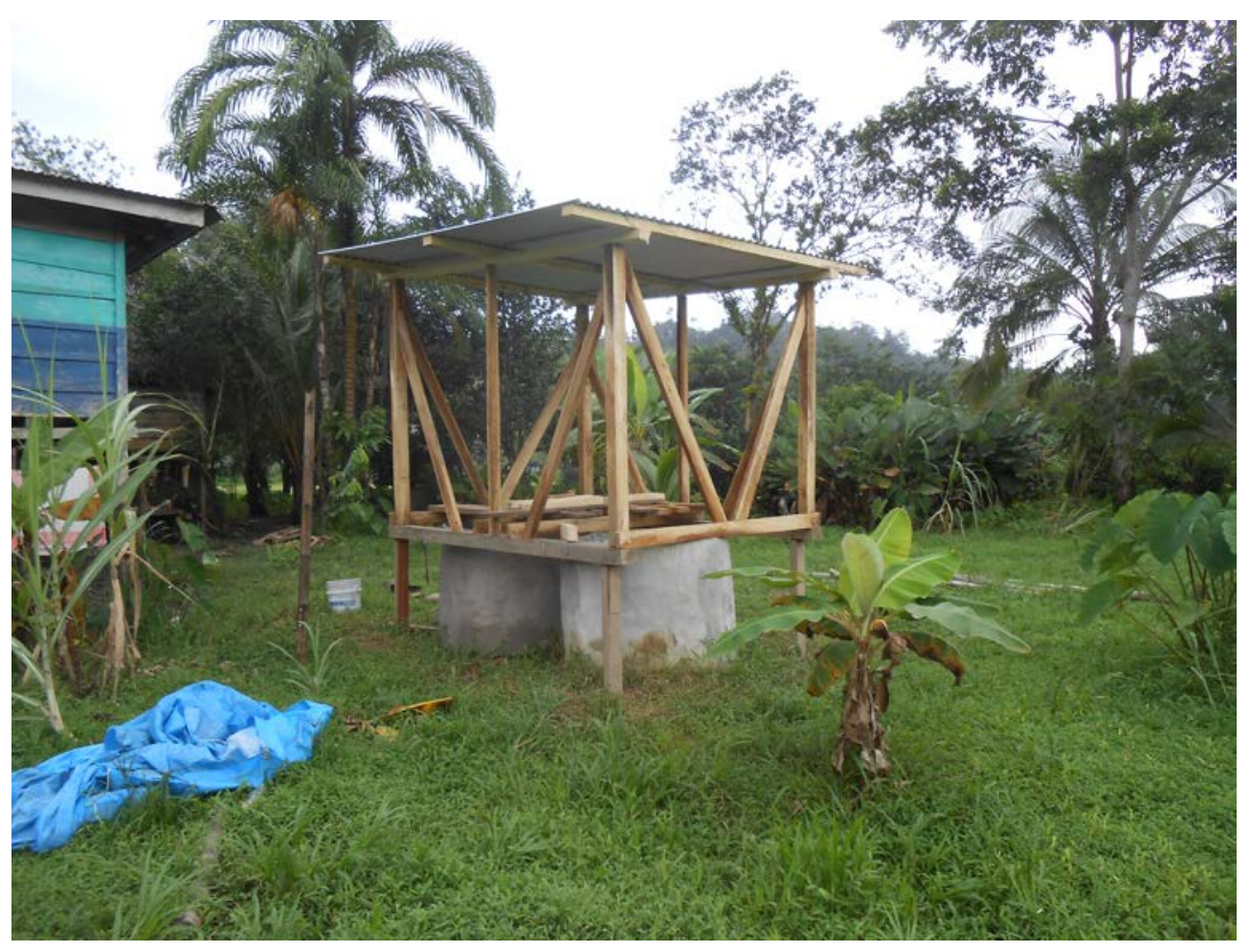

Figure 57 - Posts and frame of superstructure constructed (Photograph by Author)

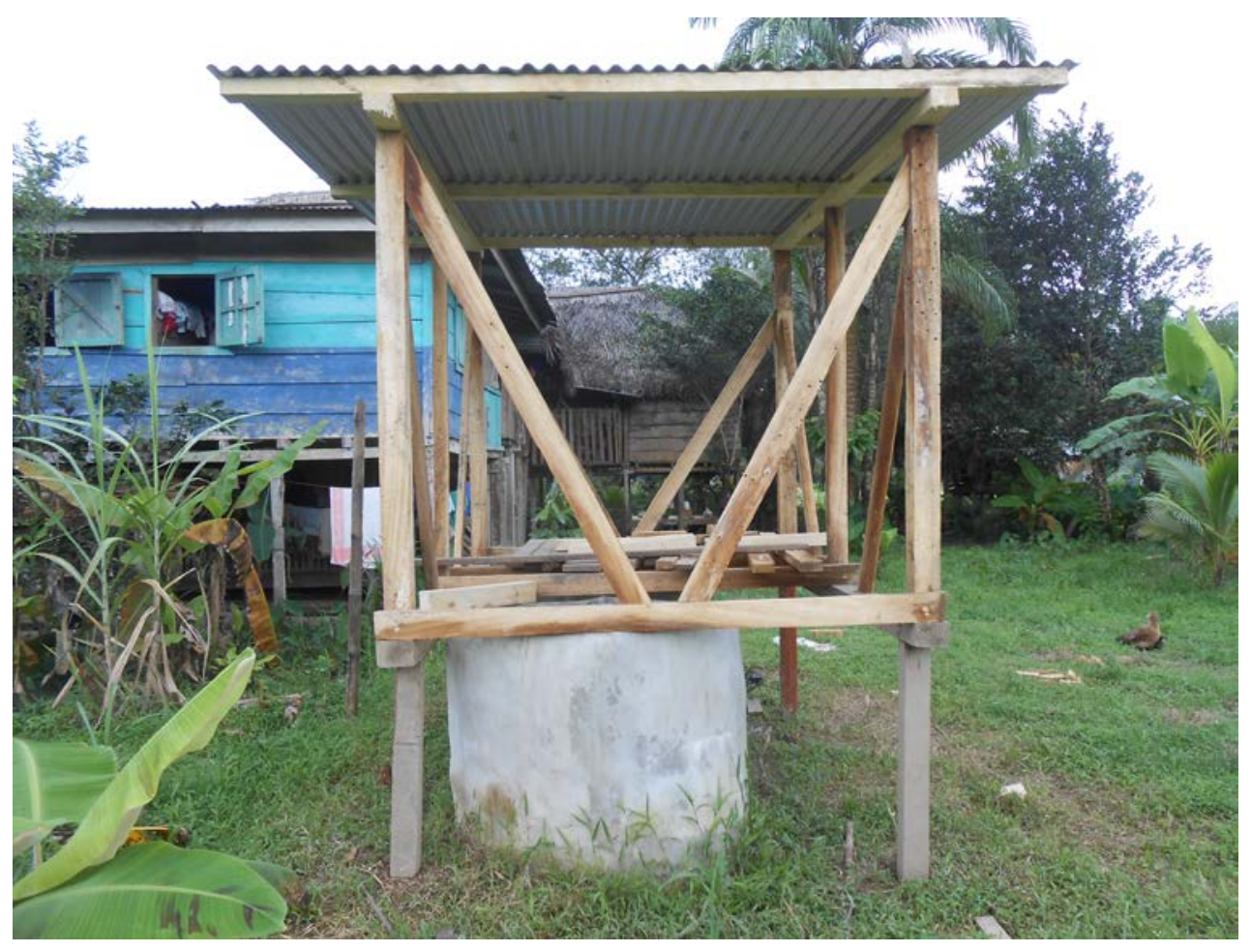

Figure 58 - Side view of superstructure frame (Photograph by Author) 


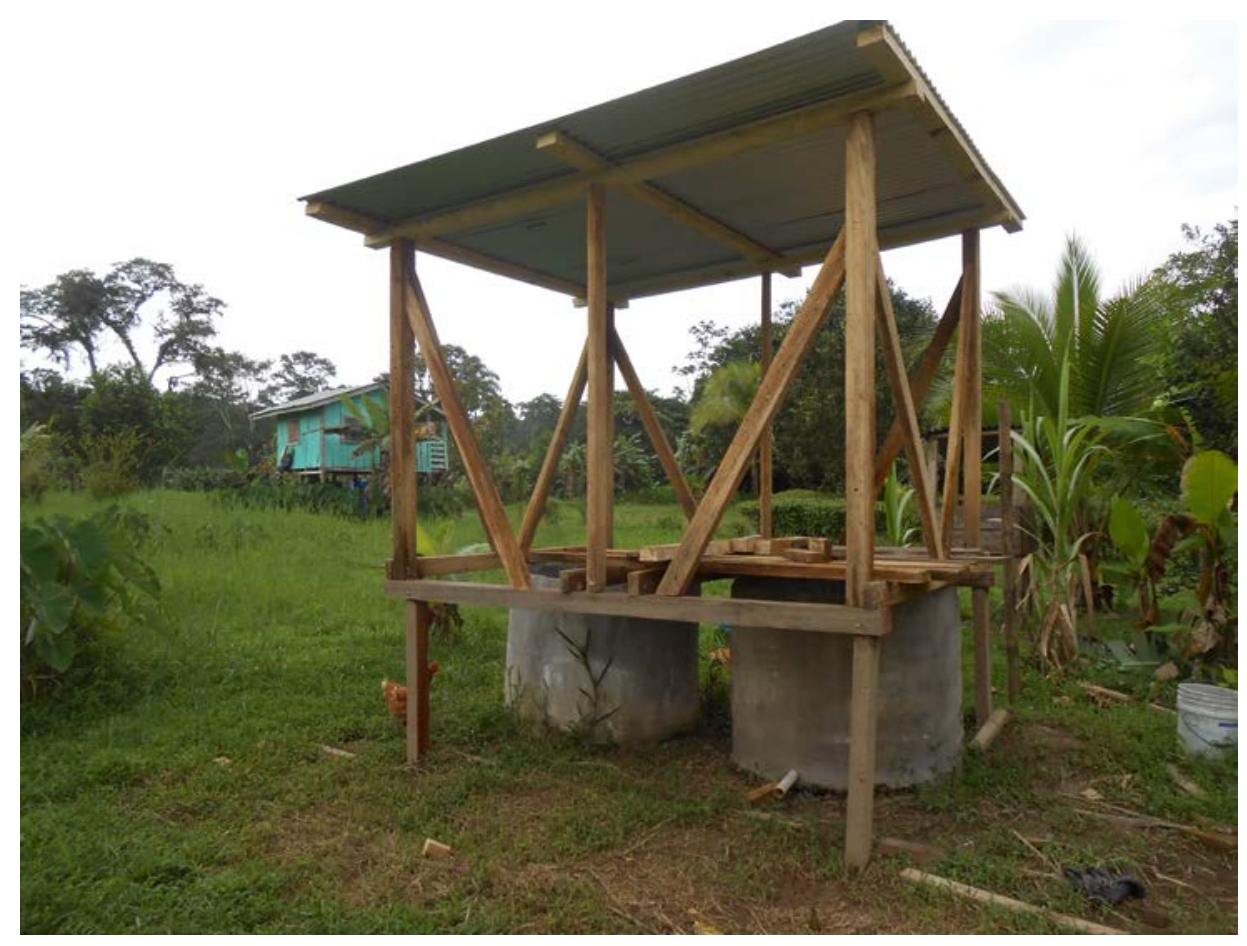

Figure 59 - Front view of superstructure frame (Photograph by Author)

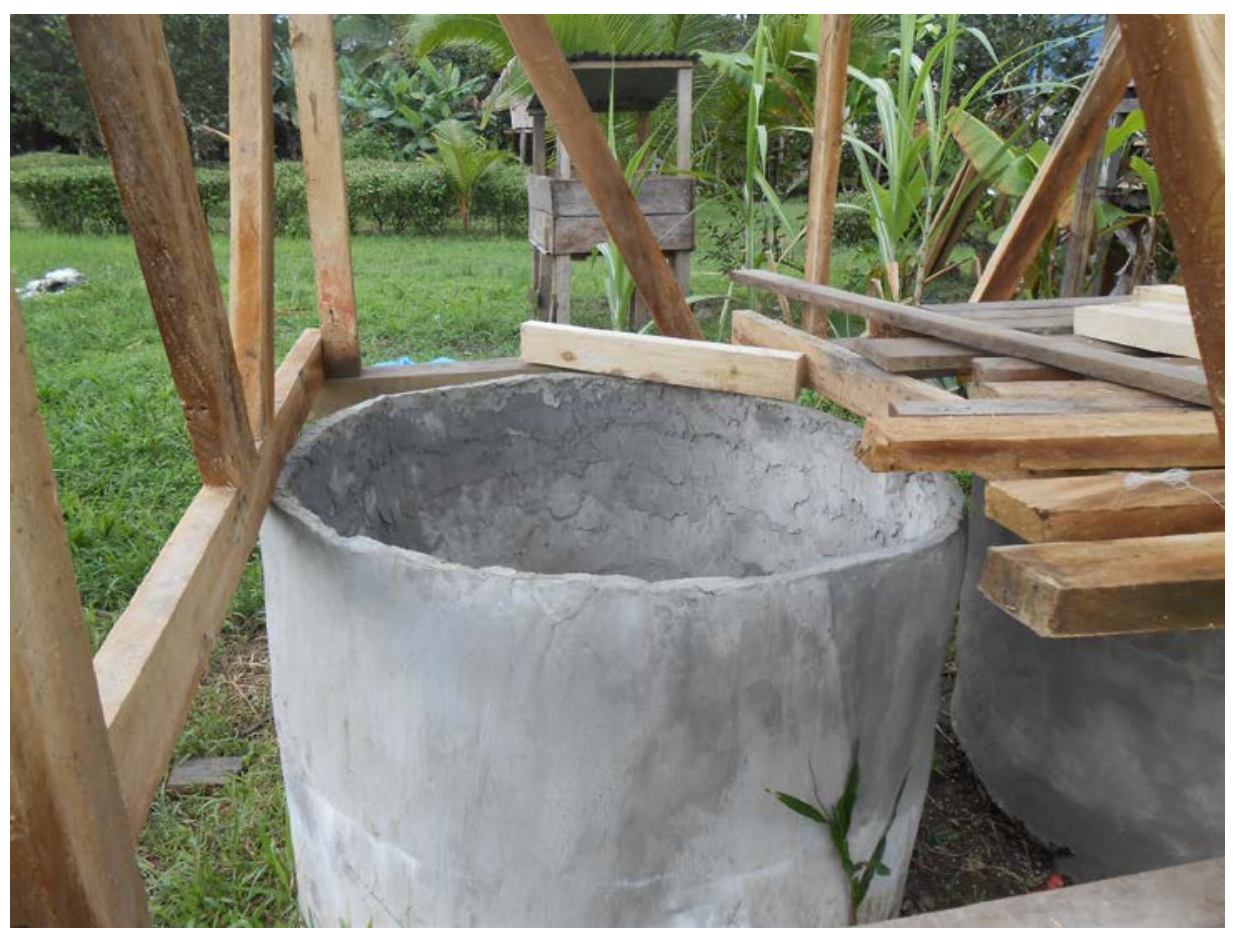


Figure 60 - A hinged false floor is constructed above the tank to facilitate compost removal (Photograph by Author)

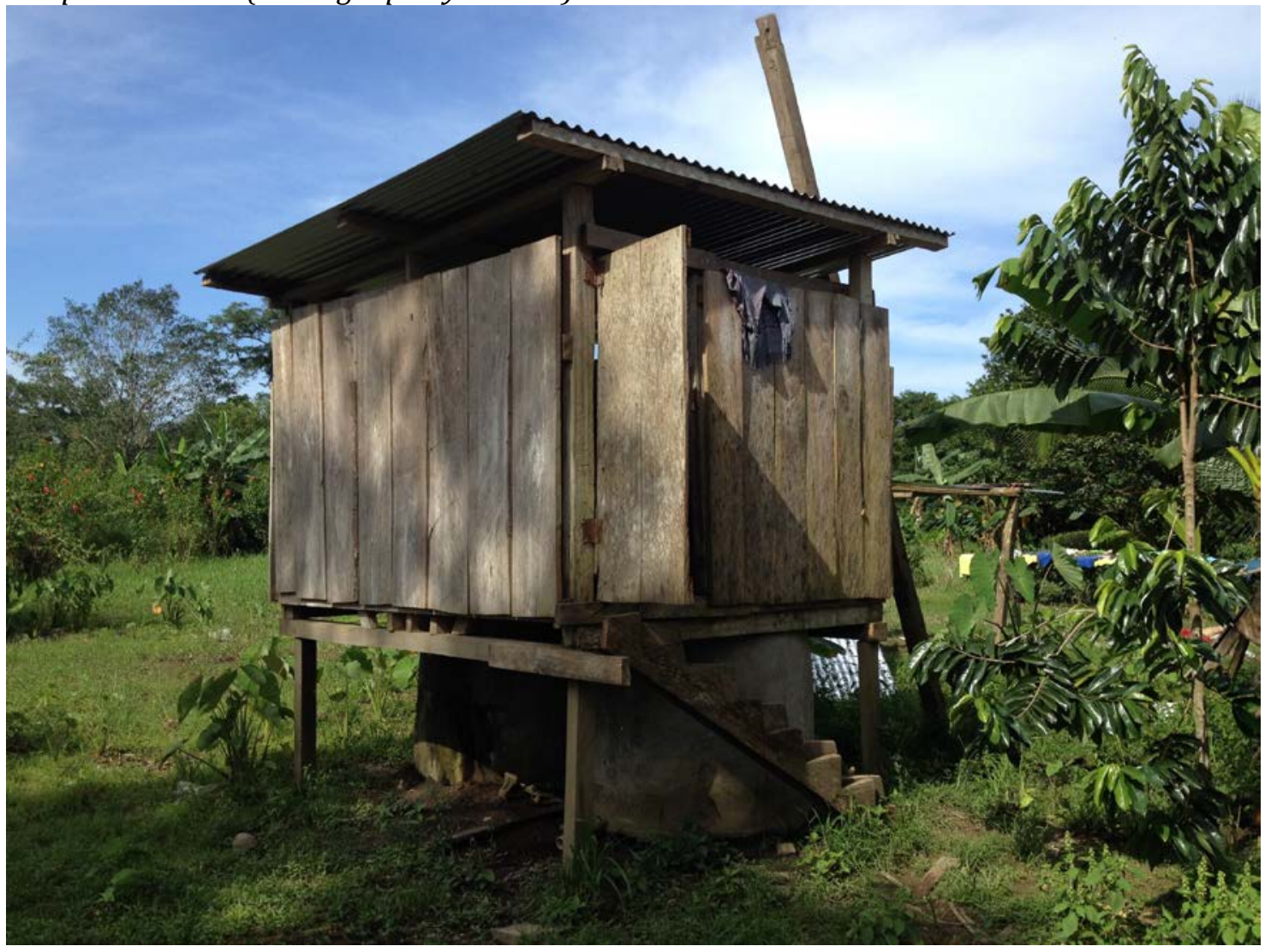

Figure 61 - Completed ferrocement composting latrine (Photograph by Author) 


\section{Appendix B: Interview Questions}

Research Question: "Why have these families adopted the use of composting latrines, how can they be improved and can new methods be adopted, as well?"

1) Can you tell me the story of how you acquired your composting latrine? When? Why? Who wanted it? What did you have to do to acquire it (money, time)?

2) Why don't others here have composting latrines?

3) Who uses the latrine? How often?

4) Have you continued to use it since acquiring it? Why or why not?

5) Have you made improvements to it over the years? If so, what are they?

6) Are there any improvements you would like to make to it that you have not yet been able to? If so, what are they? If so, why haven't you done so?

7) What has been the most difficult part of maintaining the latrine?

8) Do you foresee yourself using your composting latrine in perpetuity? If not, what are any reasons you wouldn't? If not, what will you do for your future sanitation needs?

9) If you moved to a different location, would you build another composting latrine?

10)(If yes to \#9) How much would you be willing to pay to acquire the materials necessary to construct one?

11)(If yes to \#9) How much time could you dedicate to constructing a typical composting latrine

12)Has the chamber ever filled in your current latrine? Was it emptied? By whom? How often do you think it should be emptied? Do you prefer others to empty it for you? What do you do with the compost your latrine produces? Does it have value to you as a farmer?

13)Are you comfortable handling the compost? Is there a difference to you between compost and raw excrement?

14)Are you familiar with what pathogens might be present in your excrement? Do you know if they have an impact on you or others? How important is the potential presence of pathogens in your compost?

15)Are you comfortable or uncomfortable handling urine?

16)Is urine more or less repulsive to handle than compost, or about the same?

17)Have you ever heard of the use of urine as a fertilizer? If so, tell me what you know about it.

18)Urine is considered by some to be a better and more available fertilizer than compost. Would storing urine from your composting latrine to use as a fertilizer be attractive to you or not? Why or why not? 
19)If handling and storing urine in addition to compost were necessary for a new type of latrine to function would you still be willing to use it? Why or why not?

The experiment I conducted on your compost and urine revealed that combining stored urine with fresh compost eliminated all pathogens that we discussed before. This means that compost could be harvested more frequently, about every three months or four times a year instead twice, thus making the chambers smaller and lowering the cost of the latrine. This new method requires urine to be stored in a large airtight vessel instead of being emptied into the ground. Then, after using one chamber in the same manner as your current latrine for a three-month period, the chamber would be closed off to avoid the release of odors and the urine would be added to the chamber by releasing a valve. As in the traditional design, after using the other chamber for three months, the other would be ready to remove after the excess fluids were released through piping running from the bottom of the closed chamber to a soak pit or to a simple trench.

20)The cost of this latrine would be significantly less than the traditional design (\$50 instead of \$300). Is cost an important factor to you in regards to a sanitation option?

21)This new latrine would produce compost more quickly and thus require more handling of the compost. Is compost availability important to you? Does handling the compost more frequently factor in to your acceptance of this proposed method?

22)This new composting method would more assuredly and more quickly eliminate pathogens from your compost. Is this important to you?

23)Are there any other thoughts you have on this proposed design and the new method it requires? 